\title{
AUSGRABUNGEN UND FUNDE IM JAHR 2009
}

Dagmar Bargetzi, Marco Bernasconi, Martin Block, Andrea Hagendorn, Sophie Hüglin, Urs Leuzinger, Christoph Matt, Hannele Rissanen, Udo Schön, Norbert Spichtig, Christian Stegmüller, Susan Steiner, Sven Straumann 



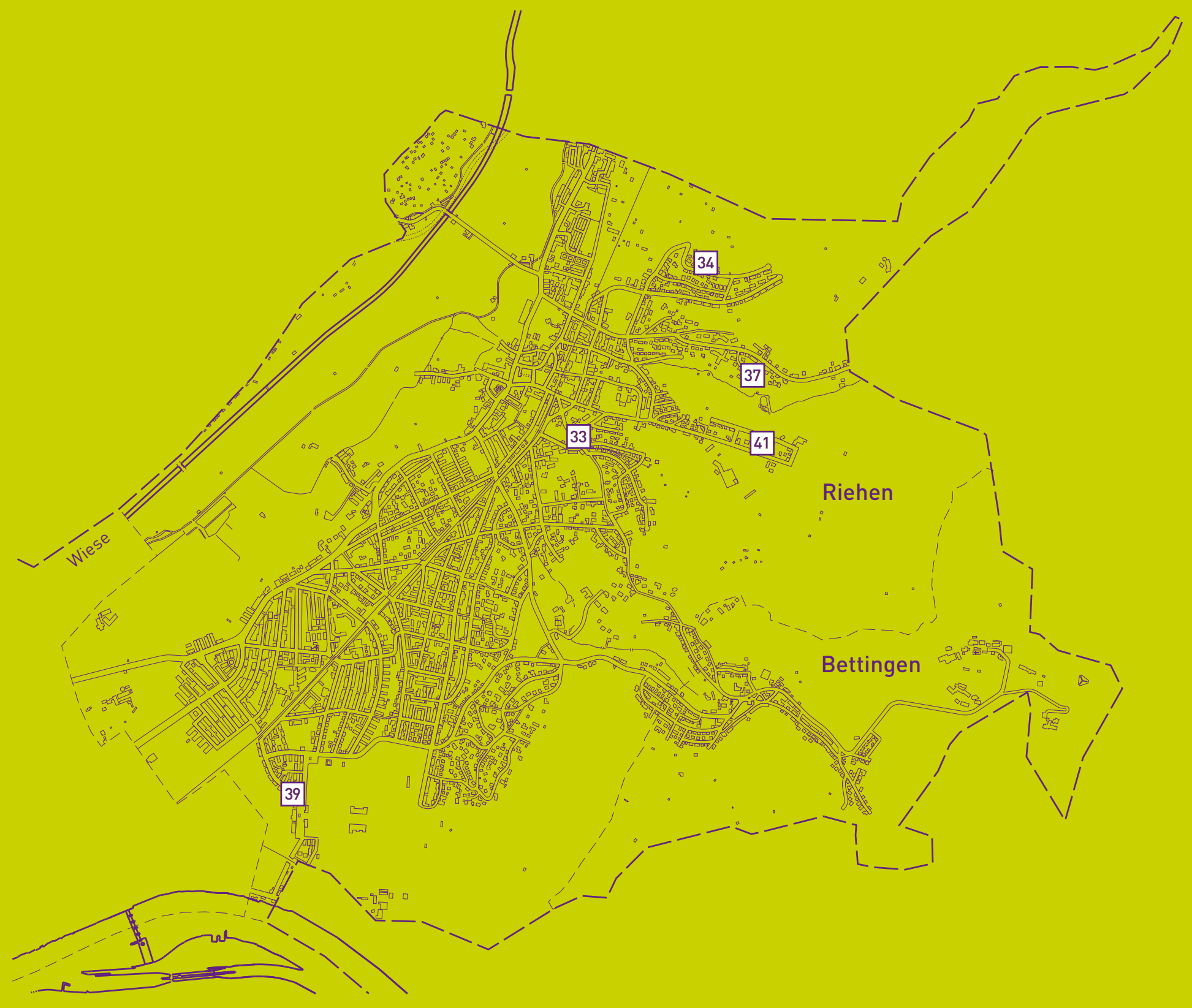

Abb. 1 Übersichtsplan des Kantons Basel-Stadt mit den Einsatzstellen der ABBS im Jahr 2009. Zu den einzelnen Einsatzstellen vgl. Abb. 2 und 3. Plangrundlage: Grundbuch- und Vermessungsamt des Kantons Basel-Stadt. Ergänzungen und Kartierung: Hansjörg Eichin. 


\section{FUNDCHRONIK 2009 ÜBERSICHT}

Nr./

\begin{tabular}{|c|c|c|c|}
\hline Abb. 1 & Lauf-Nr. & Adresse $(A=$ Allmend $)$ & Ergebnis \\
\hline 1 & 2009/1 & Kleinhüningeranlage/Weilerweg $(\mathrm{A})$ & - FMA \\
\hline 2 & $2009 / 2$ & Uferstrasse 30, Novartis, WKL-220, Zielgrube Microtunnel & • \\
\hline 3 & $2009 / 3$ & St. Alban-Kirchrain 10 & 0 \\
\hline 4 & $2009 / 4$ & Gasstrasse (A), Neugestaltung & $\mathbf{n} \mathrm{NZ} / \bullet$ \\
\hline 5 & $2009 / 5$ & Fabrikstrasse 60 , Novartis, WSJ-155, Oberflächengestaltung & 0 \\
\hline 6 & $2009 / 6$ & Glockengasse (A) & $\square N Z$ \\
\hline 7 & $2009 / 7$ & Martinskirchplatz 4 & $\mathbf{M A} / \mathbf{n Z}$ \\
\hline 8 & $2009 / 8$ & Rittergasse (A) 11-19A & $\boldsymbol{\square} \mathrm{RZ} / \mathbf{\square} \mathrm{MA}$ \\
\hline 9 & $2009 / 9$ & Totentanz 9 & $\square \mathrm{MA}$ \\
\hline 10 & $2009 / 10$ & Hüningerstrasse (A), Novartis, Oberflächengestaltung & $\mathbf{n} \mathrm{NZ} / \bullet$ \\
\hline 11 & $2009 / 11$ & Hüningerstrasse 121, Novartis, WSJ-310, ELT & $\bullet$ \\
\hline 12 & $2009 / 12$ & Hüningerstrasse 121, Novartis, WSJ-355, Oberflächengestaltung & $\bullet$ \\
\hline 13 & $2009 / 13$ & Rheingasse 11 & $\square \mathrm{NZ}$ \\
\hline 14 & $2009 / 14$ & Münsterplatz 15 & $\square \mathrm{RZ} / \boldsymbol{\square A} / \square \mathrm{NZ}$ \\
\hline 15 & $2009 / 15$ & Münsterplatz (A) & o \\
\hline 16 & $2009 / 16$ & Martinsgasse (A) & 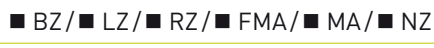 \\
\hline 17 & $2009 / 17$ & Münsterplatz (A) & 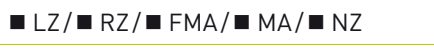 \\
\hline 18 & $2009 / 18$ & Rittergasse $(A)$ & 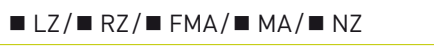 \\
\hline 19 & 2009/19 & Schalerstrasse 45 & $\bullet$ \\
\hline 20 & $2009 / 20$ & Heuberg 5/7 (Spiesshof) & $\square \mathrm{MA} / \mathbf{\mathrm { NZ }}$ \\
\hline 21 & $2009 / 21$ & Margarethenstrasse (A) 31 & $\bullet N Z$ \\
\hline 22 & $2009 / 22$ & Rheinhafen St. Johann 18, Etappe 1 & $\boldsymbol{\square} \mathrm{BZ} / \boldsymbol{\square} \mathrm{LZ} / \boldsymbol{\square} \mathrm{NZ}$ \\
\hline 23 & $2009 / 23$ & Rheinschanze $(A)$ & $\square \mathrm{NZ}$ \\
\hline 24 & $2009 / 24$ & Petersgraben 4 (Universitätsspital) & $\square \mathrm{NZ}$ \\
\hline 25 & $2009 / 25$ & Fabrikstrasse 60, Novartis, WSJ-16, Rückbau & 0 \\
\hline 26 & $2009 / 26$ & Augustinergasse 2, Naturhistorisches Museum Basel & 0 \\
\hline 27 & $2009 / 27$ & Rheinhafen St. Johann 18, Etappe 2 & $\square \mathrm{BZ} / \boldsymbol{\square Z Z} / \mathbf{n} \mathrm{NZ}$ \\
\hline 28 & $2009 / 28$ & Lindenberg, Utengasse (A) & $\square \mathrm{NZ}$ \\
\hline 29 & $2009 / 29$ & Rheinhafen St. Johann 18, Etappe 3 & $\mathbf{n} \mathrm{NZ} / \bullet$ \\
\hline 30 & $2009 / 30$ & Barfüsserplatz (A) 7 (Barfüsserkirche) & o \\
\hline 31 & $2009 / 31$ & St. Alban-Anlage (A) 38-40 & $\square \mathrm{MA}$ \\
\hline 32 & $2009 / 32$ & Fabrikstrasse 60, Novartis, Strasse 8 & $\bullet \mathrm{ZU} / \bullet$ \\
\hline 33 & $2009 / 33$ & Riehen, Mohrhaldenstrasse 44 & $\square Z U$ \\
\hline 34 & $2009 / 34$ & Riehen, Auf der Bischoffhöhe 27 & 0 \\
\hline 35 & $2009 / 35$ & Ochsengasse $12-14$ & $\square \mathrm{NZ}$ \\
\hline 36 & $2009 / 36$ & Rheinhafen St. Johann 18, Etappe 4 & $\boldsymbol{\square} \mathrm{BZ} / \boldsymbol{\square} \mathrm{LZ} / \mathbf{\square} \mathrm{NZ}$ \\
\hline 37 & $2009 / 37$ & Riehen, Bockrainweg 20 & $\bullet$ \\
\hline 38 & $2009 / 38$ & Blumenrain (A) 34 & $\square \mathrm{MA}$ \\
\hline 39 & $2009 / 39$ & Riehen, Rauracherstrasse 156 & $\bullet \mathrm{RZ}$ \\
\hline 40 & $2009 / 40$ & Münsterplatz (A) Pfalz & $\square \mathrm{MA} / \square \mathrm{NZ}$ \\
\hline 41 & $2009 / 41$ & Riehen, Leimgrubenweg 70 & 0 \\
\hline 42 & $2009 / 42$ & Südquaistrasse 25 & 0 \\
\hline 43 & $2009 / 43$ & Webergasse (A) 1 & $\square \mathrm{NZ}$ \\
\hline 44 & $2009 / 44$ & Marktplatz (A) 2 & $\square N Z$ \\
\hline
\end{tabular}

\section{Legende}

PAL Paläolithikum

NL Neolithikum

BZ Bronzezeit

HZ Hallstattzeit

LZ Latènezeit

RZ Römische Zeit

FMA Frühmittelalter

MA Mittelalter

NZ Neuzeit

ZU Zeit unbestimmt

$\square \quad$ Befund ohne Funde

- Befund mit Funden

- Streu- und Einzelfunde/ Funde bei Prospektionsgängen

- Geologischer Befund

- Ohne Befund/Funde
Abb. 2 Im Berichtsjahr 2009 begonnene Untersuchungen der Archäologischen Bodenforschung Basel-Stadt im Kantonsgebiet nach Laufnummern. Zusammenstellung: Toni Rey. 


\begin{tabular}{|c|c|c|c|}
\hline Adresse $(\mathrm{A}=\mathrm{Allmend})$ & $\begin{array}{l}\text { Nr./ } \\
\text { Abb. } 1\end{array}$ & Lauf-Nr. & Ergebnis \\
\hline \multicolumn{4}{|l|}{ Münsterhügel } \\
\hline Augustinergasse 2, Naturhistorisches Museum Basel & 26 & $2009 / 26$ & 0 \\
\hline Martinsgasse (A) & 16 & $2009 / 16$ & 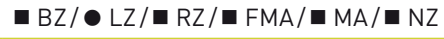 \\
\hline Martinskirchplatz 4 & 7 & 2009/7 & $\square \mathrm{MA} / \mathbf{\mathrm { NZ }}$ \\
\hline Münsterplatz 15 & 14 & $2009 / 14$ & $\square \mathrm{RZ} / \boldsymbol{\square} \mathrm{MA} / \square \mathrm{NZ}$ \\
\hline Münsterplatz (A) & 15 & $2009 / 15$ & 0 \\
\hline Münsterplatz (A) & 17 & $2009 / 17$ & 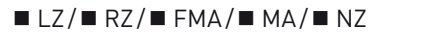 \\
\hline Münsterplatz (A) Pfalz & 40 & $2009 / 40$ & $\square \mathrm{MA} / \square \mathrm{NZ}$ \\
\hline Rittergasse (A) 11-19A & 8 & $2009 / 8$ & - $\mathrm{RZ} / \mathbf{m A}$ \\
\hline Rittergasse $(A)$ & 18 & $2009 / 18$ & 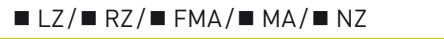 \\
\hline \multicolumn{4}{|l|}{ Innerstadt } \\
\hline Barfüsserplatz (A) 7 (Barfüsserkirche) & 30 & $2009 / 30$ & 0 \\
\hline Blumenrain (A) 34 & 38 & $2009 / 38$ & $\square \mathrm{MA}$ \\
\hline Glockengasse (A) & 6 & $2009 / 6$ & $\square \mathrm{NZ}$ \\
\hline Heuberg 5/7 (Spiesshof) & 20 & $2009 / 20$ & $\square \mathrm{MA} / \mathbf{\nabla Z Z}$ \\
\hline Lindenberg, Utengasse (A) & 28 & $2009 / 28$ & - NZ \\
\hline Marktplatz (A) 2 & 44 & $2009 / 44$ & $\square \mathrm{NZ}$ \\
\hline Ochsengasse $12-14$ & 35 & $2009 / 35$ & $\square \mathrm{NZ}$ \\
\hline Petersgraben 4 (Universitätsspital) & 24 & $2009 / 24$ & $\square \mathrm{NZ}$ \\
\hline Rheingasse 11 & 13 & $2009 / 13$ & - NZ \\
\hline Rheinschanze (A) & 23 & $2009 / 23$ & $\square \mathrm{NZ}$ \\
\hline St. Alban-Anlage (A) 38-40 & 31 & $2009 / 31$ & $\square \mathrm{MA}$ \\
\hline St. Alban-Kirchrain 10 & 3 & $2009 / 3$ & 0 \\
\hline Totentanz 9 & 9 & $2009 / 9$ & $\square \mathrm{MA}$ \\
\hline Webergasse (A) 1 & 43 & $2009 / 43$ & $\square N Z$ \\
\hline \multicolumn{4}{|l|}{ Gasfabrik } \\
\hline Fabrikstrasse 60, Novartis, Strasse 8 & 32 & $2009 / 32$ & $\bullet \mathrm{ZU} / \bullet$ \\
\hline Fabrikstrasse 60, Novartis, WSJ-16, Rückbau & 25 & $2009 / 25$ & 0 \\
\hline Fabrikstrasse 60, Novartis, WSJ-155, Oberflächengestaltung & 5 & $2009 / 5$ & 0 \\
\hline Gasstrasse (A), Neugestaltung & 4 & $2009 / 4$ & $\mathbf{n} \mathrm{NZ} / \bullet$ \\
\hline Hüningerstrasse (A), Novartis, Oberflächengestaltung & 10 & $2009 / 10$ & $\square \mathrm{NZ} / \bullet$ \\
\hline Hüningerstrasse 121, Novartis, WSJ-310, ELT & 11 & $2009 / 11$ & $\bullet$ \\
\hline Hüningerstrasse 121, Novartis, WSJ-355, Oberflächengestaltung & 12 & $2009 / 12$ & $\bullet$ \\
\hline Rheinhafen St. Johann 18, Etappe 1 & 22 & $2009 / 22$ & 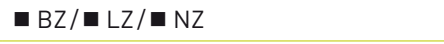 \\
\hline Rheinhafen St. Johann 18, Etappe 2 & 27 & $2009 / 27$ & 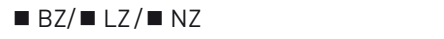 \\
\hline Rheinhafen St. Johann 18, Etappe 3 & 29 & $2009 / 29$ & - NZ/• \\
\hline Rheinhafen St. Johann 18, Etappe 4 & 36 & $2009 / 36$ & $\boldsymbol{\square} \mathrm{BZ} / \boldsymbol{\square} \mathrm{LZ} / \boldsymbol{\square} \mathrm{NZ}$ \\
\hline \multicolumn{4}{|l|}{ Aussenbezirke } \\
\hline Riehen, Auf der Bischoffhöhe 27 & 34 & $2009 / 34$ & 0 \\
\hline Riehen, Bockrainweg 20 & 37 & $2009 / 37$ & $\bullet$ \\
\hline Kleinhüningeranlage/Weilerweg (A) & 1 & $2009 / 1$ & - FMA \\
\hline Riehen, Leimgrubenweg 70 & 41 & $2009 / 41$ & 0 \\
\hline Margarethenstrasse (A) 31 & 21 & $2009 / 21$ & $\bullet N Z$ \\
\hline Riehen, Mohrhaldenstrasse 44 & 33 & $2009 / 33$ & $\square Z U$ \\
\hline Riehen, Rauracherstrasse 156 & 39 & $2009 / 39$ & $\bullet \mathrm{RZ}$ \\
\hline Schalerstrasse 45 & 19 & $2009 / 19$ & $\bullet$ \\
\hline Südquaistrasse 25 & 42 & $2009 / 42$ & 0 \\
\hline Uferstrasse 30 , Novartis, WKL-220, Zielgrube Microtunnel & 2 & $2009 / 2$ & $\bullet$ \\
\hline
\end{tabular}

\section{Legende}

PAL Paläolithikum

NL Neolithikum

BZ Bronzezeit

$\mathrm{HZ}$ Hallstattzeit

LZ Latènezeit

RZ Römische Zeit

FMA Frühmittelalter

MA Mittelalter

NZ Neuzeit

ZU Zeit unbestimmt

$\square \quad$ Befund ohne Funde

- Befund mit Funden

- Streu- und Einzelfunde/ Funde bei Prospektionsgängen

- Geologischer Befund

- Ohne Befund/Funde
Abb. 3 Im Berichtsjahr 2009 begonnene Untersuchungen der Archäologischen Bodenforschung Basel-Stadt im Kantonsgebiet nach Ressort und Adresse. Zusammenstellung: Toni Rey. 


\section{MÜNSTERHÜGEL}

\section{8/3 MÜNSTERPLATZ 19, MUSEUM DER KULTUREN}

Anlass: Umbau des Museums der Kulturen Zeitstellung: Bronzezeit, Spätlatènezeit, Römische Zeit, Mittelalter, Neuzeit Untersuchungsdauer: Januar bis Mai und Juli bis Dezember 2009 Verantwortlich: Andrea Hagendorn, Sven Straumann Text: Sven Straumann

Nach Abschluss der Plangrabung im Dezember 2008 wurden im Schürhof-Areal zwischen Januar und Mai 2009 relativ umfangreiche, den Bauvorgang begleitende Untersuchungen durchgeführt. Darauf folgten weitere Dokumentationsarbeiten in der zweiten Jahreshälfte. ${ }^{1}$ Ausserhalb der bereits gegrabenen Fläche im Schürhof-Areal ${ }^{2}$ fanden auch im Klosterhof sowie im Untergeschoss des Museumsgebäudes Tiefbauarbeiten statt, die eine archäologische Begleitung nötig machten (Abb. 4). Daraus resultierten äusserst wertvolle Erkenntnisse, die einen wichtigen Beitrag zum besseren Verständnis der übrigen Befunde leisten. Insbesondere im Westen des Grabungsareals konnten auf einer relativ grossen Fläche spätlatènezeitliche Siedlungsspuren dokumentiert werden (Abb.5). Es handelte sich dabei um mehrere Gehhorizonte, wovon einer aus einem dünnen Mörtelbelag bestand. Auch Reste von Holzbauten, wie Ost-West ausgerichtete Balkengräbchen sowie Pfostenlöcher, liessen sich nachweisen. Chronologisch wohl gleich einzustufen ist eine weitere Pferdedeponierung (Abb.6). Anders als beim 2008 entdeckten Pferd ist dieses Skelett allerdings wegen eines neuzeitlichen Mauerfundaments unvollständig erhalten. Doch die Halswirbel waren diesmal vorhanden.

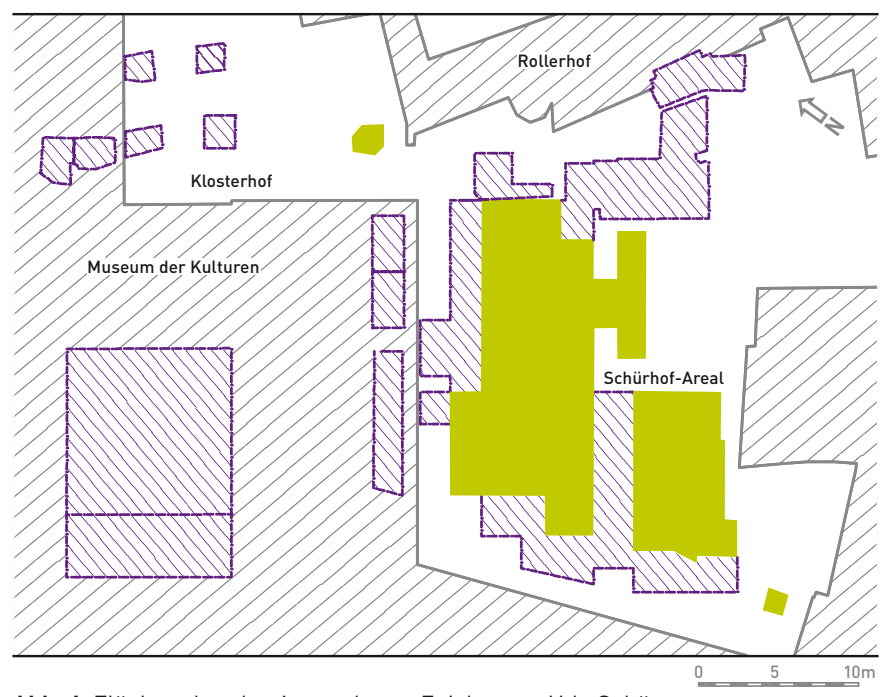

Abb. 4 Flächenplan der Ausgrabung. Zeichnung: Udo Schön.

Plangrabung $\$$ den Bauvorgang begleitende Untersuchungen
Wie sich überraschenderweise herausstellte, waren die spätlatènezeitlichen Strukturen in die Verfüllung eines wohl bronzezeitlichen Befestigungsgrabens eingetieft. Dieser liess sich in erster Linie aufgrund einer separaten Böschungsanschüttung als solcher erkennen, da das Verfüllmaterial den Anschein

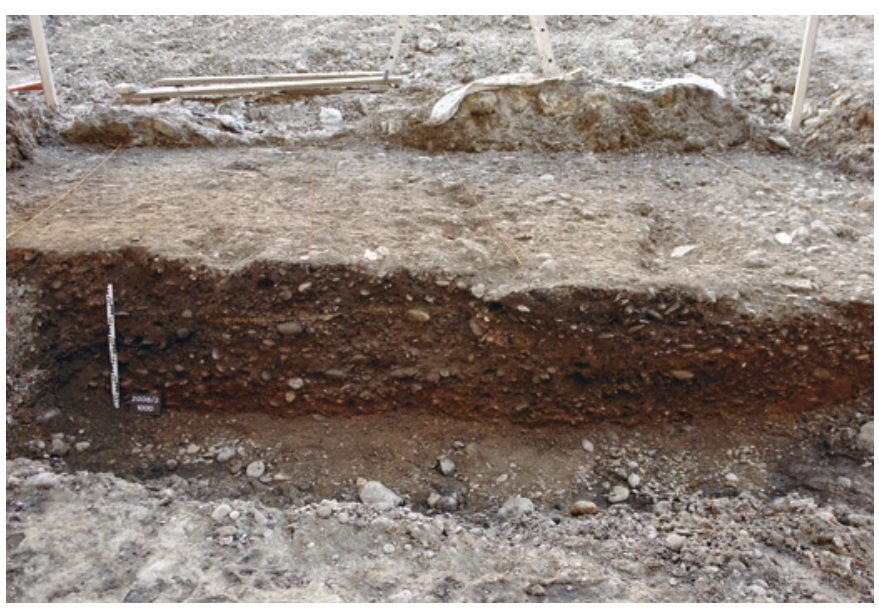

Abb. $\mathbf{5}$ In diesem Ostprofil lassen sich verschiedene spätlatènezeitliche Horizonte erkennen. Dazu zählt auch der dünne Mörtelbodenbelag. Foto: Sven Straumann.

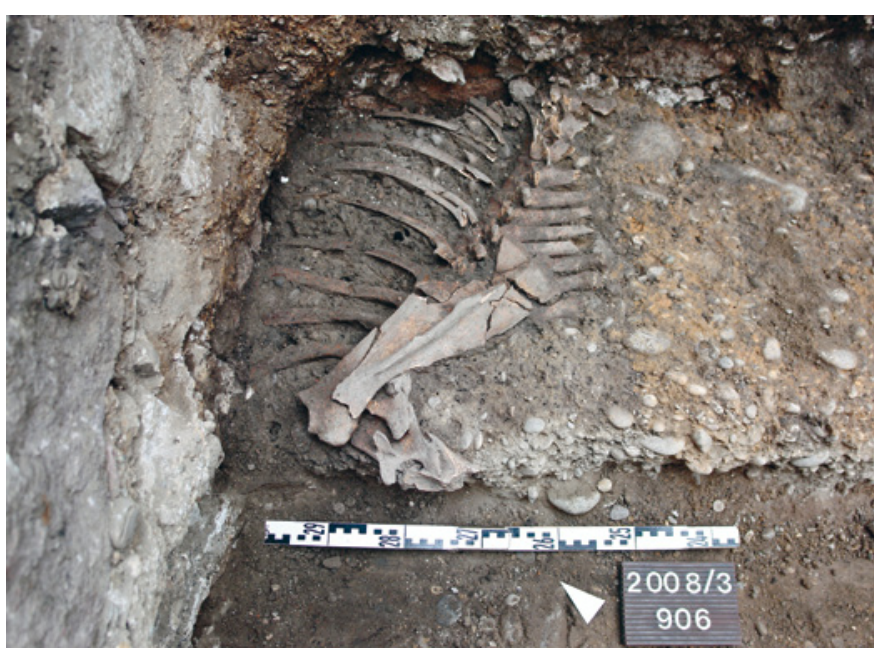

Abb. 6 Unvollständig erhaltene Pferde-Deponierung. Foto: Sven Straumann. 
von natürlich abgelagertem Rheinschotter machte. Selbst für den Geoarchäologen Philippe Rentzel war das Identifizieren der Grabenverfüllung äusserst schwierig. Fundmaterial war nicht enthalten. Deshalb muss die absolute Datierung dieses Grabens offen bleiben.

Ein weitere wichtige Entdeckung betraf die nördliche Kante des mittelalterlichen Grabens (Abb. 7). Bei der Plangrabung war lediglich die südliche Grabenkante erfasst worden. So kann nun die Breite mit 6 Metern beziffert werden. Auch bei den den Bauvorgang begleitenden Untersuchungen wurde jedoch die Grabensohle nicht erreicht. Somit fehlt allfälliges Fundmaterial, das für die Datierung der frühesten Grabenverfüllung aussagekräftig wäre.

Bei den Bauarbeiten im Untergeschoss des Museumsgebäudes kam schliesslich ein weiterer Ost-West verlaufender Graben zum Vorschein. Dabei handelt es sich um den bereits bei früheren Grabungen im Bereich der Augustinergasse angetroffenen frührömischen Spitzgraben (Abb. 8). ${ }^{3}$ Dieser durchschlägt den Verwitterungshorizont und reicht in den anstehenden glazialen Rheinschotter. Ebenfalls innerhalb des bestehenden Museumsgebäudes liess sich zudem ein mit Abbruchschutt verfüllter, gemauerter Schacht dokumentieren (Abb. 9). Möglicherweise besteht ein Zusammenhang mit dem neuzeitlichen Bachofen'schen Fabrikgebäude bzw. dem zugehörigen französischen Garten, der sich an dieser Stelle befand. ${ }^{4}$ Die funktionale Deutung ist unklar. Denkbar wäre eine Interpretation als Sodbrunnen.

Beim Neubau der Fernheizung im Schürhof-Areal öffnete sich unerwartet ein grosser unterirdischer Hohlraum: Ein Tonnengewölbe aus Backsteinen überspannte eine relativ grosse, mit Abbruchschutt verfüllte Innenfläche (Abb. 10). Es liess sich kein Zugang erkennen. Die südliche Rückwand schien allerdings flickwerkartig zugemauert zu sein. Eine direkte Zugehörigkeit zu einer benachbarten Liegenschaft konnte bisher nicht ermittelt werden. Es könnte sich beim unterirdischen Raum um einen Gewölbekeller gehandelt haben. Andererseits wäre auch eine Deutung als grosszügige Latrinengrube nicht auszuschliessen. Das eingefüllte Schuttmaterial stammte möglicherweise vom Abbruch des Bachofen'schen Fabrikgebäudes. Wahrschein-

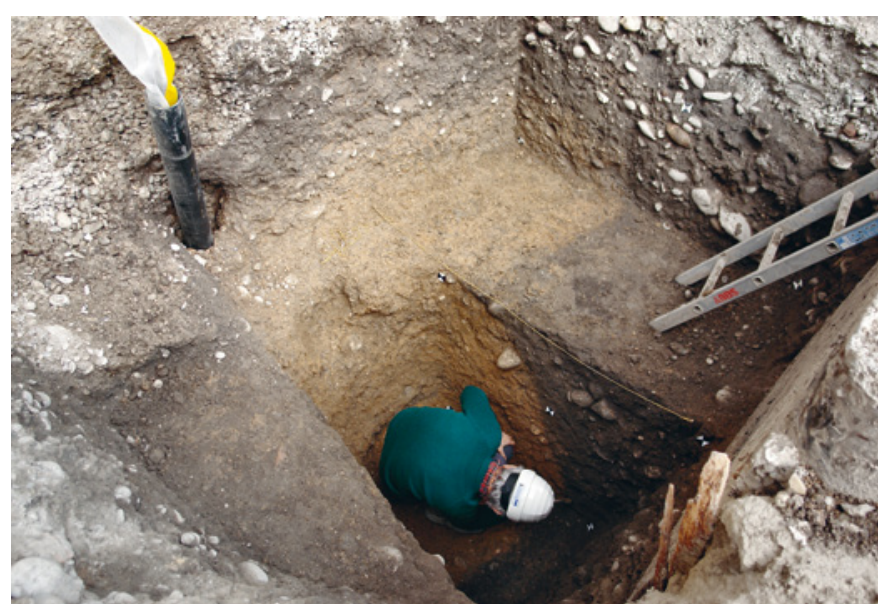

Abb. 7 Zeichnerische Dokumentation der nördlichen Kante des mittelalterlichen Grabens. Foto: Sven Straumann.

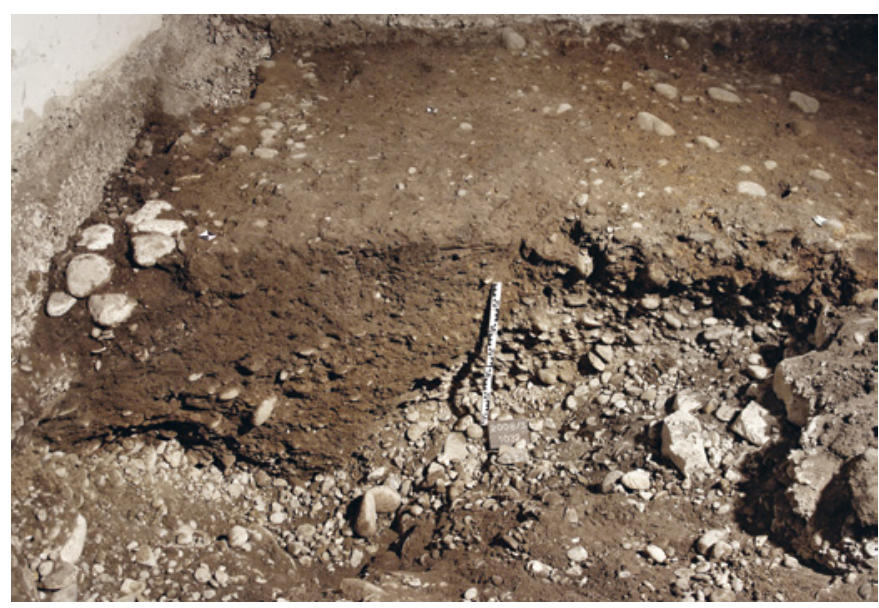

Abb. 8 Frührömischer Spitzgraben im Innern des Museums der Kulturen. Foto: Sven Straumann. 
lich kann auch das Backsteingewölbe in die Neuzeit datiert werden. Aus Sicherheitsgründen verzichtete man vorläufig auf ein Betreten und eine genauere Untersuchung des überwölbten Raumes.

Wie bereits einleitend erwähnt, wurden 2009 nicht nur im Schürhof, sondern auch im Klosterhof Bauarbeiten ausgeführt. Dort wurden vier Gruben für das Fundament des Baukrans ausgehoben (Abb.11). Diese befanden sich in teils noch ungestörten Bereichen, die sorgfältig archäologisch untersucht werden mussten. Neben Mauern aus der Zeit des mittelalterlichen Augustinerklosters kam auch der Rest eines wahrscheinlich römischen Mauerfundaments zum Vorschein.

Mit den 2009 zusätzlich untersuchten Bereichen erweiterte sich die effektive Grabungsfläche, und eine umfassende Betrachtung von archäologischen Zusammenhängen wird möglich. So können bestimmte Fragestellungen ganz gezielt weiterverfolgt werden.

Die noch geplanten Tiefbauarbeiten für neue Werkleitungen und die Oberflächengestaltung im Schürhof-Areal verursachen auch 2010 weitere den Bauvorgang begleitende Untersuchungen. Diese werden im Rahmen des Projektes «Museum der Kulturen» unter einer neuen Laufnummer (2010/5) fortgeführt.

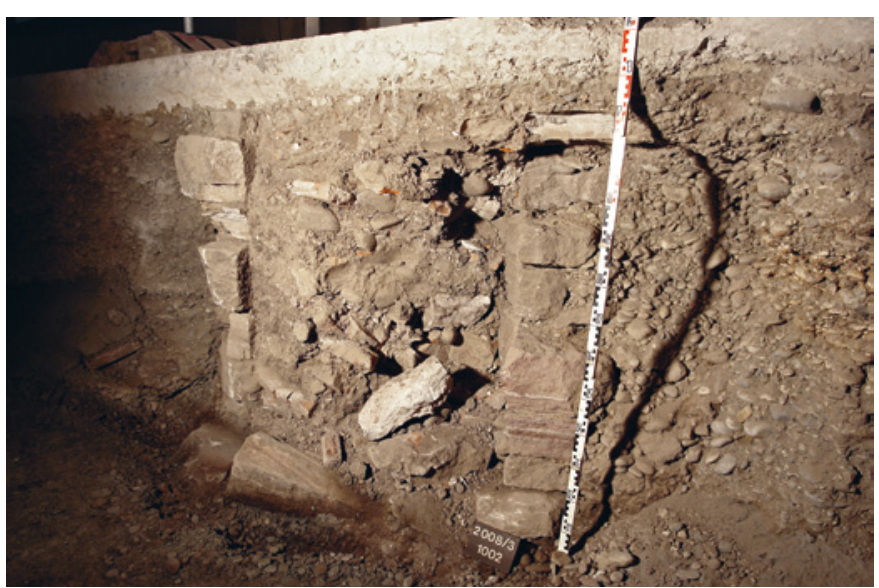

Abb. 9 Mit Abbruchschutt verfüllter kreisrunder Schacht. Foto: Sven Straumann.

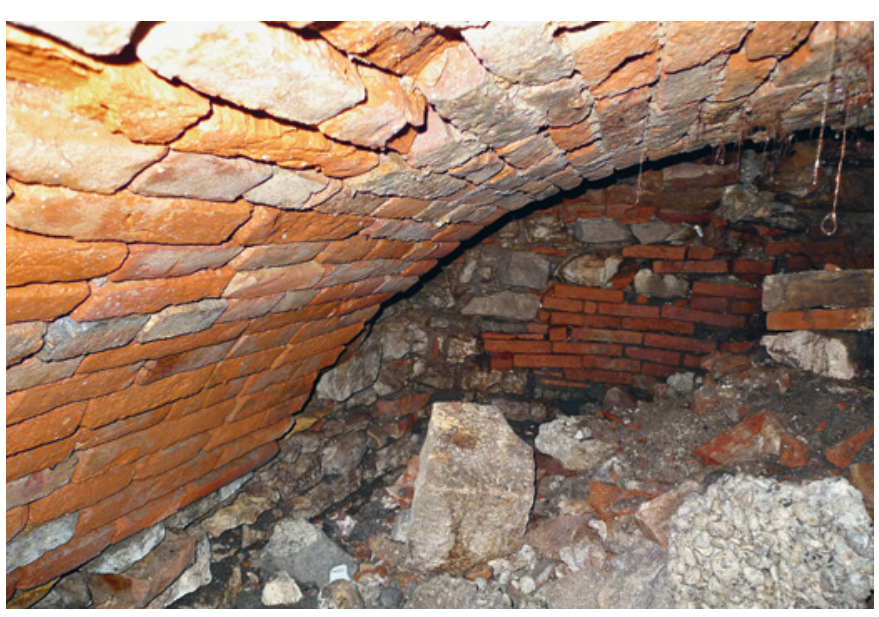

Abb. 10 Unterirdischer Raum mit Gewölbe aus Backsteinen, verfüllt mit Abbruchschutt. Foto: Sven Straumann.

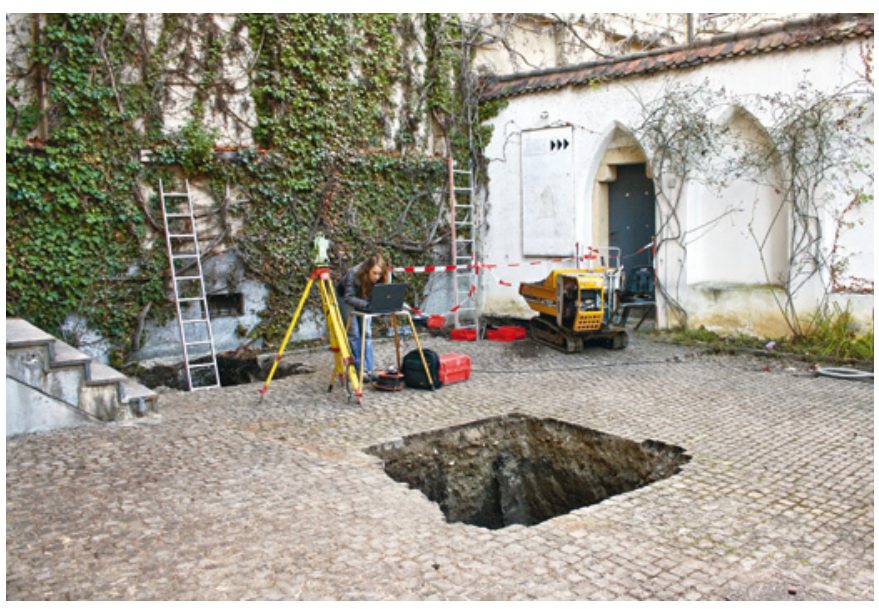

Abb. 11 Archäologische Untersuchung der Fundamentgruben für den Baukran. Foto: Michael Wenk. 
Anlass: Sanierung des Erkers über der Stützmauer des Martinskirchsporns Zeitstellung: Mittelalter, Neuzeit Untersuchungsdauer: März bis Mai 2009 Verantwortlich: Dagmar Bargetzi, Christoph Matt, Christian Stegmüller Text: Dagmar Bargetzi, Christoph Matt

In den Liegenschaften am Rheinsprung direkt unterhalb der Martinskirche kam es immer wieder zu Problemen mit der von der Terrassierungsmauer ausgehenden Feuchtigkeit, weshalb im Frühjahr 2009 der Bereich des Erkers über der Stützmauer des Martinskirchsporns beim Chorscheitel saniert wurde (Abb. 12 und 13). ${ }^{5}$ Von früheren Ausgrabungen im Umfeld dieses Erkers waren bereits mittelalterliche Mauerzüge bekannt. ${ }^{6} \mathrm{Zu}$ dem weiss man, dass die Martinskirche bzw. ihr Chor nach dem Basler Erdbeben von 1356 gegen Osten verlängert wurde, und man nahm bisher an, dass in diesem Zusammenhang die Stützmauer nötig wurde. ${ }^{7}$ Bald nach Beginn der archäologischen Untersuchungen zeigten sich wenig unter dem aktuellen Bsetzisteinboden und einer dünnen Planierungsschicht im ganzen Bereich Mauerfundamente und eine grossflächige gemauerte Einfüllung. Die erwarteten Aufschüttungen in Form von Erdmaterial oder gar Erdbebenschutt wurden nicht angetroffen. Die Analyse der verschiedenen Mauerteile ergab folgendes: Unmittelbar beim Stützpfeiler des Chors, also am hinteren Ende des Erkers, zeigte sich unerwartet eine Mauer von guter Qualität, die aufgrund ihrer Machart und des verwendeten Mörtels wohl ins 13. Jahrhundert gehört. ${ }^{8}$ Das Spezielle an dieser Mauer war, dass darin an vier Stellen grosse helle Sandsteinquader eingelassen waren. Diese Quader waren als Konsolen ausgebildet; sie ragten rechtwinklig über die Mauerflucht vor und waren in der Art von Kragsteinen unten gerundet, aber nicht weiter verziert (Abb. 14 und 15). Nachgewiesen sind in einem Fall zwei übereinander liegende Konsolsteine, von denen der obere den unteren um gegen 0,5 m überragt. Der obere Stein kragt insgesamt 78 Zentimeter aus der Mauer heraus. Die drei andern Steine liegen ohne überlagernden Konsolstein in der Mauer drin. Alle vier Konsolen bestanden ursprünglich

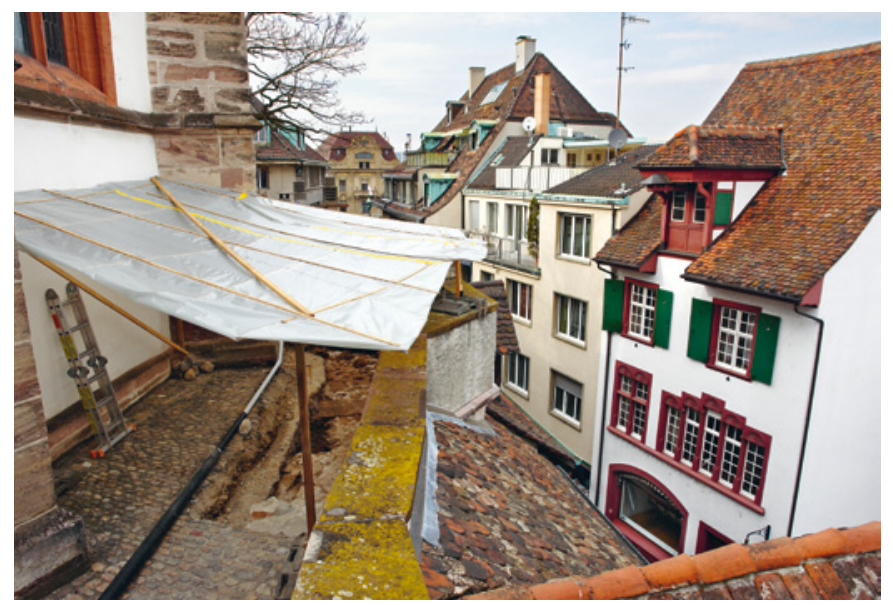

Abb. 12 Blick auf die Stützmauer mit dem Erker zwischen der Martinskirche und den Häusern am Rheinsprung. Unter der Zeltplane liegt die Ausgrabungsfläche. Foto: Christian Stegmüller. wahrscheinlich aus je drei Kragsteinen; diese hypothetische dritte Lage wurde wohl beim Bau des neuen Chors bzw. der jüngeren Stützmauer beseitigt. An einem Stein wurde eine Art Steinmetzzeichen (oder Versatzmarke?) in Form eines einfachen Kreuzes beobachtet - falls es sich nicht um eine zufällige Verletzung der Oberfläche handelt (Abb. 15). ${ }^{9}$

Durch diese insgesamt vier Konsolen wurde eine wenigstens 3,7 $\mathrm{m}$ breite Plattform realisiert, die (bei drei Konsolsteinen übereinander) eine Tiefe von um die 1,3 $\mathrm{m}$ aufgewiesen haben dürfte. Mit andern Worten: Der in der aktuellen Stützmauer heute vorhandene Erker hatte einen Vorgänger. Die neu ausgegrabene Mauer mit den Konsolsteinen lässt sich gut mit den Befunden der Grabung aus dem Jahr 1982 in Einklang bringen.

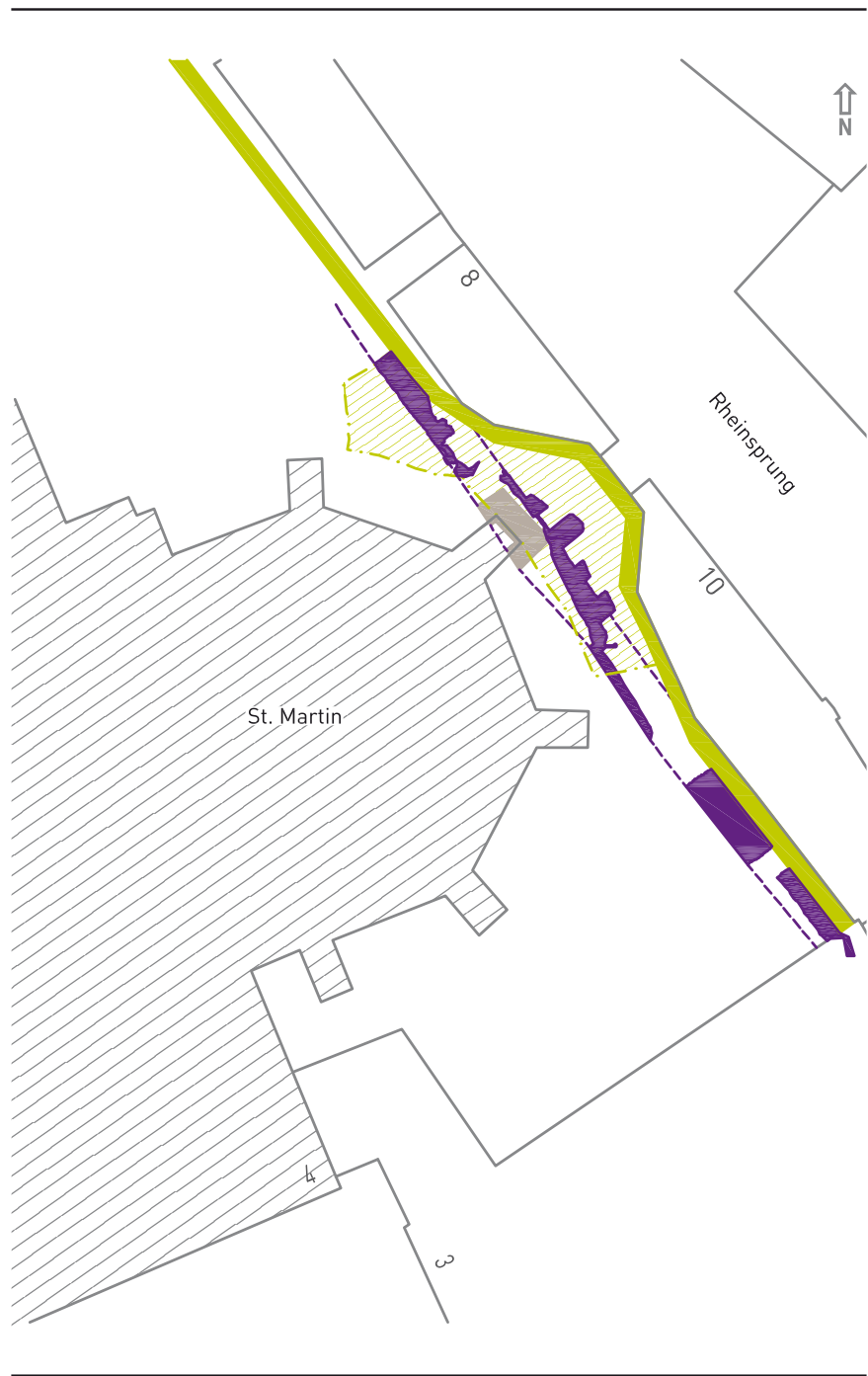

Abb. 13 Plan mit den bisher entdeckten Mauerfundamenten der älteren Stützmauer mit den vier Konsolsteinen. Massstab 1:250. Zeichnung: Christian Stegmüller. 
Damals wurde die gleiche Mauer und zwei der vier Konsolen beim Strebepfeiler des Chors angetroffen, wobei die Kragsteine allerdings nicht als solche erkannt wurden. ${ }^{10}-$ Der Chor der Kirche des 13. Jh. ist und bleibt unbekannt, da seine Fundamente beim Bau des Heizungskellers unter dem heutigen Chor im späten 19. Jh. restlos beseitigt wurden. Man nimmt einen relativ kurzen Rechteckchor an, der nach dem 1356er Erdbeben durch den heutigen Polygonalchor ersetzt wurde. ${ }^{11}$

Das nächst jüngere Element ist die aktuelle Stützmauer, woran sich am Rheinsprung die kleinen Fachwerkhäuser anlehnen. Diese Stützmauer selber entstand wohl gegen Ende des 14. Jh. und ist im Zusammenhang mit dem Neubau des 1398 geweihten Chors zu sehen. Sie wurde vor kurzem anlässlich der Renovation der Häuser Rheinsprung 8-10 untersucht und ausführlich dargestellt. ${ }^{12}$ Der dabei errichtete Erker (Abb. 12 und 13) nimmt die von der älteren Stützmauer und ihrer konsolgetragenen Plattform geprägte Tradition auf und bringt inhaltlich somit eigentlich nichts Neues. - Zur Funktion dieser Plattform (bzw. zur Vorgängerplattform) lässt sich nur vermuten, dass der Erker am ehesten als repräsentatives Architekturelement interpretiert werden darf. Er ist nicht der einzige seiner Art in Basel: Ein Jahrhundert später wurde eine ähnliche «Kanzel» als Bekrönung der Basler Pfalzmauer erbaut. ${ }^{13}$ Wie der Zwischenraum zwischen der alten und neuen Stützmauer ursprünglich verfüllt war, entzieht sich unserer Kenntnis; vielleicht wurde dort wirklich beim Erdbeben und der Kirchenrenovation angefallener Bauschutt abgelagert. Zu einem späteren Zeitpunkt (Neuzeit) wurde der Zwischenraum bis zu einer unbekannten Tiefe ausgehoben und mit einem «Mauerpfropfen» ausgefüllt, der zuerst etwas verwirrte. Eine Analyse des Mörtels, die Suche nach unterschiedlichen Mörtelausbildungen und -grenzen sowie ein gezielter lokaler Abbau der

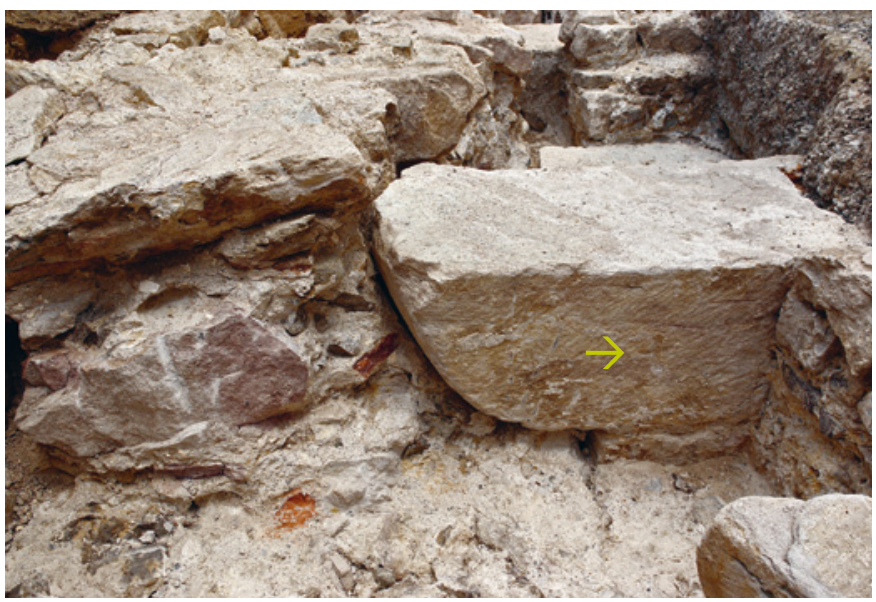

Abb. 15 Seitliche Ansicht der mittelalterlichen Konsole mit dem Steinmetz zeichen (?) in Form eines Kreuzes (Pfeil). Foto: Christian Stegmüller.
Mörtelverfüllung liessen dann die sich abzeichnenden Konsolsteine klar hervortreten (Abb. 14 und 15). ${ }^{14}$ Aufgrund der vielen vermauerten Baukeramikabfälle konnten wir die Zumauerung zwischen den beiden Stützmauern als nachmittelalterlich definieren. Die ursprünglich vorgesehene Ausgrabung des Zwischenraums zwecks Trockenlegung (bzw. das Abspitzen des eingefüllten Mauerwerks) erübrigte sich somit, und eine wasserfeste Abdichtung des Bereichs in und neben dem Erker sollte den darunter liegenden Häuslein zur nötigen Trockenheit verhelfen. Damit bleiben ein bedeutender Teil der mittelalterlichen Hangstützmauern sowie die Konsolensteine im Boden erhalten.

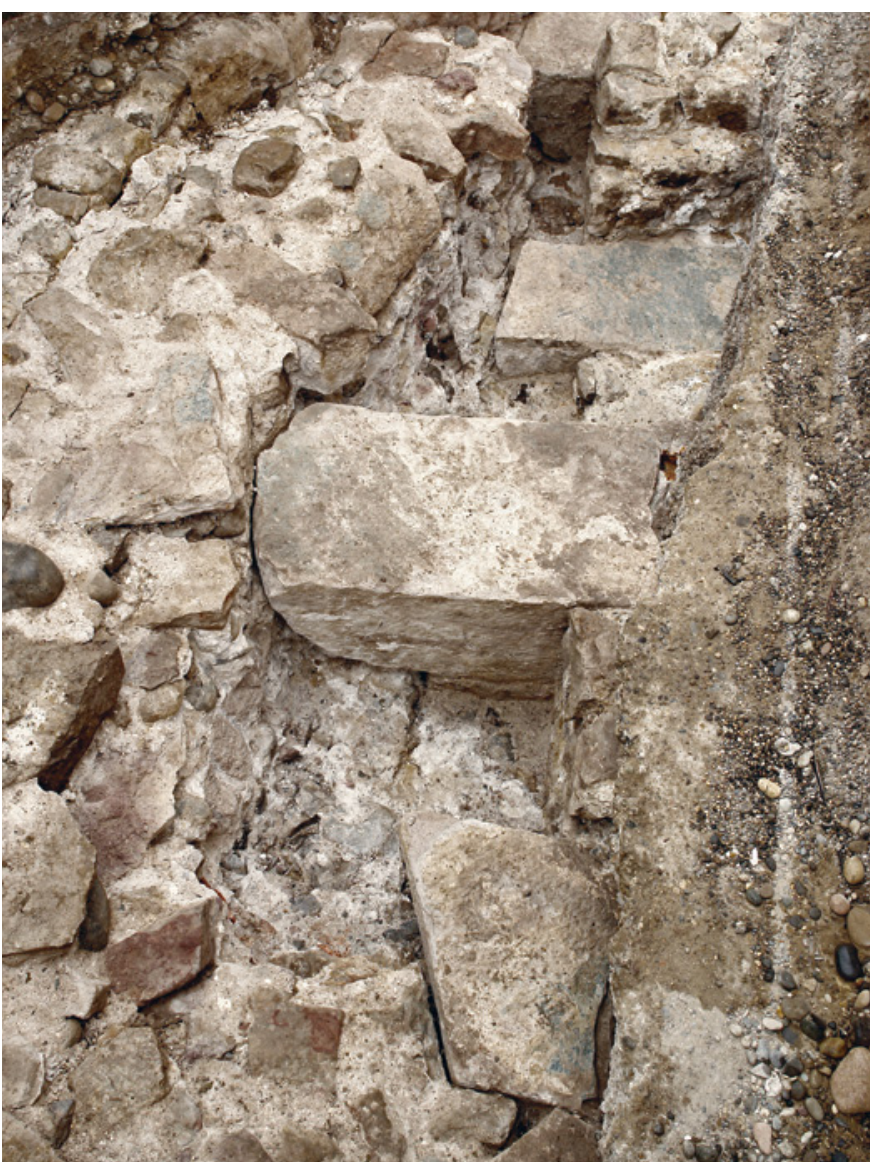

Abb. 14 Blick auf die neu entdeckte mittelalterliche Mauer mit den über die Mauerflucht nach Osten vorkragenden Konsolsteinen. Foto: Christian Stegmüller. 
2009/8 RITTERGASSE (A) 11-19A

Anlass: Neuverlegung einer Gasleitung Zeitstellung: Römische Zeit, Mittelalter Untersuchungsdauer: April bis Mai 2009 Verantwortlich: Dagmar Bargetzi, Christian Stegmüller Text: Dagmar Bargetzi

Bei der Neuverlegung einer Gasleitung kamen vor der Liegenschaft Rittergasse 19A noch ungestörte Kulturschichten zum Vorschein. Aufgrund der Funde gehören diese Schichten in die römische bis mittelalterliche Zeit. Der anstehende Boden wurde an dieser Stelle nicht erreicht, da der Graben für den Hausanschluss nur gerade 1,1 Meter tief reichte.

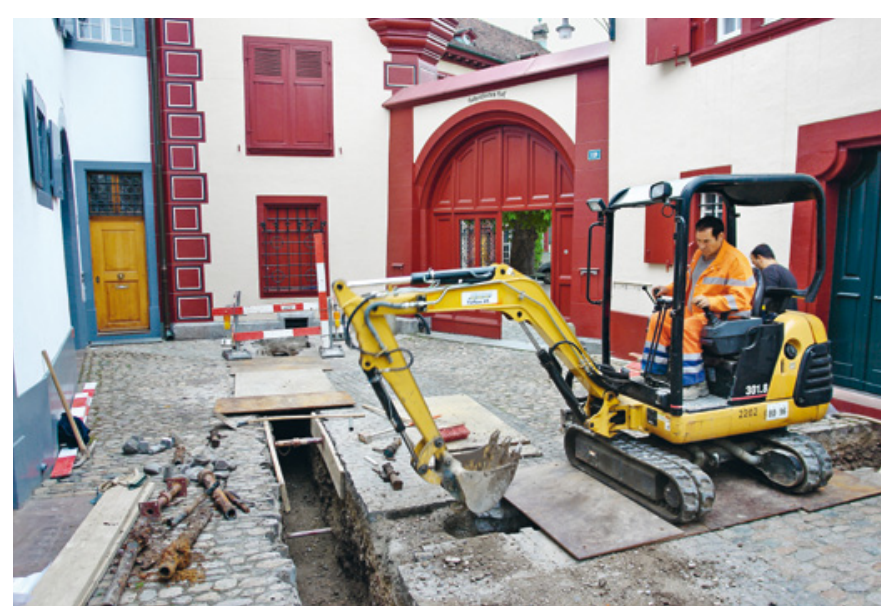

Abb. 16 Rittergasse (A) 11-19A, 2009/8. Das Baugeschäft öffnet die Gräben für die neue Gasleitung in der Rittergasse. Foto: Christian Stegmüller
2009/14 MÜNSTERPLATZ 15 (A), PARZNR. 0041

(SCHULE AUF BURG, INNENHOF)

Anlass: Sanierung Sanitärleitungen Zeitstellung: Römische Zeit, Mittelalter, Neuzeit Untersuchungsdauer: Mai bis Juli 2009 Verantwortlich: Andrea Hagendorn, Marco Bernasconi, Martin Block, Christian Stegmüller Text: Marco Bernasconi

In mehreren Etappen wurden die Platzentwässerungs-Leitungen und Wassersammler im Innenhof des Gymnasiums saniert. Zu grossen Teilen wurden die Profile in den bestehenden Trassees untersucht; eine Plangrabung wurde wegen der Versetzung eines Wassersammlers notwendig.

Es konnten zwei Pflästerungen festgestellt werden. ${ }^{15}$ Ferner wurden mehrere - vermutlich spätmittelalterliche oder frühneuzeitliche - Eingriffe gefasst, so Fundamente von kleinen Mäuerchen, möglicherweise ehemalige Parzellengrenzen oder Garteneinfriedungen. Hinweise auf ein Brunnenfundament konnten im nördlichen Bereich des Grabungsareals festgestellt werden. Direkt darunter konnten so genannte dark earth-Schichten dokumentiert werden. Da in diesen Schichten keine eindeutigen Strukturen erkannt oder bauliche Konstruktionen gefasst wurden, kann davon ausgegangen werden, dass es in diesem Bereich keine fundamentierten Gebäude gab. Ausplanierter Abbruchschutt deutet jedoch auf Bautätigkeit in spätrömischer oder frühmittelalterlicher Zeit hin. 


\section{9/16 MARTINSGASSE (A)}

Anlass: Werkleitungsbau Zeitstellung: Bronzezeit, Spätlatènezeit, Römische Zeit, Mittelalter, Neuzeit Untersuchungsdauer: Juni bis Dezember 2009 (Arbeiten werden 2010 fortgesetzt) Verantwortlich: Andrea Hagendorn, Marco Bernasconi, Martin Block, Christian Stegmüller, Sven Straumann Text: Marco Bernasconi, Sven Straumann

Anlass der den Bauvorgang begleitenden archäologischen Massnahmen sind die Gesamterneuerungsarbeiten an den teilweise über hundertjährigen Werkleitungen sowie mehrere neue Leitungsstränge, die in ungestörte Kulturschichten verlegt werden sollen. Damit einhergehend werden alle Strassenund Platzbeläge auf dem Münsterhügel erneuert.

Im etappierten Projekt wurden 2007/08 die Arbeiten am Rheinsprung und in der Augustinergasse und von Juni 2009 bis Dezember 2010 auf dem Martinskirchplatz, im Archivgässlein, in der Martinsgasse, am Stapfelberg, in den östlichen Abschnitten des Münsterbergs und Schlüsselbergs sowie auf dem Kleinen und Grossen Münsterplatz, auf der Pfalz und in der Rittergasse und danach wieder am Münsterberg und Schlüsselberg archäologisch begleitet. Aufgrund der Verbreiterung der bestehenden Leitungstrassees und der Neuverlegung von Werkleitungen in ungestörte Zonen sind neben baubegleitenden Untersuchungen auch Rettungsgrabungen nötig. Vor der laufenden Bauetappe wurden 2008 in zwei Bereichen des grossen Münsterplatzes Georadar-Untersuchungen gemacht. Die vorgängige fachgerechte Untersuchung und Dokumentation der nach den Tiefbauarbeiten zerstörten archäologischen Kultur-

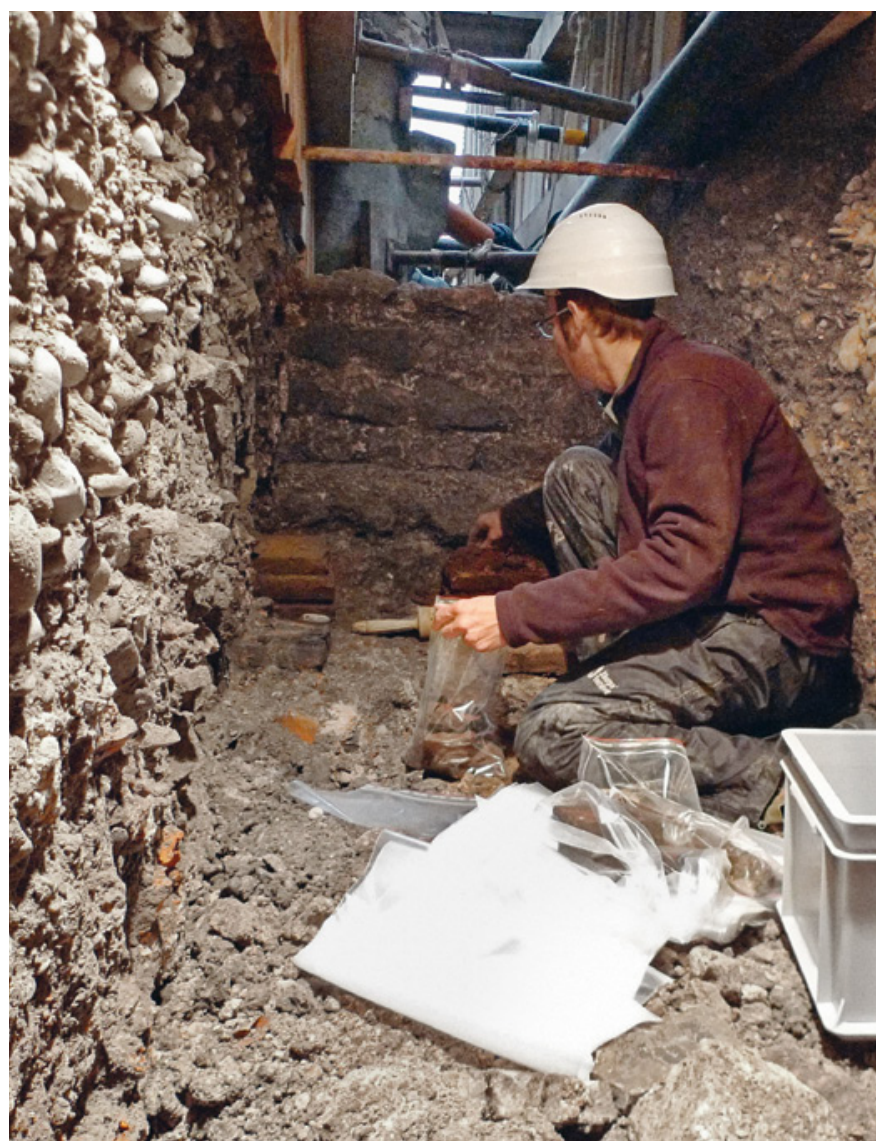

Abb. 17 Materialbeprobung in einer Tiefe von $3 \mathrm{~m}$ unter der modernen Belagsoberfläche. schichten des seit mehr als 3000 Jahren besiedelten Basler Münsterhügels ist von grösster Bedeutung für das Verständnis der Stadtentwicklung. Ein Einblick in dieser Grössenordnung ist zudem einzigartig und wird es erlauben, mehrere heute ungeklärte Sachverhalte und offene Fragen auf besserer Grundlage anzugehen.

Die ältesten Strukturen und Funde kamen auf dem Martinskirchsporn zum Vorschein. Dort wurde eine rund $3 \mathrm{~m}$ mächtige Stratigraphie dokumentiert (Abb. 17). Eine Plangrabung auf dem Martinskirchplatz lieferte zahlreiche bronzezeitliche Keramikfragmente als Überreste der urgeschichtlichen Siedlung. An der Martinsgasse wurde im Innenhof der Liegenschaft Rheinsprung 18 («Weisses Haus») der schon bekannte spätbronzezeitliche Graben erneut gefasst. Dabei konnte die südliche Grabenkante und damit der bisher nur vermutete weitere Verlauf nach Osten nachgewiesen werden. Dieser Graben wurde bei einer 1978 durchgeführten Ausgrabung im Hofbereich der Liegenschaft Martinsgasse 12 erstmals nachgewiesen. Allerdings wurde damals in der Grabungsfläche nur ein kleiner Ausschnitt der nördlichen Grabenwand erfasst. In der Martinsgasse 6+8 konnte 2004 der Graben in seiner ganzen Dimension dokumen-

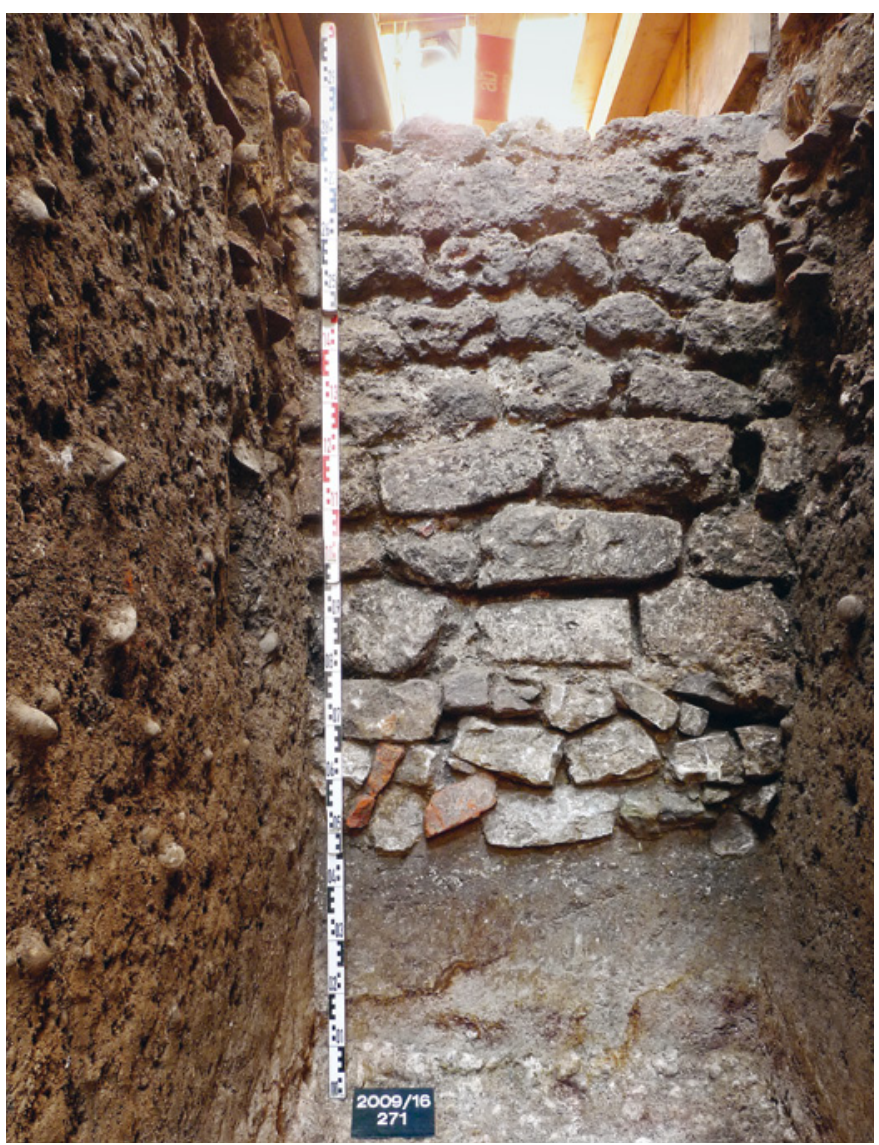

Abb. 18 Fundament einer römischen Gebäudemauer. Foto: Katia Schaer. 
tiert werden. ${ }^{16} \mathrm{Er}$ hat eine Breite von ca. $10 \mathrm{~m}$ sowie eine Tiefe von ca. $3 \mathrm{~m}$. Es ist davon auszugehen, dass der Graben bereits in der Spätbronzezeit wieder aufgegeben und eingeebnet wurde. Von einer nächst jüngeren Siedlungsphase im Bereich des Martinskirchsporns zeugen spätlatènezeitliche Spuren. So enthielt eine Grube zahlreiche Keramikscherben dieser Zeitstellung. Baustrukturen liessen sich jedoch keine feststellen.

Aus der römischen Zeit hingegen haben sich deutliche Befunde erhalten, die eine Besiedlung des Martinskirchsporns belegen. Es handelt sich um die Reste eines Steingebäudes, das über sorgfältig gefertigte, gemörtelte Mauern verfügte (Abb. 18). Als Baumaterial diente u. a. Tuffstein. Im Bereich der Fundamentschüttung fanden sich aber auch Baukeramikfragmente. Direkt anschliessend an die südliche Gebäude-Aussenmauer kamen in einer wohl als Abfallgrube anzusprechenden Struktur zahlreiche Tierknochen und Baukeramikfragmente zum Vorschein.

Der Innenraum des Steinbaus war mit einem qualitativ hochwertigen Mörtelboden ausgestattet (Abb. 19). ${ }^{17}$ Darüber errichtete man in einer späteren Phase einen Hypokaust. Dessen Pfeiler waren noch relativ zahlreich vorhanden. Aufgrund von Vergleichswerten lässt sich das zugehörige Gehniveau des beheizten Raumes rekonstruieren. Dieses liegt in Bezug zur dokumentierten Stratigraphie verhältnismässig tief. Daraus stellt sich für die römische Belegung des Martinskirchsporns die Frage, ob allenfalls mit einer terrassenartigen Bebauungsstruktur zu rechnen ist. Auch die Überlegungen in Zusammenhang mit dem erst sehr tief angetroffenen Rheinschotter, dem natürlich anstehenden Boden, bieten Raum für eine derartige Interpretation. Zwar wurde das Fundmaterial bisher erst grob gesichtet. Trotzdem können die Baubefunde wahrscheinlich in spätrömische Zeit datiert werden. Neben den Fundmünzen spricht auch das Erscheinungsbild der Steinmauern für eine solche zeitliche Einstufung.

Wie das Schuttmaterial zeigt, wurde das Gebäude vermutlich noch in spätrömischer Zeit abgebrochen. Spätestens im Frühmittelalter kam es im Areal der Gebäude-Ruinen zu einer funktionalen Umnutzung. Im spätrömischen Abbruchschutt lag nämlich ein Steinplattengrab (Abb. 20). Diese Bestattungsweise deutet auf eine Datierung ins 7./8. Jahrhundert. Folglich wurde der Martinskirchplatz bereits im Frühmittelalter als Friedhof genutzt. Dieser erstmalige Nachweis einer frühmittelalterlichen Nutzung des Martinskirchsporns als Bestattungsplatz ist von grosser Bedeutung, denn die gängige Forschungsmeinung vermutet dort eine auf fränkische Zeit zurückreichende Pfarrkirche.
Zahlreiche weitere mittelalterliche und neuzeitliche Körperbestattungen auf dem Martinskirchplatz gehören zum ehemaligen Friedhof um die St. Martinskirche. Dieser war bis zur Einweihung des St. Elisabethengottesackers 1818 in Betrieb. ${ }^{\mathbf{1 8}}$ An mehreren Stellen konnten aufgegebene (früh)neuzeitliche Entwässerungssysteme dokumentiert werden: Entlang der Fassaden der Liegenschaften Martinskirchplatz 1, 2 und 3 sowie im Archivgässlein zeugt ein sehr sorgfältig bearbeiteter sandsteinerner Kanal von den Bemühungen um die Platzentwässerung und eine effiziente Wassernutzung.

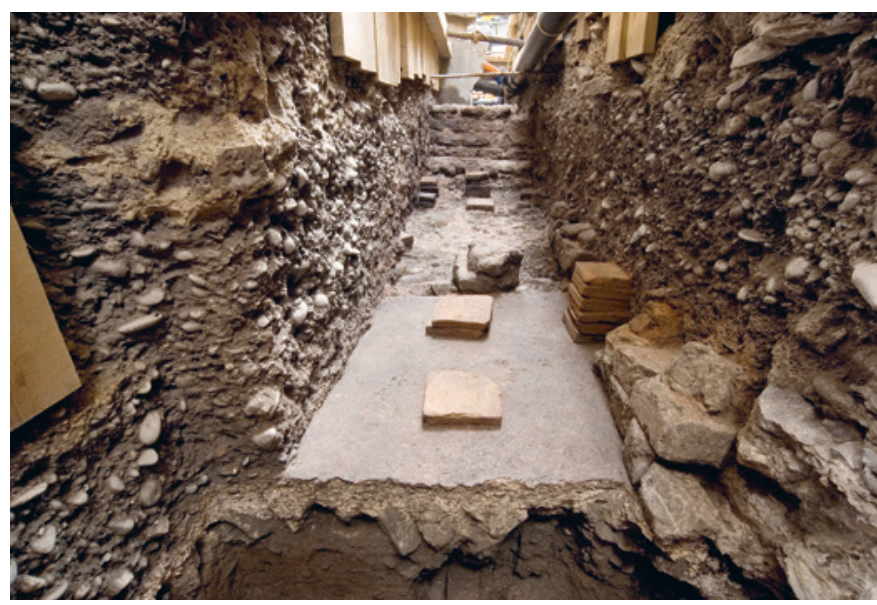

Abb. 19 Reste eines römischen Steingebäudes mit Mörtelboden und Hypokaust. Foto: Philippe Saurbeck.

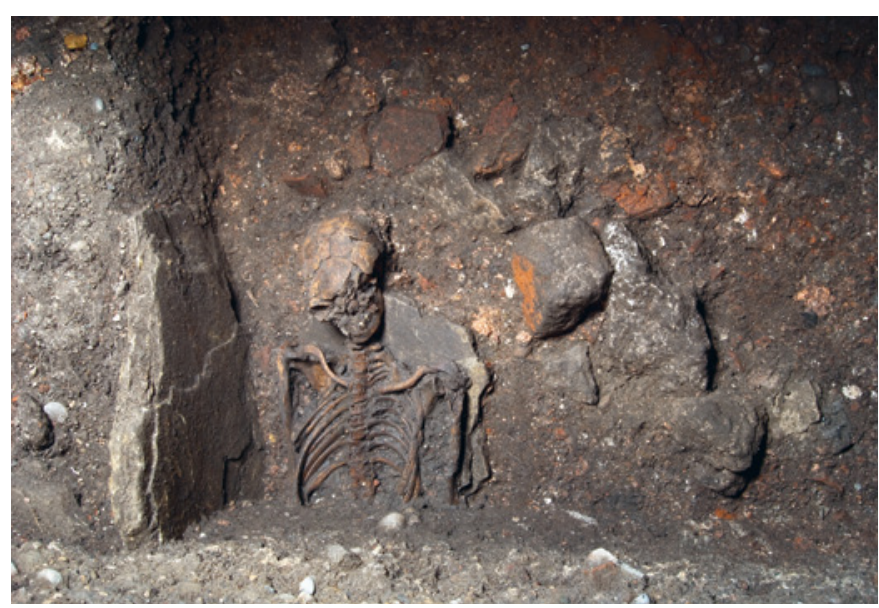

Abb. 20 Frühmittelalterliches Steinplattengrab. Foto: Philippe Saurbeck. 


\section{9/17 MÜNSTERPLATZ (A)}

Anlass: Werkleitungsbau Zeitstellung: Spätlatènezeit, Römische Zeit, Mittelalter, Neuzeit Untersuchungsdauer: Juni bis Dezember 2009 (Arbeiten werden 2010 fortgesetzt) Verantwortlich: Andrea Hagendorn, Marco Bernasconi, Martin Block, Christian Stegmüller, Sven Straumann Text: Marco Bernasconi, Sven Straumann

Aus demselben Anlass und zeitgleich mit den Ausgrabungen 2009/16 und 2009/18 wurden auch auf dem Münsterplatz archäologische Untersuchungen durchgeführt.

Anders als beim Martinskirchsporn beschränken sich die ältesten archäologischen Zeugnisse hier auf die Spätlatènezeit und die frührömische Epoche. Die verschiedenen Aufschlüsse waren praktisch über den gesamten Kleinen und Grossen Münsterplatz verstreut. So konnten jeweils relativ kleinflächig Befunde dokumentiert werden. Es liessen sich jedoch keine eigentlichen Baubefunde erfassen. Meist handelte es sich um Planieschichten und Gehniveaus. Darin kamen aber durchaus besondere Fundobjekte zum Vorschein. Dazu zählt beispielsweise ein aus Knochen geschnitzter römischer Schreibgriffel (stilus), einer der nunmehr vielen Hinweise auf den Gebrauch der Schrift in Basel ab der römischen Zeit (Abb. 21).

Auf dem Münsterplatz liessen sich auch verschiedene frühmittelalterliche Zeugnisse nachweisen. Zwar zeichneten sich in den für diese Zeit typischen dunklen sog. dark earth-Schichten kaum deutliche Befunde ab, doch enthielten sie frühmittelalterliche Fundobjekte. Neben der charakteristischen Gefässkeramik ist beispielsweise ein beinerner Spinnwirtel aus dem 6./7. Jahrhundert hervorzuheben (Abb. 22). Vereinzelt konnten früh- oder hochmittelalterliche Bestattungen festgestellt werden. Unmittelbar vor der Liegenschaft Münsterplatz 14 zeigen diese Gräber die Minimalausdehnung des Friedhofbereichs in westlicher Richtung vor dem Münster an.

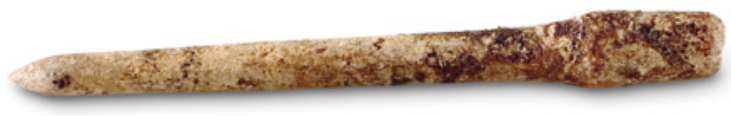

Abb. 21 Aus Knochen geschnitzter römischer Schreibgriffel. Länge: 7,5 cm. Foto: Philippe Saurbeck.

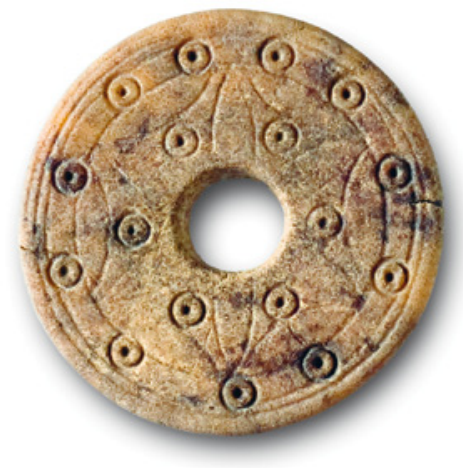

Abb. 22 Beinerner frühmittelalterlicher Spinnwirtel. Durchmesser: 3,6 cm Foto: Philippe Saurbeck.

\section{9/18 RITTERGASSE (A)}

Anlass: Werkleitungsbau Zeitstellung: Spätlatènezeit, Römische Zeit, Mittelalter, Neuzeit Untersuchungsdauer: Juni bis Dezember 2009 (Arbeiten werden 2010 fortgesetzt) Verantwortlich: Andrea Hagendorn, Marco Bernasconi, Martin Block, Christian Stegmüller, Sven Straumann

Text: Marco Bernasconi, Sven Straumann

Auch diese Grabung war Teil des Grossprojektes «Werkleitungsbauten» und wurde parallel zu den Untersuchungen 2009/16 und 2009/17 durchgeführt. In der Rittergasse wurde an zwei Stellen erneut der Murus Gallicus angetroffen (Abb. 23). Unter den Versturz- und Planieschichten des Murus konnten noch drei aufgehende Steinlagen ${ }^{19}$, Spuren des Balkengitters mit einem erhaltenen Eisennagel sowie ein Ausschnitt der südlich anschliessenden Berme festgestellt werden. Auf der Berme wurden der Bauhorizont des Murus und Hinweise auf Eisenverarbeitung und Reparaturarbeiten an der Befestigungsanlage gefunden.

In römischer Zeit wurde an der heutigen Rittergasse über einen langen Zeitraum kontinuierlich gesiedelt. Dies schlägt sich auch in der Anzahl Befunde und Funde deutlich nieder. Bei den umfangreichen Profilaufschlüssen vor den Liegenschaften Rittergasse 1-4 liess sich eine rund 1,5 m mächtige Stratigraphie fassen (Abb. 24). Über den spätkeltischen Siedlungsspuren folgte eine Reihe von römischen Kulturschichten (Abb. 25). Dabei handelte es sich zumeist um die ausplanierten Reste von Holzfachwerk-Lehmbauten, die einst entlang der Hauptverkehrsachse standen. Bemerkenswert ist auch eine Abfolge von

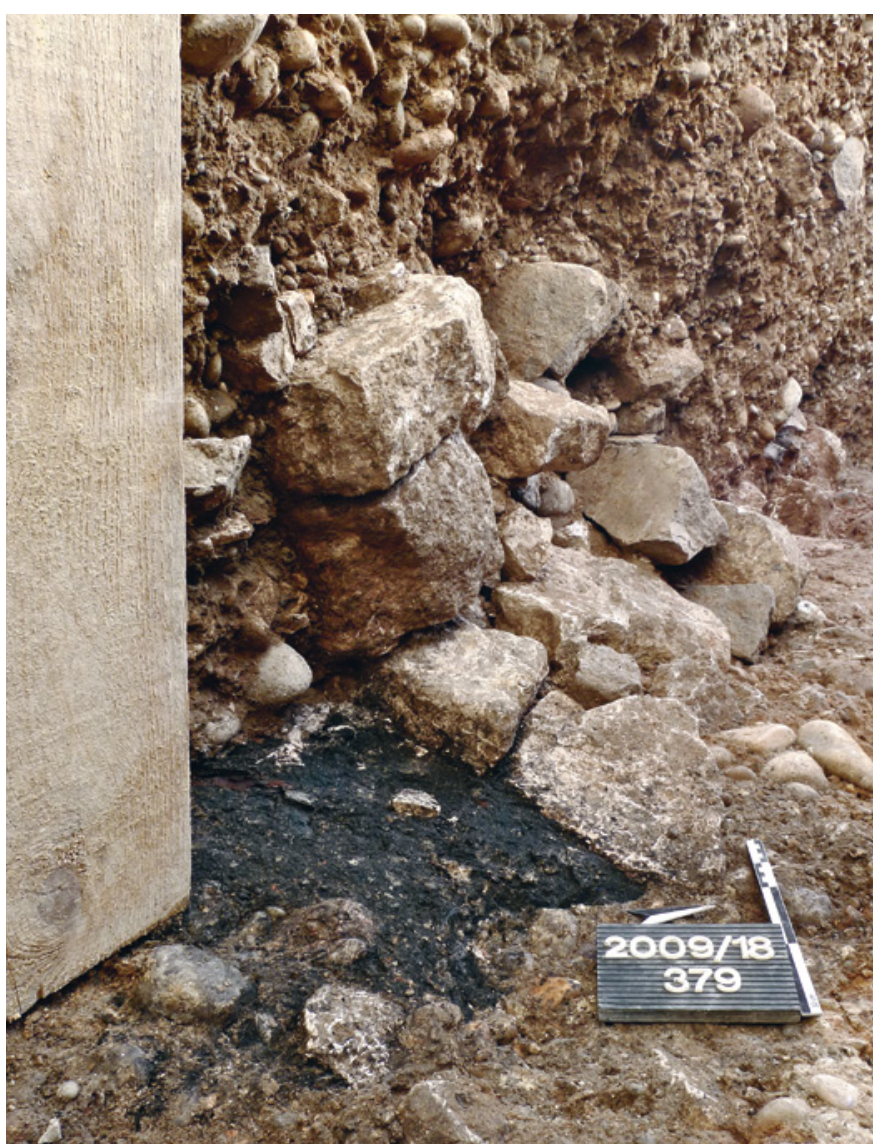

Abb. 23 Drei Steinlagen des Aufgehenden des Murus Gallicus. Foto: Katia Schaer. 
mehreren Brandhorizonten. Die Substruktion der spätkeltischrömischen Hauptstrasse, bestehend aus Kieselwacken, konnte in einem Teilbereich ebenfalls dokumentiert werden. Ferner gab es Hinweise auf abzweigende Verkehrswege. Ergänzend zu den archäologischen Beobachtungen wurden gezielt geoarchäologische Proben entnommen. Deren naturwissenschaftliche Untersuchung ergibt hoffentlich spannende Aussagen zur Schichtgenese und ermöglicht evtl. die Identifikation von Gehhorizonten, die mit blossem Auge nicht erkennbar waren. Genauere Angaben zur Chronologie dieser Abfolge von Kulturschichten können noch nicht gemacht werden. Es konnte jedoch zuweisbares Fundmaterial geborgen werden. Besonders interessant wird eine Korrelation mit vergleichbaren Schichtaufschlüssen in der Umgebung. Durch diese Verknüpfung lassen sich möglicherweise auch Rückschlüsse auf die Bebauungsstruktur entlang der damaligen Hauptverkehrsachse gewinnen. Im Bereich vor den Liegenschaften Rittergasse 2, 4 und 10 konnten mehrfach Überreste mittelalterlicher und frühneuzeitlicher Gebäude festgestellt werden. Wie erwartet, wurden unmittelbar östlich vor dem Haus Rittergasse 2 Fundamentmauern und verfüllte Kellerabschnitte des ehemaligen Antistitiums gefasst. Weiter südlich, im Bereich vor der Liegenschaft Rittergasse 4, konnten nur noch geringe Überreste des Schönauerhofs festgestellt werden. Beim von Samuel Werenfels 1760 erbauten Haus zum Delphin (Rittergasse 10) wurde ein vermutlich tonnengewölbter Keller nachgewiesen. Alle diese Gebäude wurden im 19. Jahrhundert durch verschiedene Strassenverbreiterungs- und Nivellierungsarbeiten verkleinert oder abgebrochen. Im Zuge dieser Massnahmen kam es auch auf der östlichen Strassenseite zu grösseren Eingriffen. Im Bereich vor dem Kreuzgang und der St. Maria-Magdalena-Kapelle konnten mehrere Mauerpartien des mehrphasigen domherrlichen Pfrundkellers dokumentiert werden. Der massive mehrstöckige Bau ging in seinem Kern sicher auf das 14. Jahrhundert zurück; die Existenz eines Vorgängerbaus aus dem 11. Jahrhundert ist durch schriftliche Quellen zwar belegt, kann an dieser Stelle allerdings nur vermutet werden.

Westlich vor der an den Kreuzgang anschliessenden MariaMagdalena-Kapelle wurde eine Nord-Süd ausgerichtete Holzsargbestattung eines weiblichen Individuums freigelegt (Abb. 26). ${ }^{20}$ Kopf und Oberkörper waren komplett erhalten, Becken und untere Extremitäten nicht mehr vorhanden. Die noch nicht abgeschlossene anthropologische Untersuchung hat ergeben,

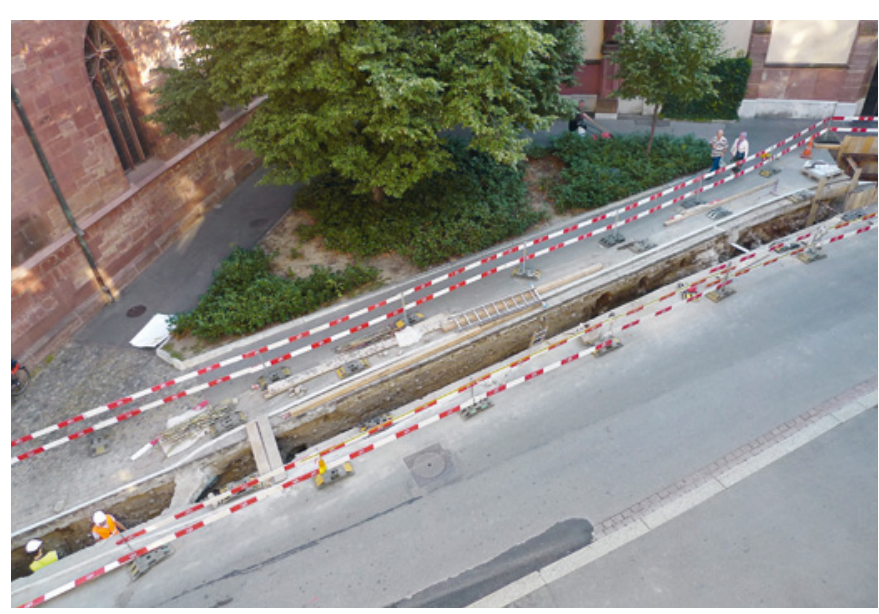

Abb. 24 Profilaufschluss entlang der Gasse, im Hintergrund sind Münster und Kreuzgang zu sehen. Foto: Jan Baur.

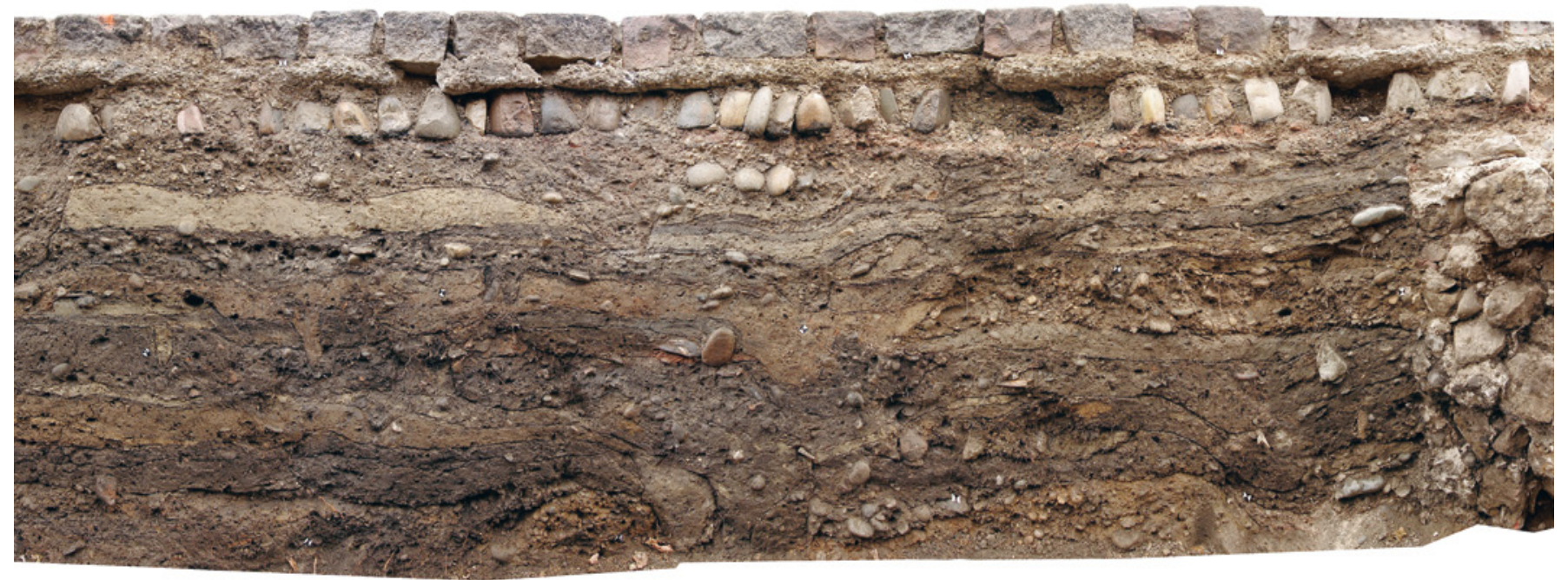

Abb. 25 Profil mit einer dichten Abfolge von Kulturschichten. Foto: Katia Schaer. Bearbeitung: Serafin Pazdera. 
dass das Individuum ein Alter von 25 bis 48 Jahren erreicht hatte. Ausser zwei Gewandhäkchen konnte ein Goldohrringpaar in Trachtlage geborgen werden. Die Ohrringe wurden durch kunsthistorische Vergleiche ins 17. Jahrhundert datiert. Aufgrund überlieferter Pläne und schriftlicher Quellen ist davon auszugehen, dass die Tote im ehemaligen Westbereich der 1860 um rund $4 \mathrm{~m}$ verkürzten St. Maria-Magdalena-Kapelle bestattet wurde. Mit Hilfe des 1761 erstellten Gräberplans von J.J. Fechter sowie weiterer Hinweise aus Stammbäumen, Familienbüchern und Epitaphien konnten erste Hypothesen zur Identität der Verstorbenen aufgestellt werden.

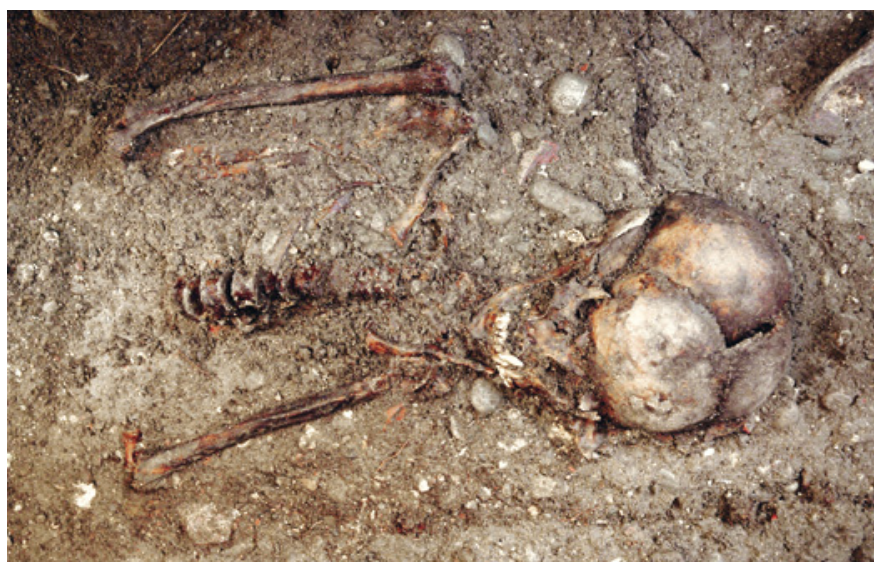

Abb. 26 Neuzeitliche Körperbestattung mit Beigabe eines goldenen Ohrringpaares. Foto: Sven Straumann. 


\section{9/40 MÜNSTERPLATZ (A), PARZNR. 9007 (PFALZ) UND PARZNR. 0871 (RHEINUFERWEG)}

Anlass: Bau von Stromleitungen und Fundamenten für eine neue Pfalzbeleuchtung Zeitstellung: Mittelalter, Neuzeit Untersuchungsdauer: November 2009 Verantwortlich: Andrea Hagendorn, Martin Block, Sven Straumann Text: Sven Straumann

Parallel zur Sanierung der Werkleitungsbauten auf dem Münsterhügel wurden im Bereich der Pfalz resp. entlang des dortigen Rheinufer-Abschnitts neue Stromleitungen für die Beleuchtung verlegt. Die punktuellen und relativ kleinflächigen Bodeneingriffe wurden den Bauvorgang begleitend untersucht. Erwartungsgemäss konnten kaum archäologische Befunde nachgewiesen werden. Einzig in einer kleinen Grube ergab sich ein interessanter Profilaufschluss: Unter der rund $40 \mathrm{~cm}$ mächtigen, recht stark durchwurzelten Humusschicht kam eine homogene rote Schicht aus Sandsteinbruchstücken und Sandsteinmehl zum Vorschein (Abb. 27). Das ausgesprochen einheitliche Bild dieser mindestens $20 \mathrm{~cm}$ dicken Schicht spricht für eine Deutung als Bauhorizont. Datierendes Fundmaterial konnte darin leider nicht festgestellt werden.

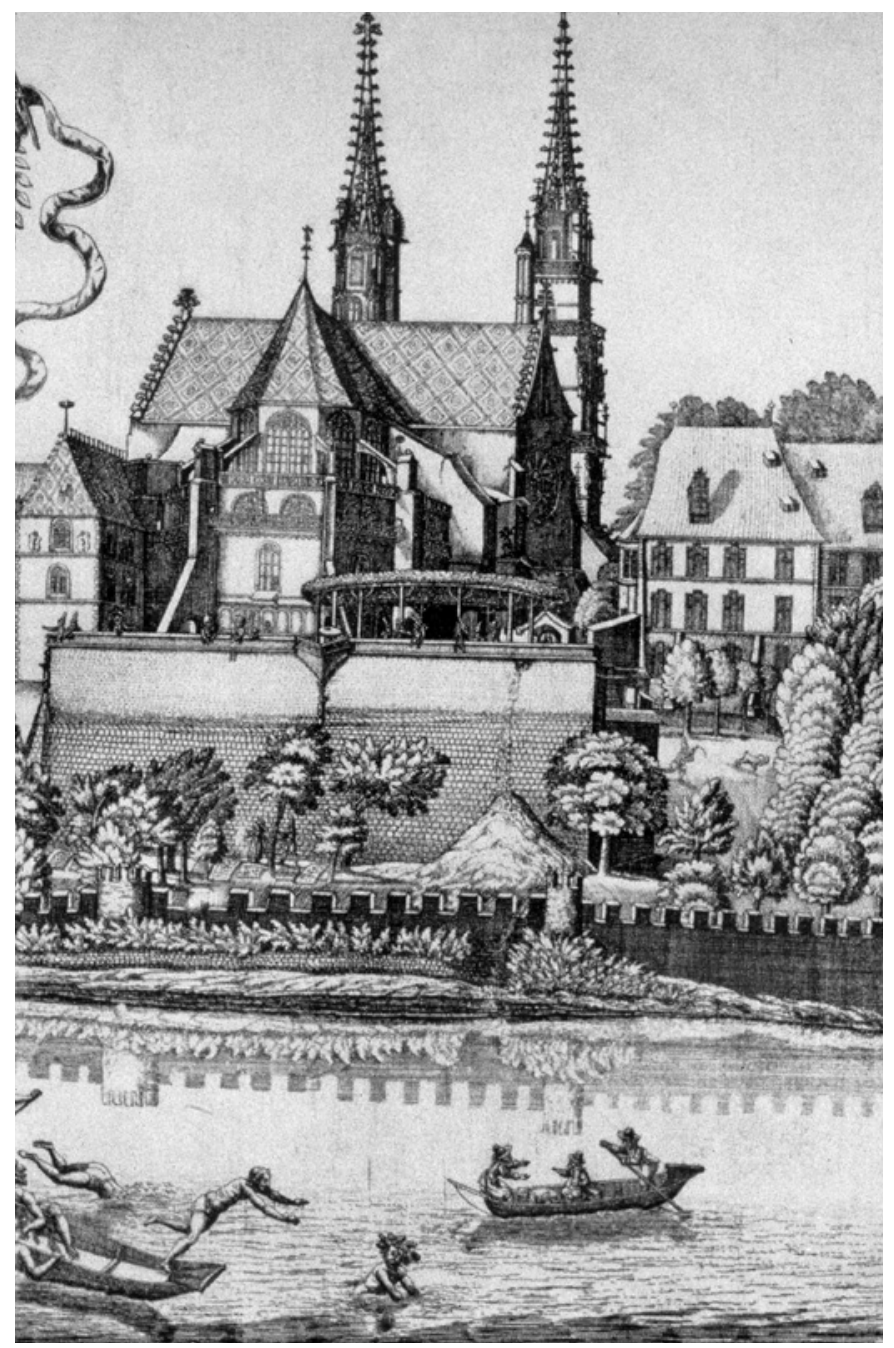

Abb. 28 Ausschnitt des Kupferstichs des Hans Heinrich Glaser aus dem Jahr 1642 mit Blick auf Niklauskapelle, Münster und Pfalz. Unterhalb der Pfalzmauer erhebt sich ein Abfallberg (Historisches Museum Basel, Inv. Nr. 1942.293).
Ein Zusammenhang mit dem Bau der nahe gelegenen, $18 \mathrm{Me}-$ ter hohen Pfalzmauer scheint durchaus plausibel. Es würde sich folglich bei den Sandsteinabfällen um beim Fertigstellen des Bossenquader-Mauerwerks angefallenes Material handeln. Chronologisch lassen sich diese Arbeiten vermutlich in den Zeitraum der Erneuerung der Pfalzmauer zwischen 1503 und 1510 einstufen. ${ }^{21}$

Berücksichtigt man eine Bildquelle aus dem Jahr 1642, ist aber eine andere Erklärung des Ursprungs dieser Abfallschicht nicht ganz auszuschliessen. ${ }^{22}$ Auf dem Kupferstich von Hans Heinrich Glaser erhebt sich nämlich direkt unterhalb der Pfalzmauer ein Abfallberg (Abb. 28). ${ }^{23}$ Auch wenn dessen Lage erstaunlich gut mit derjenigen des festgestellten Sandsteinhorizontes übereinstimmt, muss man doch erwägen: Ein Abfallberg am Fusse der Pfalz würde sich kaum derart homogen im archäologischen Befund zeigen. Es wäre mit verschiedensten Ablagerungen zu rechnen. Dazu würde sicher auch unterschiedlicher Bauschutt gehören.

Die ausgeprägte Sandsteinschicht konnte im Rahmen der Grabung 2009/40 zwar lediglich in einem kleinen Aufschluss festgestellt werden. Dennoch ist anzunehmen, dass es sich wohl um ein grossflächiges Phänomen entlang der Pfalzmauer handelt. Jedenfalls ist eine Deutung als Bauhorizont der Pfalzmauer am wahrscheinlichsten.

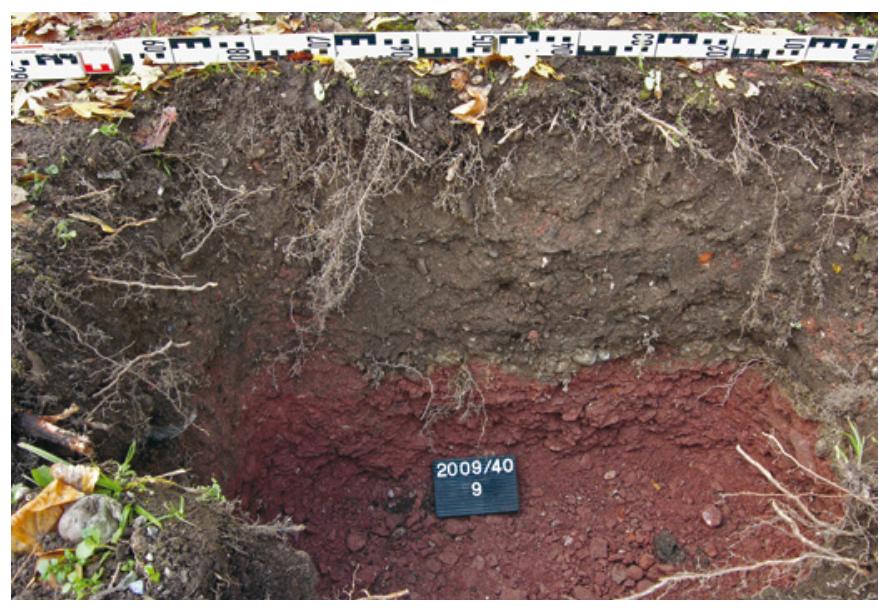

Abb. 27 Fläche 1c, Westprofil: Diese homogene Schicht aus rotem SandsteinAbfall kann wohl als Bauhorizont der Pfalzmauer gedeutet werden. Foto: Jan Baur. 


\section{9/3 ST. ALBAN-KIRCHRAIN 10 (JUGENDHERBERGE)}

Anlass: Erweiterungsbauten/Umgebungsarbeiten Untersuchungsdauer: Januar 2009 Verantwortlich: Christoph Matt Text: Christoph Matt

Im «Dalbeloch» liegt die Jugendherberge der Stadt Basel. Sie wurde vor 30 Jahren in einer ehemaligen Seidenbandfabrik untergebracht (erbaut 1850/51). Das mittlerweile etwas in die Jahre gekommene Gebäude wurde einer umfassenden Sanierung unterzogen. ${ }^{24}$ Dabei wurde auch das östliche Vorgelände baulich verändert (Abb. 29). Dort verlief schon das Trassee der Fernheizung, und auch andere Bodeneingriffe z.B. vom Bau von Terrassierungsmauern waren vorhanden, so dass unsere Hoffnung auf archäologische Funde nicht gross war. Trotzdem haben wir die Baustelle wegen der Nähe zum St. Alban-Kloster und wegen des Vorkommens römischer und prähistorischer Funde im «Dalbeloch» beobachtet. Allerdings zeigte sich nichts von Interesse. Immerhin konnte die nahe gelegene Münsterbauhütte von unserer Aktion profitieren, denn im Aushub kamen einige grosse Blöcke aus Wiesentäler Sandstein zum Vorschein. Sie stammten wohl vom Bau der Fabrik. Diese konnten wir in Absprache mit dem Polier der Bauhütte vermitteln, wo sie entweder im Rahmen der Lehrlingsausbildung für Übungsarbeiten zur Verfügung stehen oder vielleicht auch einmal als Ersatzstücke am Münster verbaut werden können.

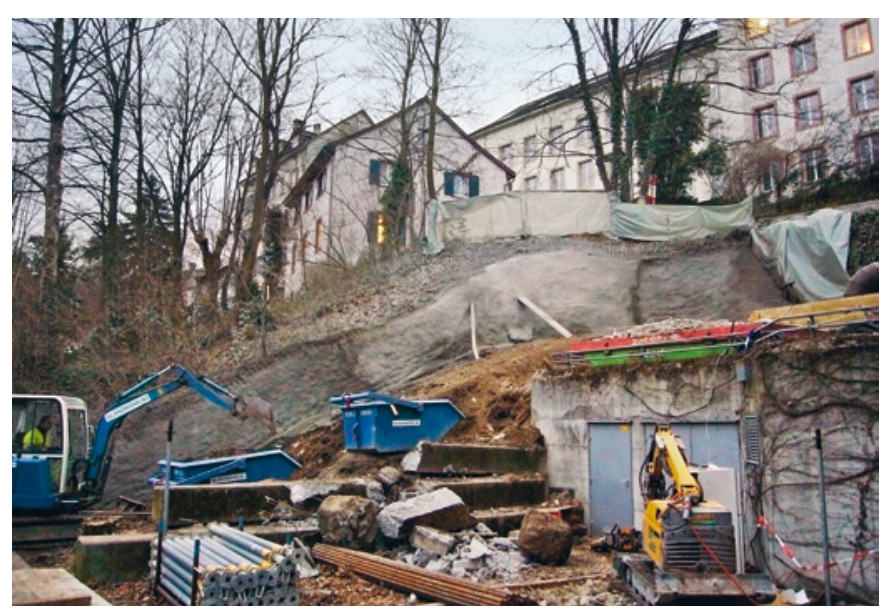

Abb. 29 Blick über die Baustelle östlich des langgezogenen Fabrikgebäudes am Fusse des Talhangs unmittelbar neben dem Gewerbekanal ldem «Dalbedych»: links hinter dem Bagger, nicht sichtbar). Foto: Christoph Matt.

\section{9/6 GLOCKENGASSE (A)}

Anlass: Leitungsersatzbau Zeitstellung: Neuzeit Untersuchungsdauer: März 2009 Verantwortlich: Udo Schön, Christoph Matt Text: Christoph Matt

In der kurzen und engen Altstadtgasse musste die alte, mehrfach gebrochene Wasserleitung ersetzt werden. Dies war nicht mit grossen archäologischen Hoffnungen verbunden, handelte es sich doch um das Auswechseln einer bestehenden Leitung an Ort und Stelle in einer Gasse, die von verschiedenen Werkleitungen schon ziemlich durchpflügt ist (Abb.30). ${ }^{25}$ Alte Gassenniveaus waren demzufolge nicht mehr zu erwarten, zumal sich die heutige Glockengasse nur zum kleinsten Teil mit ihrer historischen Vorläuferin, dem Sackgasse-Fortsatz der Sattelgasse, deckt. Diese Sackgasse trug Ende des 13. Jahrhunderts den wenig ehrenvollen Namen «Gesslin hinder ars»; der (neue) Name «Glockengasse» geht auf das zwischen 1907 und 1909 abgebrochene Haus «Zur Glocke» an der Hutgasse zurück, das

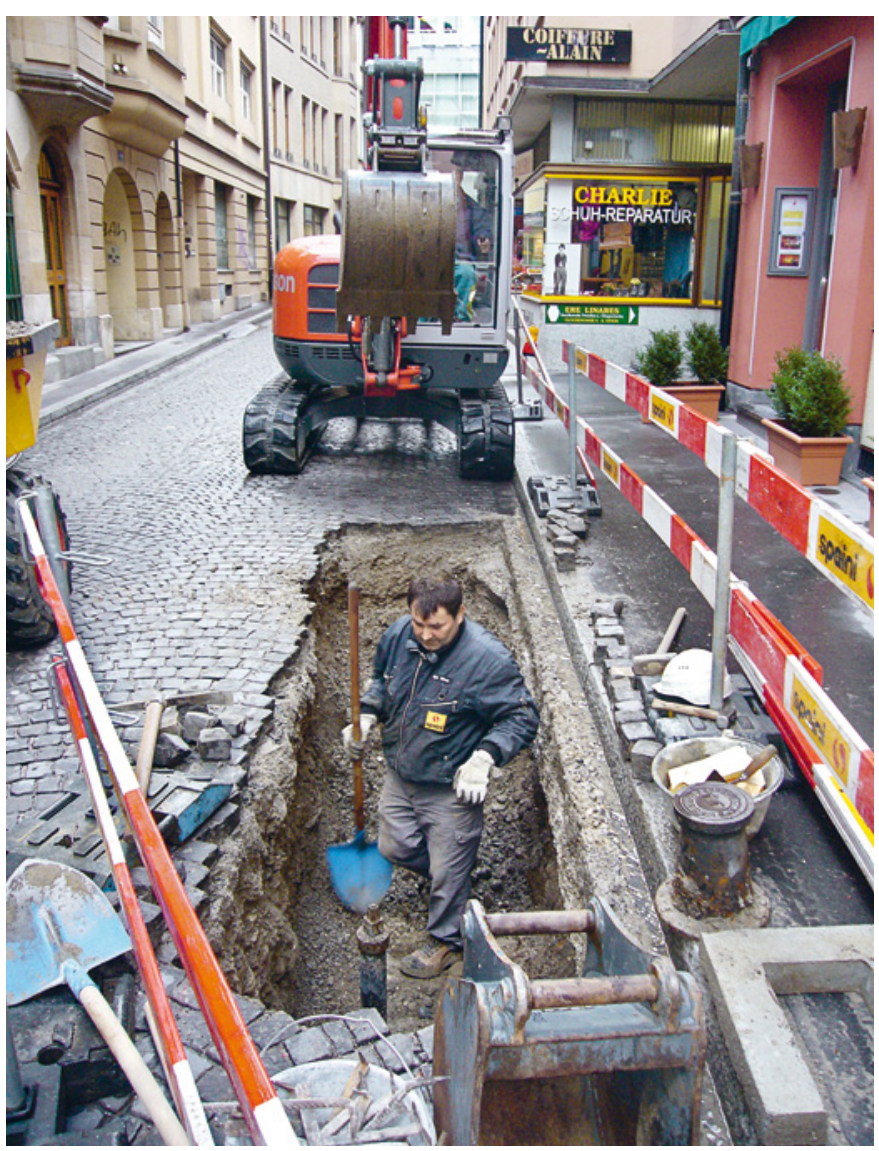

Abb. 30 Blick über die Baustelle. Foto: Christoph Matt. 


\title{
2009/9 TOTENTANZ 9
}

\author{
Anlass: Totalrenovation eines Altstadthauses, Lifteinbau \\ Zeitstellung: Mittelalter Untersuchungsdauer: April 2009 \\ Verantwortlich: Christoph Matt Text: Christoph Matt
}

heute genau in der Einmündung zwischen den Häusern Hutgasse 4 und 6 stehen würde. ${ }^{26}$ Das Vorgänger-Gässlein lag mehrheitlich etwas westlich der heutigen Glockengasse. Wir erwarteten somit das eine oder andere Mauerfundament von Gebäuden zwischen dem ehemaligen «Hinterarsch-Gässlein», der Hutgasse und dem heutigen Marktplatz (früher Kornmarkt). Es kamen denn auch - trotz grosser Störungen durch bestehende Werkleitungen - noch einige Fundamentreste zum Vorschein. Zu nennen ist ein solcher mit modern wirkendem betonartigen Putz vor dem Restaurant «La Fonda» (ehemals Sattelgasse 11: Haus «Zum alten Rebstock»), und etwas weiter südlich ein etwa $2 \mathrm{~m}$ langer Rest desselben Fundamentes, das hier einen Mauerkern aus einem grauen Mörtel und v.a. Kieselwacken besass, was auf das 13. Jahrhundert verweist (Abb. 31). Weiter wurde nahe bei der Hutgasse ein recht jung wirkender Mauerwinkel aus Backsteinen - vermutlich eines Wassersammlers wohl des 19. Jahrhunderts - freigelegt.

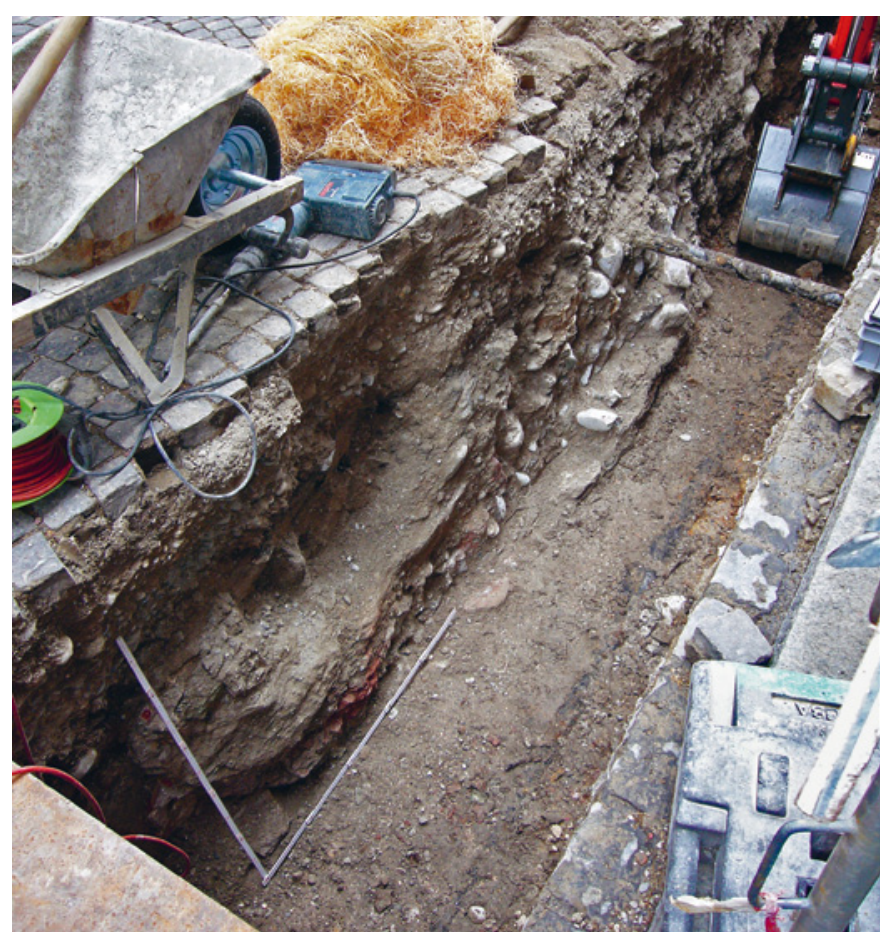

Abb. 31 Letzte Fundamentreste wohl des 13. Jahrhunderts vor dem Haus Glockengasse 4. Foto: Christoph Matt.
Die Häuserzeile zwischen Totentanz und St. Johanns-Rheinweg steht auf der steilen Rheinhalde. Eines dieser Altstadthäuser wurde umfassend renoviert und umgebaut. ${ }^{27}$ Das Haus teilt sich in eine land- und eine rheinseitige Hälfte auf. Erstere war nur ein Geschoss tief unterkellert, letztere hingegen hat drei Untergeschosse, wobei das unterste auf gleicher Höhe wie der St. Johanns-Rheinweg liegt. Die beiden Hälften werden in den Untergeschossen durch eine starke Binnenmauer getrennt. Die Liegenschaften an diesem Ort sind aus verschiedenen Gründen interessant: Sie können einerseits alte, in die Frühzeit der Vorstadt zurückreichende Gebäudeteile enthalten (13./14. Jahrhundert), und zum andern liegen sie im Bereich eines spätantiken Gräberfeldes (Körper- und Brandgräber, spätes 3. bis frühes 5. Jahrhundert). ${ }^{\mathbf{2}}$ Aus diesem Grunde haben wir den Aushub für Leitungsanschlüsse am Totentanz und für einen in der Mitte der Liegenschaft geplanten Liftschacht begleitet.

Nehmen wir die Frage nach spätrömischen Gräbern vorweg: Weder in den Leitungsgräben vor dem Haus noch im Hausinnern kam irgend ein Hinweis auf römische Bestattungen zum Vorschein. Dafür war das Vorgelände der Liegenschaft zu stark gestört, und der Liftschachtaushub im Hausinnern setzte im 2. Untergeschoss in einer Tiefe an, wo nur noch der glaziale Kies ansteht. Von den einstmals auch in dieser Parzelle zweifellos vorhandenen Gräbern war somit nichts mehr erhalten.

Der Liftschacht erschloss uns nur einen winzigen Ausschnitt der vorhandenen Mauern, woraus sich natürlich keine Baugeschichte des ganzen Gebäudes herleiten lässt. Ziemlich genau in der Mitte der Parzelle liegt eine starke Binnenmauer, welche das Haus - wie eingangs erwähnt - in eine rheinnahe Hälfte mit drei Untergeschossen und eine strassenseitige Hälfte mit bloss einem Untergeschoss unterteilt. Diese Mauer war im 2. und 3. Untergeschoss der Rheinseite noch vollständig erhalten, und nach oben setzt sie sich gemäss der Untersuchung der Denkmalpflege noch wenigstens bis zur Höhe des Erdgeschossbodens fort. Gegen Westen ist diese Mauer gegen den anstehenden glazialen Kies gemauert (keine erkennbare Baugrube). Sie besteht dort - wie auch im Mauerkern - aus grösseren Kieselwacken, einem Baumaterial, wie es beim Abbau der Rheinhalde und am Rheinufer eben zum Vorschein kommt. Daneben gibt es an der Aussenseite auch grössere quaderarti- 
ge Blöcke aus Muschelkalk. Der bläulich-grünliche MolasseSandstein wurde auch recht häufig vermauert. Der Mörtel ist schmutzig-weiss, mit viel Beischlag von Kieseln von $1 / 2$ bis $2 \mathrm{~cm}$ Grösse. Die Mauer dürfte aufgrund von Steinmaterial und Bautechnik etwa ins 13. Jahrhundert datieren. - Auf Bodenniveau zwischen 1. und 2. Untergeschoss liess sich ein Wechsel im Mauerwerk beobachten: der obere Bereich war nur etwa $60 \mathrm{~cm}$ breit, unter Fussbodenniveau jedoch $20 \mathrm{~cm}$ breiter. Dies entspricht einer Grenze zwischen zwei Bauetappen, die sich auch an einem flachen Mörtelabschluss des unteren FundamentTeils und einer Schmutzfuge darauf ablesen lässt (Abb. 32). Die Untersuchungen der Basler Denkmalpflege ermöglichten es, die von uns nur an der Rückseite begutachtete Mauer in den Zusammenhang der Baugeschichte des ganzen Hauses und der beiden Nachbarhäuser zu stellen: Auch die Häuser Toten$\operatorname{tanz} 8$ und 10 enthalten Binnenmauern der gleichen Art, die zusammen mit der Binnenmauer in Nr. 9 ein Gefüge von Terrassierungsmauern ohne einheitlich durchgehende Flucht bilden. Das südliche Nachbarhaus Nr. 8 enthält im mittleren Parzellenbereich einen turmartigen Kernbau wohl aus dem letzten Viertel des 13. Jahrhunderts. ${ }^{29}$ Dessen landseitige Flucht lag über einen Meter hinter der Binnenmauer des Hauses 9, also weiter landeinwärts. Und aus historischen Plänen des Nachbarhauses Nr. 10 ergibt sich eine noch weiter landeinwärts liegende Mauer, so dass die Terrassierungsmauern, worauf sich die drei Häuser stützen, drei verschiedene Fluchten besitzen und entsprechend mit rechtwinklig dazu verlaufenden Mauern verbunden werden mussten. Dies lässt sich wohl nur so erklären: Die bereits definierten Landparzellen an der Ausfallachse Totentanz/St. Johanns-Vorstadt mussten behelfsmässig terrassiert werden, damit die recht steile und wohl ziemlich unregelmässig ausgebildete Rheinhalde überbaut werden konnte.
Die Gebäude wurden kaum gleichzeitig, aber vermutlich kurz nacheinander erbaut. Damit zeichnet sich im Vorgelände des St. Johann-Schwibbogens eine interessante Entwicklung ab, denn die landseitigen Parzellen in der St. Johanns-Vorstadt sind im Allgemeinen breiter und natürlich sehr viel tiefer. Es würde sich zweifellos lohnen, anhand des «Historischen Grundbuches» (StABS) der Frage nachzugehen, ob die Hauseigentümer der Rheinseite im 13./14. Jahrhundert einen bescheideneren sozialen und wirtschaftlichen Status als diejenigen der Landseite hatten. Die Besitzergeschichte des obgenannten südlichen Nachbarhauses Nr. 8 scheint in diese Richtung zu weisen.

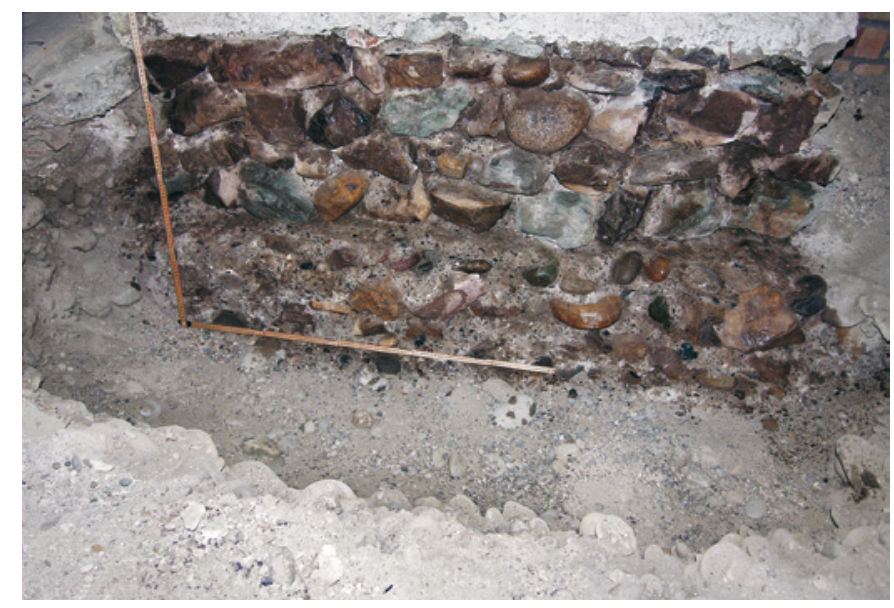

Abb. 32 Das freigelegte Fundament-Mauerwerk mit der unten breiteren Bauetappe im 1. Untergeschoss. Foto: Christoph Matt. 


\section{9/13 RHEINGASSE 11}

Anlass: Absenkung eines aufplanierten Hofniveaus Zeitstellung: Neuzeit Untersuchungsdauer: April und Oktober 2009 Verantwortlich: Christoph Matt Text: Christoph Matt

Hinter dem schmalen Kleinbasler Altstadthaus verbirgt sich von der Gasse nicht einsehbar - ein noch schmalerer Laubenflügel und ein Hinterhöflein (Abb. 33). Die Liegenschaft - sie war in einem schlechten Zustand - wurde vom Eigentümer des Nachbarhauses Rheingassse 13 erworben und umfassend renoviert. ${ }^{30}$ Eigenartig am Hinterhöflein war dessen hohes $\mathrm{Ni}$ veau: Es lag fast auf der Höhe des Simses des Erdgeschossfensters der Hinterfassade. Um ins Höflein zu gelangen, musste man im Hausgang über eine kleine Treppe hinaufsteigen. Dem Anschein nach entsprach dies nicht dem ursprünglichen Terrain. Woher diese Aufplanierung stammt und weshalb sie vorgenommen wurde, ist allerdings unbekannt. Das Fenster des Laubenflügels nimmt auf dieses Niveau Rücksicht, wohl ein Hinweis auf eine Datierung der Aufschüttung in die Zeit vor 1830.31 - Es war durchaus verständlich, dass man beim Umbau das Terrain teilweise auf die Höhe des Hausgangs und des benachbarten Höfleins absenken wollte, zumal es mit diesem durch eine Türe verbunden werden sollte.

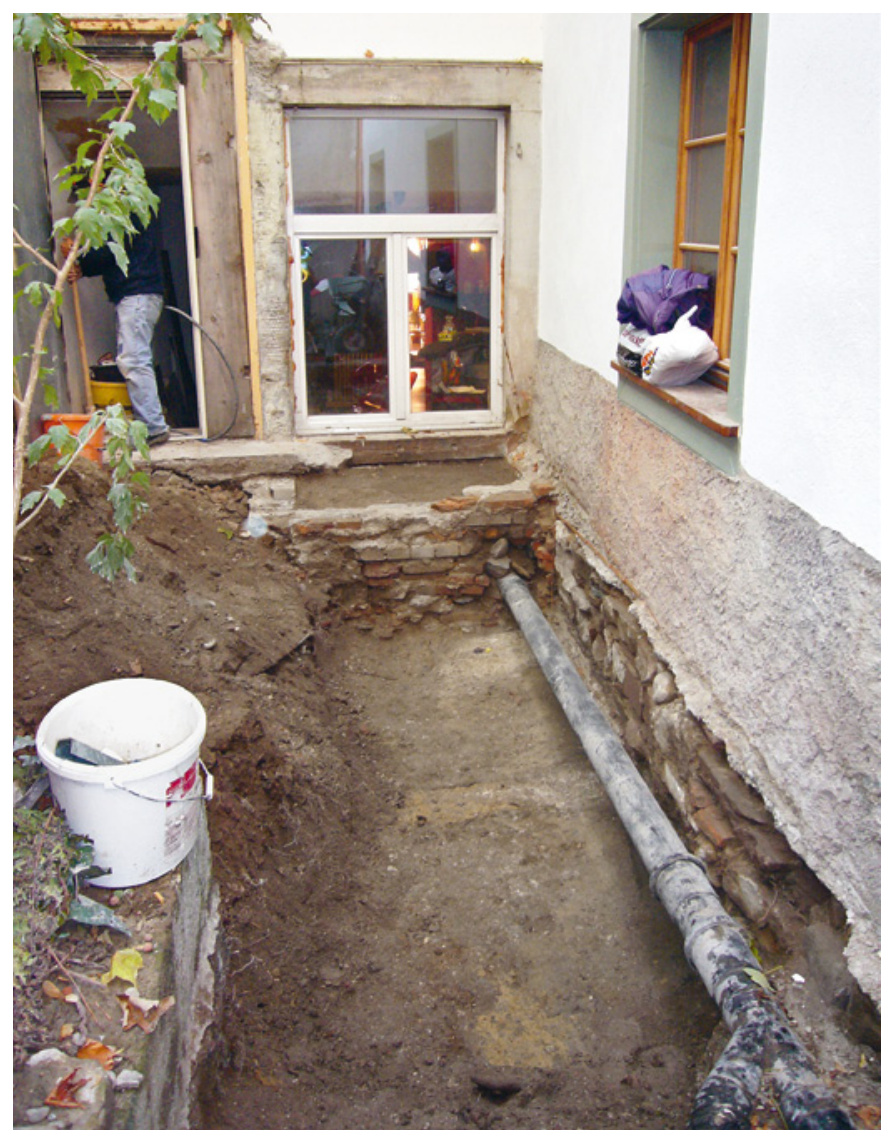

Abb. 33 Blick über das schmale Hinterhöflein mit der Sondierfläche 2. Foto: Christoph Matt.
Eine nicht besonders alte, offenbar nachträgliche Aufschüttung hätten wir in einer ähnlichen Situation normalerweise wahrscheinlich kaum beachtet, doch hier bestand aufgrund der historischen Quellenlage unsererseits ein Interesse. Im 1363 erstmals urkundlich erwähnten Haus wohnten seit der Mitte des 15. Jahrhunderts bis ins Jahr 1867 Hafner. Das zeigte sich auch darin, dass verschiedentlich Bruchstücke von Ofenkacheln und anderer Keramik im Haus vermauert oder in Zwischenböden eingelagert wurden. Auch in den beiden Nachbarliegenschaften wohnten zeitweise Hafner. ${ }^{32}$ Die Parzelle war ursprünglich viel länger: Sie reichte noch um 1700 bis zur Utengasse. Wir hofften somit auf zum Hafnerhandwerk passende Funde in dieser Planierung (z.B. Halbfabrikate, Fehlbrände, Brennhilfen oder Model). Leider wurden diese Hoffnungen zunächst nicht erfüllt. ${ }^{33}$ Es kamen beim Aushub von zwei Testflächen ausschliesslich spätmittelalterliche und neuzeitliche Gefäss- und Ofenkachel-Reste zum Vorschein, wie sie im Prinzip in jeder andern vergleichbaren Liegenschaft auch

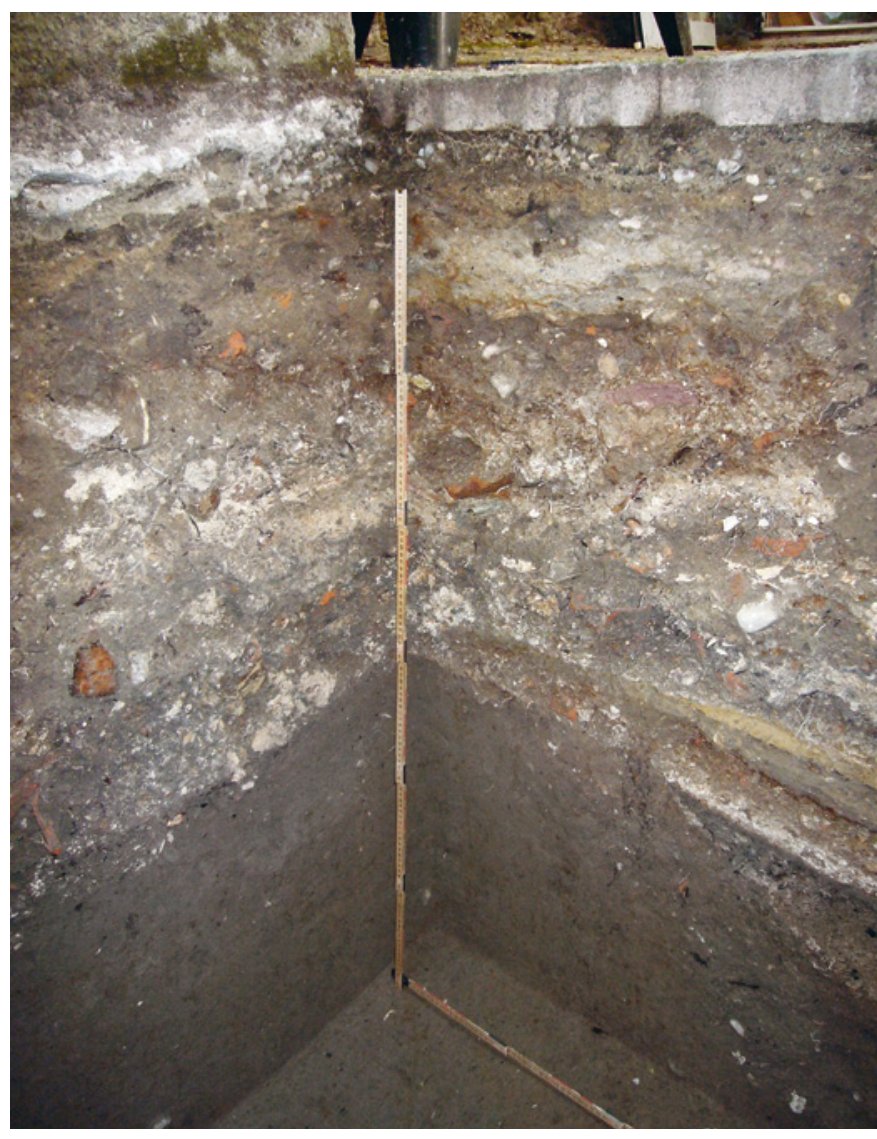

Abb. 34 Blick in die Sondierfläche 1 mit Schwemmsand lunten, in ca. 0,8 m Tiefe) und den verschiedenen angeschütteten Planierungsschichten. Foto: Christoph Matt. 
Anlass: Totalrenovation eines Altstadthauses Zeitstellung: Mittelalter, Neuzeit Untersuchungsdauer: Mai bis Juni 2009 Verantwortlich: Christoph Matt, Martin Block, Christian Stegmüller Text: Christoph Matt

gefunden werden. Erst beim Inventarisieren der gewaschenen Funde zeigten sich doch noch einige Scherben, die als Halbfabrikate oder Brennhilfen und damit als letzte Zeugen der alten Hafnerei interpretiert werden können. ${ }^{34}$

Der Untergrund des Höfleins erwies sich als stark gestört. Unmittelbar neben dem Laubenflügel griff eine moderne Kanalisationsleitung in den Boden ein. In etwa einem Meter Tiefe, also ungefähr auf der Höhe der Rheingasse, stand der Schwemmsand an (Abb.34), wie wir ihn in Kleinbasel kennen. Er war allerdings vielerorts von Bodeneingriffen tangiert, so durch eine Grube mit viel Baukeramik und brandigem Material mit Keramikscherben des späten Mittelalters und insbes. der Neuzeit darin. Auch der Schwemmsand selbst war nicht rein, sondern enthielt einige kleine Scherben wohl prähistorischer Zeitstellung. ${ }^{35}$

Nach Abschluss der archäologischen Untersuchungen kam während des Herrichtens des Untergrundes für den neuen Bsetzistein-Boden unmittelbar beim Hinterausgang noch ein Sodbrunnen zum Vorschein. ${ }^{36}$ Er reichte einige Meter in den Boden hinein (originale Sohle nicht sichtbar, heute trocken). Datieren lässt er sich nicht. Wahrscheinlich diente er fürs Hafnergewerbe, das ja auf Wasser angewiesen war. Nach seiner Auflassung scheint etwas Schutt eingebracht worden zu sein, und dann wurde er mit einer schweren sandsteinernen Ofenbodenplatte abgedeckt. Die originalen, meist ins Rund gehauenen Steine der Wände des Sods reichen bis ca. $30 \mathrm{~cm}$ unter das aktuelle Hofniveau. In welchem zeitlichen Verhältnis die Einrichtung zur Aufplanierung des Hinterhöfleins steht, liess sich nicht mehr eruieren.
Am Heuberg liegt ein für Altstadtverhältnisse riesiger Gebäudekomplex: der Spiesshof. Er wurde nach dem Verkauf der Liegenschaft umfassend umgebaut. ${ }^{37}$ Der eigentliche Spiesshof besteht aus drei Gebäudeteilen, die um einen am Heuberg liegenden Hof gruppiert sind. Der Zugang führt leicht schräg vom Heuberg her am westlichen Seitenflügel vorbei zum zentralen Hof. Der sogenannte Renaissancebau steht nördlich des Hofes zwischen Seitenflügel und Hauptbau, und östlich fügt sich der Haupt- oder Barockbau an, an den sich noch weiter östlich ein grosser Garten anschliesst. Der Hof liegt eine Geschosstiefe unter dem Gassenniveau, und entsprechend senkt sich auch der von einem Torbogen abgeschlossene breite Zugang. - Bodeneingriffe fanden beim Umbau nur wenige statt, nämlich eine Bodenabsenkung im westlichen Seitenflügel, der Einbau eines Kanalisations-Schachtes im Hof sowie einer Kanalisationsleitung unmittelbar östlich des Barockbaus im Garten. Die beiden Kanalisationen lagen in gestörtem Gebiet, weshalb die Überwachung des Aushubes resultatlos blieb. Die Bodenabsenkung des Hauptraums im Seitenflügel betrug zwar nur wenige Dezimeter, doch dabei wurden alle Fundamente freigelegt. Zudem wurde bauseits der Wandverputz in Teilen abgespitzt, so dass wir zusammen mit den Kollegen der Basler Denkmalpflege auch das aufgehende Mauerwerk untersuchen konnten. ${ }^{38}$

Der Spiesshof ist eine faszinierende Liegenschaft. Benannt wurde er nach einer von ursprünglich fünf separaten Liegenschaften, dem 1293 erstmals erwähnten «Haus zum Spiess». Knappe 100 Jahre nach der Erstnennung wurde der grösste Teil dieser Liegenschaften unter einer Hand vereinigt. 1546 erwarb ein gewisser Johann von Brügge den Spiesshof, also niemand anders als der berüchtigte Wiedertäufer David Joris, der nach seiner Flucht aus den Niederlanden hier unerkannt bis zu seinem Tode 1576 lebte! Bekannt ist der Spiesshof aber insbesondere durch seinen im späten 16. Jahrhundert erbauten Renaissanceflügel hinter dem Hof, eine der wenigen Basler Bauten aus dieser Zeit. ${ }^{39}$

Die Denkmalpflege konnte bereits 1999 eine kleinere Untersuchung in dieser Liegenschaft machen. Damals wurde der Putz des runden Torbogens und der Hoffassade des Westflügels teilweise ersetzt. Das Tor steht in der Lücke zwischen der Stützmauer entlang der Gasse und dem Westflügel. So konnte die Baugeschichte eines kleinen, aber doch zentralen Bereichs untersucht werden. ${ }^{40}$ Dabei zeigte sich, dass Torbogen und Erdgeschoss des westlichen Seitenflügels zu einer einzigen Bauphase gehören. Ein möglicherweise originales Balkenlager ist vorerst schwierig zu interpretieren; jedenfalls zeigt es kaum das Nordende dieser Mauer an. In diese Wand wurde im 16. Jahrhundert ein Renaissanceportal eingebrochen (Abb. 35). Bei der Datierung der Mauer mit dem Rundbogentor dachte 
man ans 13. oder frühe 14. Jahrhundert - soweit die Ausgangslage bei der Untersuchung der Innenraum-Fundamente. Die Fundamente des zentralen Raums im Westflügel waren bei der West- und Nordmauer dank einer Bodenabsenkung etwa einen guten halben Meter tief zu sehen, darüber hinaus wurde wegen Feuchtigkeitsschäden an der Ost- und Südmauer über eine Höhe von 1,5 m auch der Putz im aufgehenden Bereich erneuert (Abb.37). Wir konnten folgende Beobachtungen machen: Als ältestes Fundament erwies sich erwartungsgemäss dasjenige der Hoffassade (Ostmauer) in der Fortsetzung des oben genannten runden Torbogens. Daran stossen im Norden (Abb. 36) und im Süden eine Mauer an. Der Westabschluss des Raums wird von einer später zwischen diese beiden Mauern

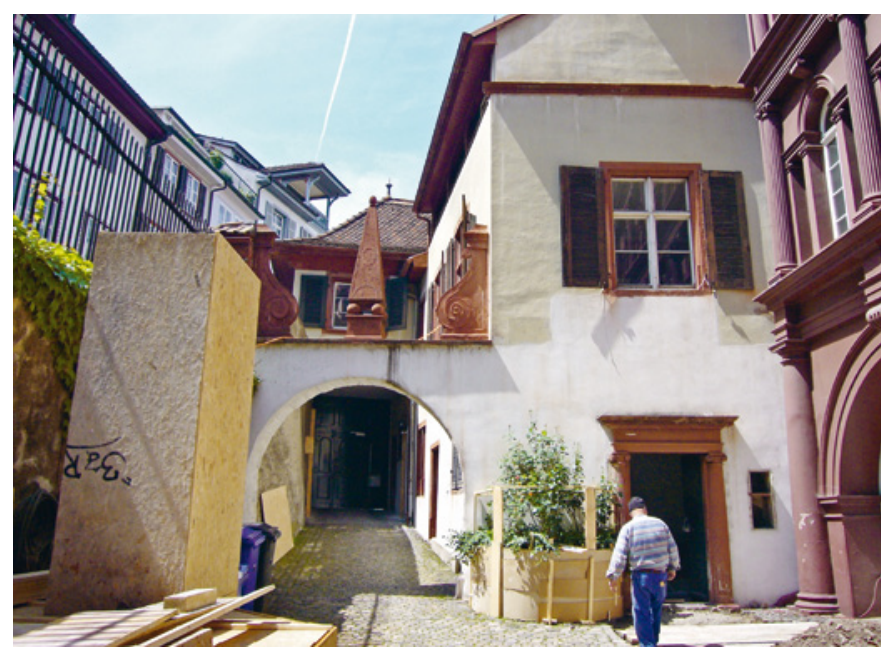

Abb. 35 Blick auf die Zufahrt zum Heuberg mit dem Torbogen und dem westlichen Seitenflügel mit dem Renaissanceportal. Rechts schliesst der Renaissanceflügel an. Foto: Christoph Matt.

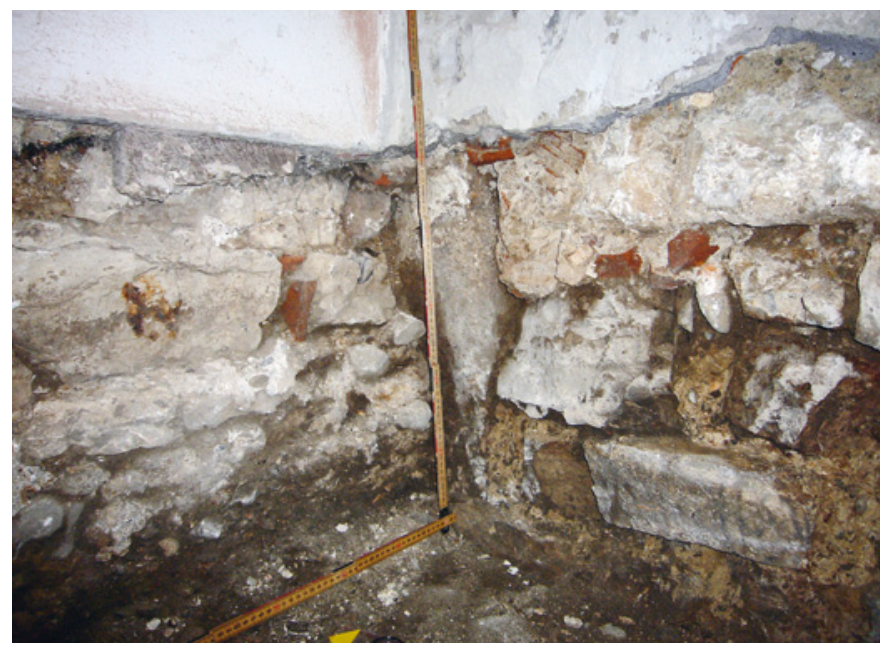

Abb. 36 Westlicher Seitenflügel: Blick nach Nordosten in die Ecke zwischen ältester Mauer (Hoffassade; rechts) und anstossender nördlicher Mauer (links). In der Ecke hinter dem Doppelmeter der zur ältesten Mauer gehörende senkrechte Türgewändestein. Foto: Christoph Matt. eingespannten Mauer gebildet (Abb. 37: rechts). - Zur Datierung der Mauern möchten wir uns wie folgt äussern: Dem Datierungsansatz der Denkmalpflege für die älteste Mauer ins 13. Jahrhundert können wir uns aufgrund des Mauerbildes anschliessen. Die an der Zufahrt liegende Südmauer wird wegen der eingeschossenen Backsteinlagen in die Zeit um 1400 bzw. ins 15. Jahrhundert zu datieren sein. Die Nordmauer dürfte jünger sein (wohl barockzeitlich), und die dazwischen eingespannte Mauer ist nochmals jünger (18./19. Jahrhundert?). Oben wurde aufgrund der Untersuchungen der Denkmalpflege im Jahre 1999 vermutet, dass die Mauer mit dem Rundbogentor von der Gasse über das Renaissanceportal hinaus weiter talwärts ziehe (Abb. 35). Dafür kann als neues Indiz der Ansatz einer Türe in der erwähnten Torbogenmauer angeführt werden. Fast durch die anstossende Mauer verdeckt, doch eben noch sichtbar, kam eine senkrechte steinerne Türleibung zum Vorschein (Abb. 36). Die eigentliche Türe liegt nördlich davon. Nimmt man für ein Portal samt Leibung eine Breite von gegen $1,5 \mathrm{~m}$ an, so bleiben bloss noch wenige Meter bis zur nördlichen Brandmauer, dem mutmasslichen Ende der genannten Tormauer. Wie diese jetzt etwas isoliert dastehende Mauer mit dem Rundbogentor architektonisch letztlich zu interpretieren ist, werden hoffentlich die noch nicht abgeschlossenen Bauuntersuchungen der Basler Denkmalpflege zeigen. Bei allfälligen zukünftigen Bodeneingriffen im Hof zwischen Renaissanceflügel und Gasse wäre der Suche nach allfälligen älteren Böden oder Mauerzügen grosse Aufmerksamkeit zu schenken.

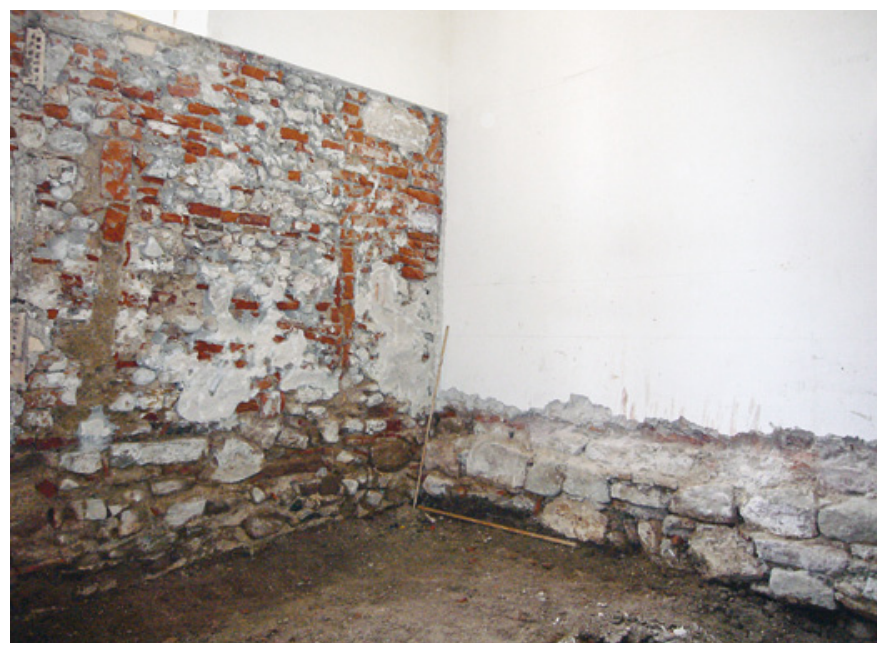

Abb. 37 Westlicher Seitenflügel: Blick auf die stark gestörte Mauer mit vielen Backsteinvormauerungen neben der Zufahrt (links), rechts die junge Zwischenmauer. Foto: Christoph Matt. 


\section{9/23 RHEINSCHANZE (A)}

Anlass: Leitungserneuerung Zeitstellung: Neuzeit Untersuchungsdauer: Juli bis September 2009 Verantwortlich: Christoph Matt Text: Christoph Matt

Die «Rheinschanze» genannte kleine Strasse liegt zwischen dem Rhein und der St. Johanns-Vorstadt und trägt ihren $\mathrm{Na-}$ men nach dem heute noch in etwa bestehenden Kanonenwall (jetzt Grünanlage auf der Nordseite der Strasse) hinter der gekappten Äusseren Stadtmauer. Die Vorstadt erhielt ihren Namen nach der 1206 erstmals genannten, damals noch weit ausserhalb der Stadt gelegenen Johanniterkommende ${ }^{41}$. Die Kommende schloss sich südlich an die heutige Rheinschanze an. Die im späten 19. Jahrhundert neu angelegte Strasse kappte teilweise die das Kommenden-Areal gegen Norden begrenzende Mauer mitsamt einigen angebauten Gebäuden. Die Grundrisse dieser Gebäude ziehen sich gewissermassen schräg von Osten nach Westen zunehmend in die Rheinschanze hinein, da letztere keine Rücksicht auf die Orientierung der alten Umfassungsmauer nahm. - Wir erhofften uns von den Grabarbeiten für die Werkleitungen (Erneuerung von Fernwärme, Wasser, Elektrisch) Aufschlüsse zur Kommenden-Mauer und zu den Anbauten daran. ${ }^{42}$ Da es um ein Auswechseln von Leitungen in bestehendem Trassee ging, kamen jedoch nur vorne beim Eckhaus Rheinschanze 2 (neben der Fassade an der St. JohannsVorstadt und weiter in Richtung Rhein beim Garteneingang) Mauern zum Vorschein. Dort wurden zwei wohl recht junge Fundamentreste angeschnitten (barockzeitlich, jünger?). Sie gehören zu den 1879/80 beim Anlegen des Strässchens abgebrochenen Gebäuden.

\section{9/24 PETERSGRABEN 4 \\ (UNIVERSITÄTSSPITAL)}

Anlass: Kernbohrungen (Bodenproben für Neubau) Zeitstellung: Neuzeit Untersuchungsdauer: Juli 2009 Verantwortlich: Christoph Matt Text: Christoph Matt

Ein Gebäudetrakt des Universitätsspitals zwischen Petersgraben 4 und Spitalstrasse 17-21 soll durch einen grösseren Neubau ersetzt werden. Es handelt sich um den OP I= Operationssaall West. Im Zuge der Planung fand im Spitalgarten eine sog. Rotationskernbohrung statt, welche Bohrkerne mit einem Durchmesser von über $10 \mathrm{~cm}$ lieferte. ${ }^{\mathbf{4} 3}$ Zufällig entdeckten wir die dort kurze Zeit offen in ihren Kisten liegenden Bohrkerne (Abb. 38), führte doch der mittägliche Weg zur Spitalkantine daran vorbei. Weder der geplante Neubau noch die Bohrungen sind aus archäologischer Sicht problematisch, denn das leider längst abgerissene Predigerkloster liegt vollumfänglich im Bereich der heutigen Spitalgebäude. Merians Vogelschaupläne (17. Jahrhundert) zeigen im Areal des geplanten Neubaus bloss Gärten. Später entstanden hier im 19. Jahrhundert Spitalbauten. ${ }^{4 \mathbf{4}}$ Entsprechend enthielt der Bohrkern oben Abbruchschutt, in der Mitte Niederterrassenschotter und unten den sog. Blauen Letten (Septarienton).

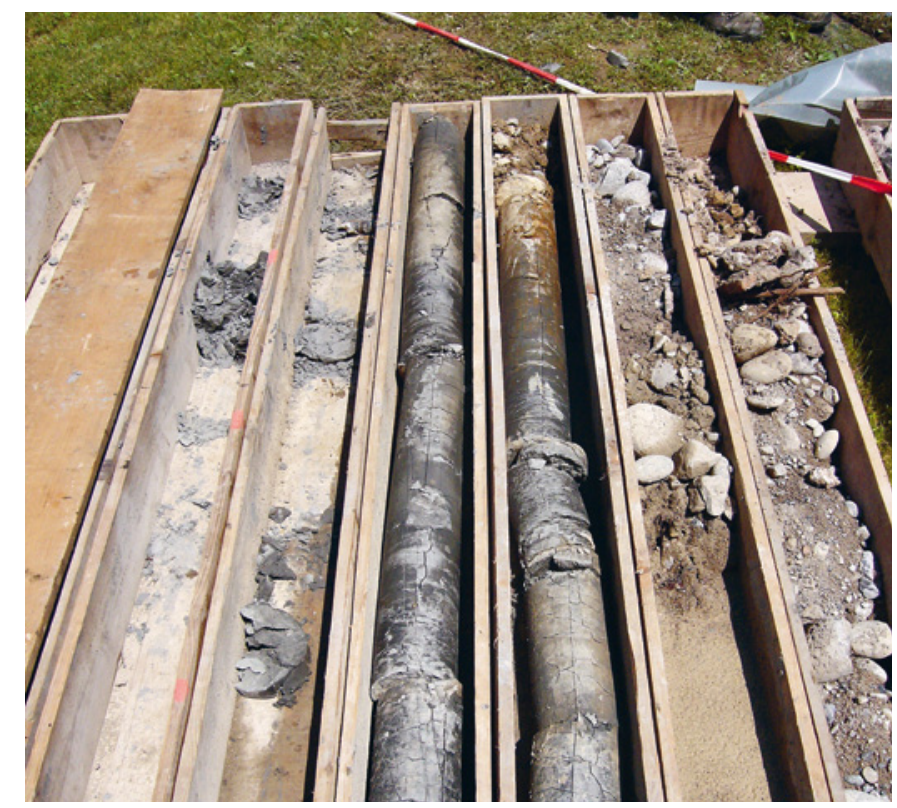

Abb. 38 Blick auf die in Kisten eingepackten Bohrkerne im Spitalgarten. Foto: Christoph Matt 


\section{9/28 LINDENBERG / UTENGASSE (A)}

Anlass: Ersatz von Leitungen Zeitstellung: Neuzeit Untersuchungsdauer: September bis November 2009 (wird 2010 fortgesetzt) Verantwortlich: Christoph Matt Text: Christoph Matt

Eine wohl bis 2011 bestehende Grossbaustelle wegen des Ersatzes der alten Kanalisation mit entsprechenden Hausanschlüssen und wegen weiterer Leitungsbauten wandert in Etappen durch halb Kleinbasel (Abb. 39). Die Arbeiten im Abschnitt vom Lindenberg zur Riehentorstrasse wurden im Berichtsjahr begonnen, aber nicht vollendet. Wir behandeln die Fundstelle nach Abschluss der Untersuchungen.

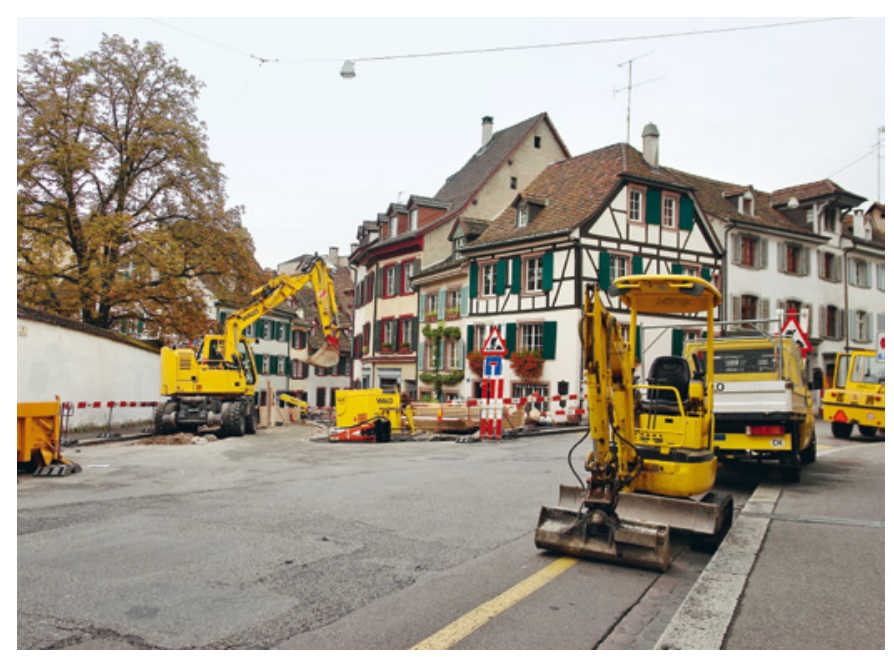

Abb. 39 Blick auf die Leitungsgraben-Baustelle. Foto: Christian Stegmüller.

\section{9/31 ST. ALBAN-ANLAGE (A) 38-40}

Anlass: Leitungsbau Zeitstellung: Mittelalter Untersuchungsdauer: August bis September 2009 Verantwortlich: Christoph Matt Text: Christoph Matt
Zwischen Aeschenplatz und Hardstrasse gab es eine grossflächige Baustelle: Fahrbahn und Tramgeleise sowie Werkleitungen wurden erneuert. ${ }^{\mathbf{4 5}}$ Diese Arbeiten fanden knapp ausserhalb der Äusseren Stadtmauer und ihres vorgelagerten Grabens in einer archäologisch somit unproblematischen Zone statt. An zwei Orten wurde allerdings die St. Alban-Anlage bzw. der dort verlaufende ehemalige Stadtgraben für Leitungsbauten durchquert. Dabei wurde die sog. Kontermauer angeschnitten, die den Graben auf der Feldseite begrenzende Stützmauer (Abb. 40). Die Abbruchkante der Kontermauer lag einen knappen Meter unter dem modernen Strassenniveau. Die Mauer reichte selbstverständlich über die Aushubtiefe von $1,5 \mathrm{~m}$ weiter hinunter (Grabentiefe: um die 6 Meter). Sie war ca. 0,6 m breit und in einem schlechten Zustand (durchfeuchteter weicher Mörtel). Die schmale, tunnelartige Grube und die Lage unmittelbar unter dem befahrenen Tramgeleise und dem Trottoir-Randstein erschwerten Einmessung und Dokumentation erheblich. Die Stadtbefestigungen entstanden in der Zeit zwischen 1361-1398; 1858/59 wurde der Graben zugeschüttet. ${ }^{46}$ - Die übrigen baubedingten Bodenaufschlüsse in der St. Alban-Anlage und auf dem Aeschenplatz wurden nicht weiter begutachtet.

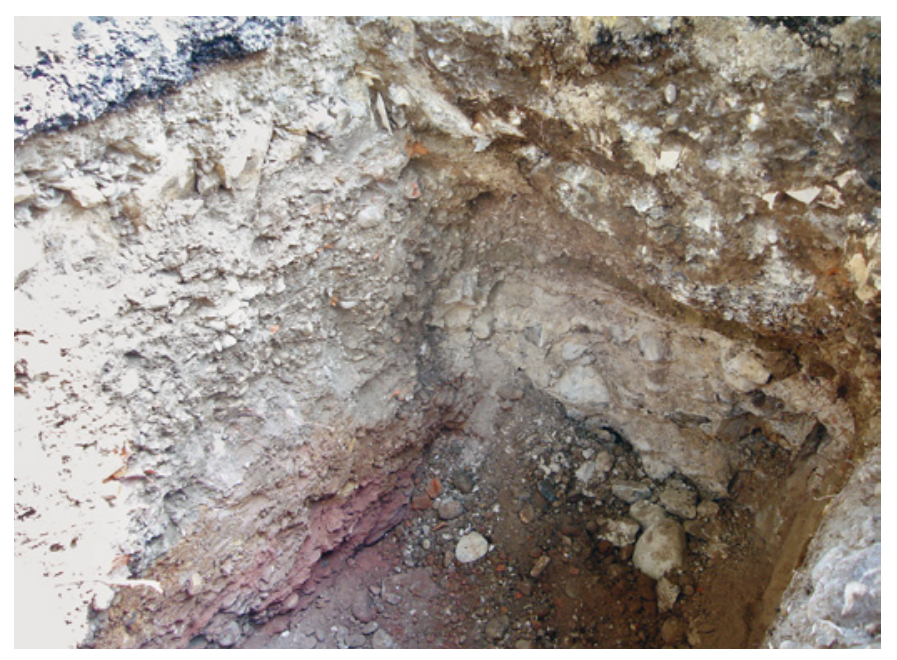

Abb. 40 Blick auf die Reste der Kontermauer (rechts unten) und die von links anstossenden Einfüllungen im ehemaligen Stadtgraben. Foto: Christoph Matt. 


\section{9/35 OCHSENGASSE 12-14}

Anlass: Kanalisations-Erneuerung Zeitstellung: Neuzeit Untersuchungsdauer: November 2009 Verantwortlich: Christoph Matt Text: Christoph Matt

Wir wurden darauf hingewiesen, «dass man in der Ochsengasse am Lochen» sei. ${ }^{47}$ Es zeigte sich bei einem Augenschein, dass es sich dabei um eine Kanalisations-Sanierung zwischen den beiden Gebäuden Ochsengasse 12 und 14 handelte. Die Stelle lag also nicht auf Allmend, sondern auf privatem Grund im Bereich des mittleren der drei ehemaligen Teiche (Kanäle), die hinter der Drahtzugschanze in die Stadt münden (Abb.41). Die beiden Häuser sind demnach ehemalige Mühlen: die Rotochsenmühle (Nr. 12) und die Schwarzeselmühle (Nr. 14) ${ }^{48}$. Im über $3 \mathrm{~m}$ tiefen Loch zeigten sich bis unten verputzte Hauswände, nämlich die ehemaligen Kanalwangen. Am Boden des 1907 aufgehobenen Kanals lagen schwärzliche Sedimente, die wohl auf Färbereien und ihren unbesorgten Umgang mit flüssigen Abfällen zurückgehen ${ }^{49}$, sowie Schwemmsand und rotes Sandsteinmehl (Abbruchschutt). Die Parzellengrenze zur Gasse wurde von einem imposanten Backsteingewölbe überspannt: Es handelt sich um die Kanalüberdeckung des Mittleren Teiches im Bereich der Ochsengasse. Diese tonnenförmige Überdeckung geht kaum ins Mittelalter zurück, sie wird wohl barockzeitlich sein. Etwa einen Monat später sollten wir wieder auf denselben Teich stossen: siehe 2009/43, Webergasse (A) 1.

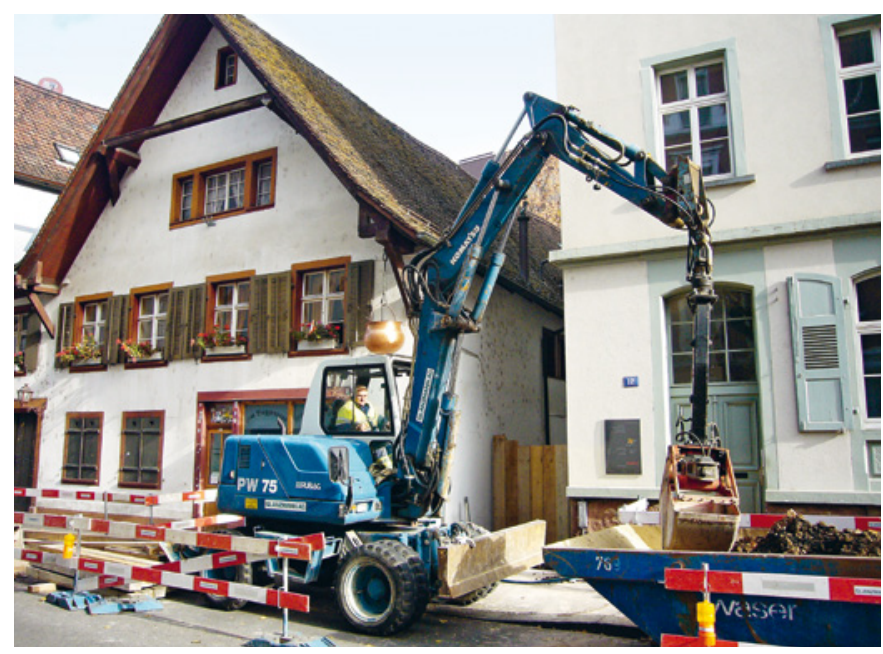

Abb. 41 Blick auf die Baustelle zwischen den Häusern Nr. 12 (rechts) und 14 (links). Foto: Christoph Matt.

\section{9/38 BLUMENRAIN (A) 34}

Anlass: Leitungserneuerung Zeitstellung: Mittelalter Untersuchungsdauer: November 2009 Verantwortlich: Christoph Matt Text: Christoph Matt

Unmittelbar vor dem «Seidenhof», dem bedeutenden historischen Kopfbau am oberen Ende des Blumenrains, wurden alte Elektroleitungen ersetzt. Dafür wurde an drei Stellen der Boden geöffnet und etwas über einen Meter tief aufgegraben (Abb. 42). Zum Seidenhof selbst gab es keine verwertbaren Aufschlüsse, denn die einzige Stelle neben der Eingangstreppe, wo das Fundament frei lag, zeigte eine moderne Betonschalung, die von einem früheren Bodeneingriff herrührt. Dafür ragten zwei aufschlussreiche Fundament-Stummel über die Flucht des Seidenhofes in die Strasse hinein (Abb. 43): Es handelt sich um die wohl letzten Reste des 1860 abgebrochenen St. Johann-Schwibbogens (auch Kreuztor genannt). Das Stadttor besitzt eine bewegte Bau- und Abbruchgeschichte. Es gehörte zur Inneren Stadtmauer und dürfte-aufgrund seines aus bossierten Sandsteinen errichteten Sockels zu schliessen -im Zeitraum 2. Hälfte 12. Jahrhundert bzw. um 1200 erbaut

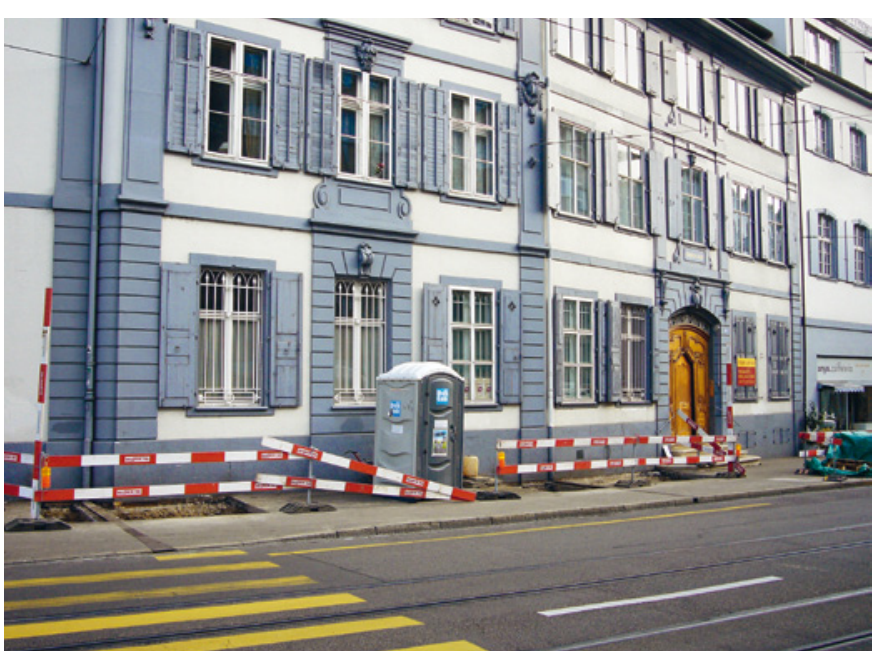

Abb. 42 Die Baustelle vor dem Seidenhof. Der ehemalige Torturm stand genau vor dem dreiachsigen Mittelteil des Seidenhofs in der linken Bildhälfte. Foto: Christoph Matt. 
worden sein. Zwischen 1601 und 1615 wurde der baufällige Turm teilweise abgerissen, doch blieben nach Ausweis von M. Merians grossem Basler Vogelschauplan (1615/17) die beiden Torbögen als eine Art Grenzmarkierung stehen. Vor 1748 wurde der Turm wieder neu aufgebaut und 1873 endgültig abgebrochen. ${ }^{\mathbf{5 0}}$

Diese ganze Baugeschichte lässt sich an den bescheidenen Fundament-Stummeln natürlich nicht ablesen, aber es wurde nun erstmals ein Rest des Turms beobachtet und die historischen Plangrundlagen konnten verifiziert werden. Die verwendeten Gesteine und der Mörtel waren so beschaffen, dass sie nicht zu jüngeren Um- oder Neubauten gehören können. Festgestellt wurden insbes. die im Mauerinnern meist verwendeten Kieselwacken (bis über Kopfgrösse), verbaut mit einem ins 12./13. Jahrhundert passenden Mörtel.

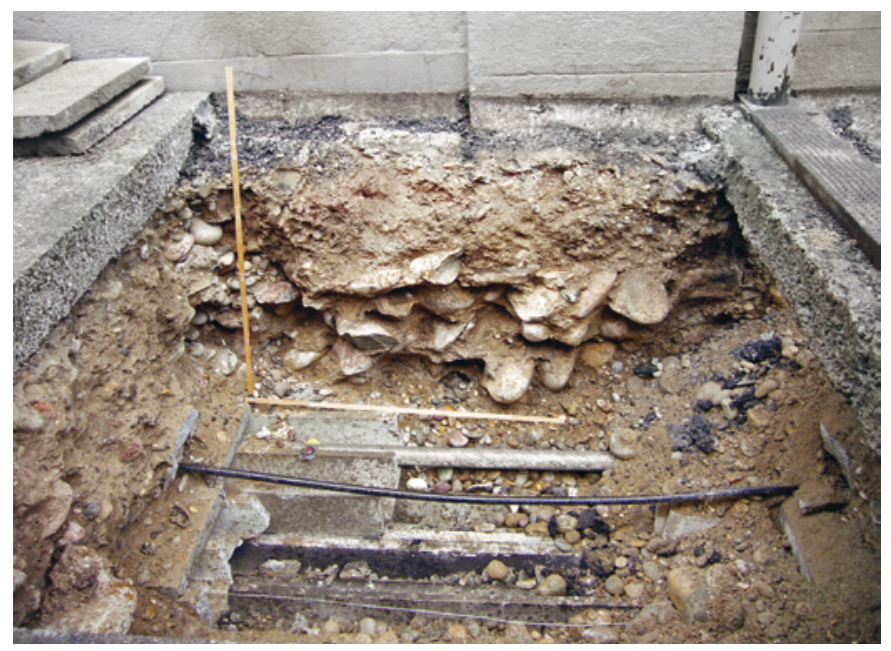

Abb. 43 Blick auf die Reste des hinteren (inneren) Turmfundamentes. Foto: Christoph Matt. 


\section{9/43 WEBERGASSE (A) 1}

Anlass: Kanalisations-Erneuerung Zeitstellung: Neuzeit Untersuchungsdauer: Dezember 2009 Verantwortlich: Christoph Matt Text: Christoph Matt

Vor dem Haus Webergasse 1 wurde ein Abwasserschacht neu angelegt. ${ }^{\mathbf{5 1}}$ Er sollte bis in $3 \mathrm{~m}$ Tiefe hinuntergehen. Während des Aushubes kam in 1,6 m Tiefe der Rest eines Gewölbes zum Vorschein. Es überdeckt denselben Teicharm, der schon bei der weiter vorne beschriebenen Fundstelle 2009/35, Ochsengasse 12-14 zum Vorschein gekommen ist. Das Gewölbe war infolge jüngerer Störungen durch Leitungsbauten nur noch teilweise intakt. Es war sehr sorgfältig aus leicht keilförmigen Sandsteinen gefügt (Masse: 17 bis $20 \mathrm{~cm}$ am schmaleren, 21 bis $25 \mathrm{~cm}$ am breiteren Ende, Dicke um die $37 \mathrm{~cm}$ ). Fast ebenso sorgfältig war der 1907 aufgehobene Teich mit Bausteinen verfüllt (Abb. 44). Offenbar hat man die Gelegenheit genutzt, den beim Bau der Kanalisation zunächst noch intakten Kanal für die Entsorgung von Material zu verwenden, das beim Abbruch von Teilen des Gewölbes anfiel.

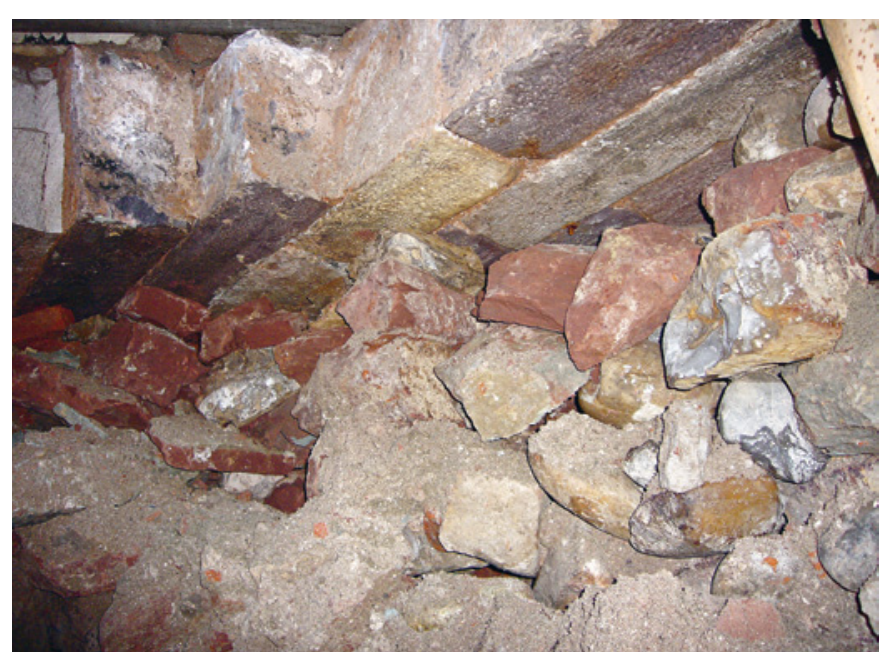

Abb. 44 Blick auf den Abbruchschutt unter dem Gewölbe. Foto: Christoph Matt.

\section{9/44 MARKTPLATZ (A) 2}

Anlass: Geologische Bohrung Zeitstellung: Mittelalter, Neuzeit Untersuchungsdauer: Juni 2009 Verantwortlich: Christoph Matt Text: Christoph Matt

Im Rahmen der «Umwelttage Basel» führte das Amt für Umwelt und Energie (AUE) am 5. und 6. Juni 2009 eine Bohrung auf dem Marktplatz durch. Dabei wurde ein mobiler Bohrturm aufgestellt, der gegen Freitagabend mit einem «Schaubohren nach Grundwasser» begann (Abb. 45). Die Bohrkerne wurden bis Samstagabend für die interessierte Öffentlichkeit ausgestellt und kommentiert. Der genaue Ort für den Bodeneingriff war lange zuvor mit der Archäologischen Bodenforschung abgesprochen worden. ${ }^{\mathbf{2}}$ Der bis ins 19. Jahrhundert «Kornmarkt» genannte Marktplatz war ursprünglich höchstens ein Viertel so gross wie heute. ${ }^{53}$ Mehr als die nördliche Hälfte war bis in die 1860er Jahre überbaut gewesen. Am Ort dieser Gebäude, von denen die meisten wohl unterkellert waren, sollte nicht gebohrt werden, war doch der dort anzunehmende Abbruchschutt nicht das Ziel der Bohrung. Der Fahrbahnbereich des Platzes ist hingegen mit Leitungen dicht belegt und konnte auch wegen des Verkehrs nicht mit einem Bohrturm versperrt werden. Das vor dem Märthof gefundene Plätzchen schien sich für eine Bohrung zu eignen, lag es doch knapp ausserhalb des Standorts der verschwundenen mittelalterlich-neuzeitlichen Gebäude. Der zutage geförderte Bohrkern lieferte allerdings keine Hinweise auf Grundwasser. Die obersten 3,5 m bestanden aus künstlichen Auffüllungen (backsteinhaltiger Abbruchschutt von Steingebäuden), darunter folgten $2 \mathrm{~m} \mathrm{Me-}$ letta-Schichten, also eine Art von Blauem Letten, und das Bohrloch blieb trocken. Offenbar kam die Bohrung in die Baugrube des vor 150 Jahren abgebrochenen Hauses Sporengasse 4 zu liegen. Die Sporengasse ging bei der erwähnten Platzerweiterung im Marktplatz auf. Wir dürfen dieses Resultat immerhin als Indiz dafür nehmen, dass das Haus zumindest in Gassennähe unterkellert war. 


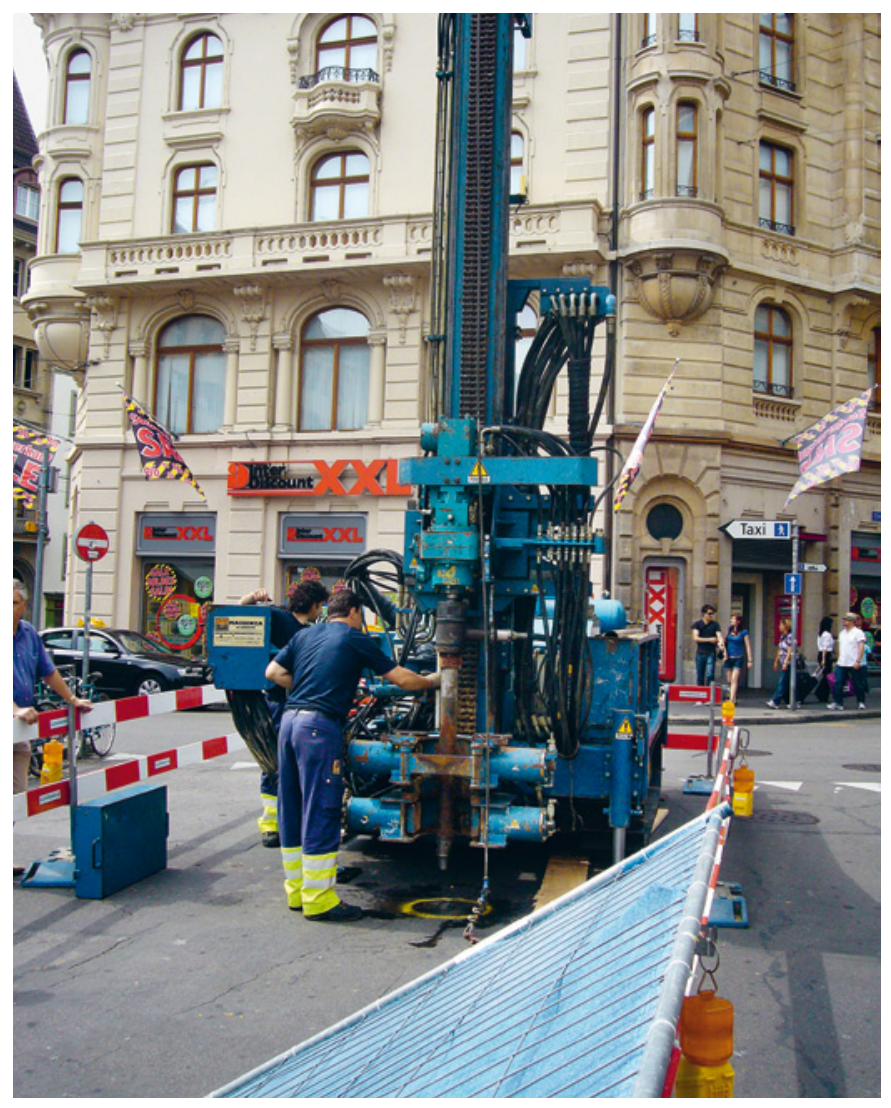

Abb. 45 Das Amt für Umwelt und Energie setzt am Basler Umwelttag zur Grundwasserbohrung an. Foto: Christoph Matt. 


\section{9/4 GASSTRASSE (A)}

Anlass: Leitungsbauten und Neugestaltung der Oberfläche Zeitstellung: Geologischer Befund, Neuzeit Untersuchungsdauer: Januar bis Juli 2009 Verantwortlich: Sophie Hüglin, Norbert Spichtig, Margit Dauner Text: Sophie Hüglin

Im Rahmen der Umgestaltung von Basel-Nord und als Abschluss des Nordtangente-Projekts wird der Bahnhof St. Johann als Verkehrsdrehscheibe eingerichtet. Der Verlauf der Tramlinie 1 wird in diesem Zusammenhang so geändert, dass sie nicht mehr vom Voltaplatz durch die Gasstrasse, sondern über die Voltastrasse und den Bahnhof St. Johann in die Entenweidstrasse führt.

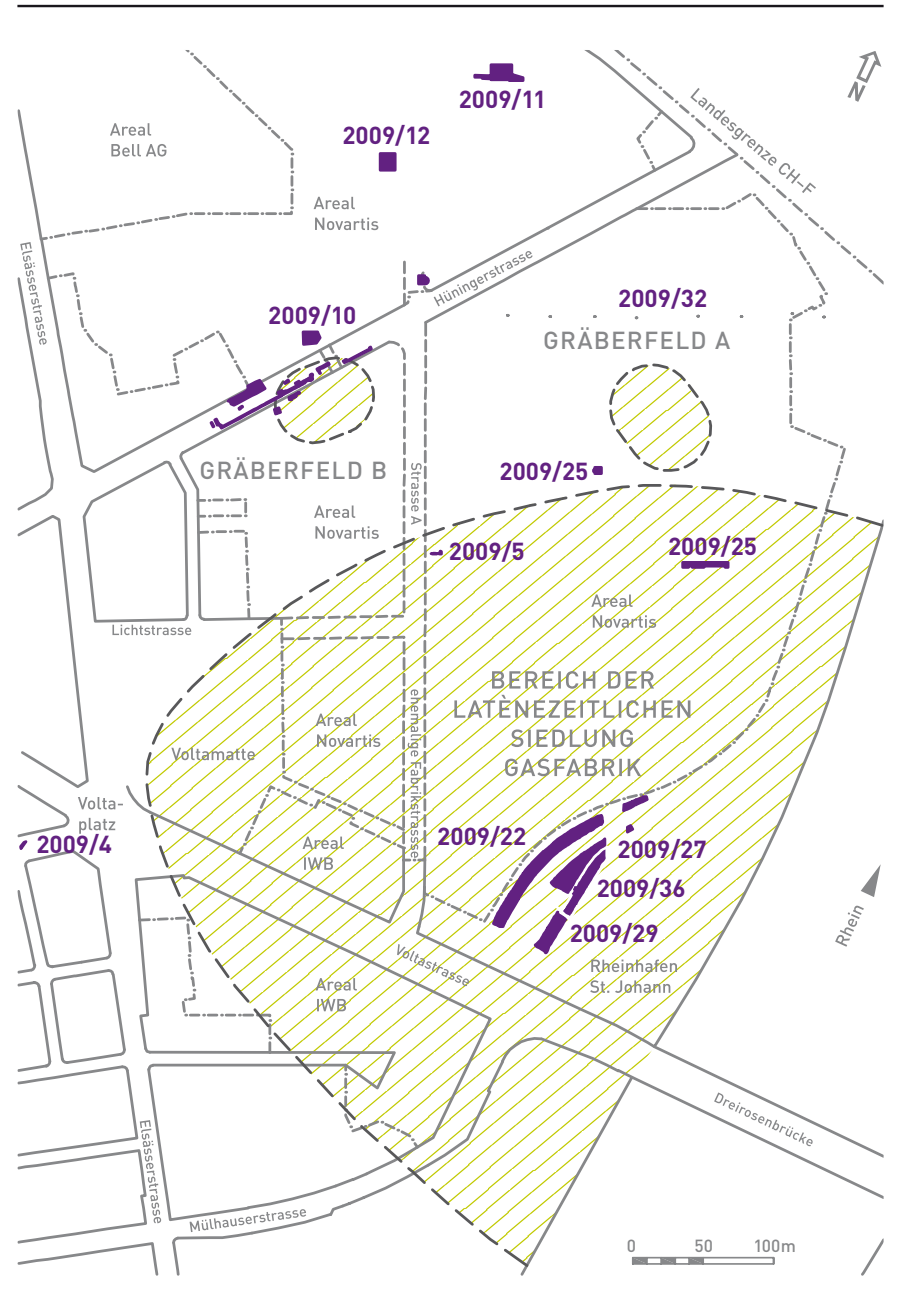

Abb. 46 Übersichtsplan mit den im Vorbericht behandelten Grabungen. Zeichnung: Peter von Holzen.
Zum Zeitpunkt der baubegleitenden Untersuchung waren bereits die Tramgleise entfernt worden und im alten Trassee wurden verschiedene Werkleitungen neu verlegt. Bei der sporadischen Begleitung der Erdarbeiten über ein halbes Jahr hinweg wurde die Schichterhaltung auf fast $450 \mathrm{~m}^{2}$ dokumentiert; dabei wurden in den punktuellen Aufschlüssen Daten zur Rekonstruktion der ursprünglichen Topographie des Geländes und des quartärgeologischen Untergrundes im Umfeld der spätlatènezeitlichen Siedlung Gasfabrik gesammelt (vgl. Abb. 46). Mehrfach wurden dabei frühneuzeitliche und neuzeitliche - teilweise gepflasterte - Gehniveaus angeschnitten, die in die Zeit vor der Aufsiedlung bzw. in frühe Phasen der industriellen Nutzung des Quartiers gehören dürften. Steinkohlepartikel in einer Schicht könnten z. B. aus der Zeit nach 1882 stammen, als das am Rhein gelegene Gaswerk einen Bahnanschluss erhielt, der durch die Gasstrasse verlief. ${ }^{54}$ Vorgeschichtliche Funde und Befunde wurden keine angetroffen. 


\section{9/10 HÜNINGERSTRASSE (A), NOVARTIS}

Anlass: Oberflächengestaltung, provisorische Absperr- und Umgestaltungsmassnahmen im Rahmen der Impropriation der Hüningerstrasse in das Firmenareal der Novartis AG

Zeitstellung: Geologischer Befund, Neuzeit Untersuchungsdauer: April bis August 2009 Verantwortlich: Sophie Hüglin, Margit Dauner Text: Sophie Hüglin

Nachdem der Grosse Rat des Kantons Basel-Stadt Ende 2008 der Abtretung des grössten Teils der Hüningerstrasse östlich der Elsässerstrasse bis an die Grenze nach Frankreich zugestimmt hat, ist der Strassenabschnitt nicht mehr Teil der Allmend, sondern rechtlich Teil des Firmenareals der Novartis. Die zunächst eher provisorischen Massnahmen zur Eingliederung der Hüningerstrasse - Einbau von Rolltor und Drehkreuzen mit zugehöriger Stromversorgung, Rückbau der ehemaligen Fussgängerunterführung, Anlage von Grünflächen und Vorabklärung wegen allfälliger Bodenbelastungen - führten zu Bodeneingriffen auf über $400 \mathrm{~m}^{2}$, die über mehrere Monate hinweg sporadisch archäologisch begleitet und dokumentiert wurden (siehe Abb.46). Vorrangiges Ziel war es dabei, intakte Flächen zu erkennen und zu schützen, damit diese erhalten bleiben und - wenn nötig - später gezielt gegraben werden können.

Eine wichtige Erkenntnis betrifft die so genannte Allschwilerbach-Dole. Dieser Bach wurde Anfang der 1980er Jahre ca. 10 m tief unter die Erde gelegt. ${ }^{55}$ Baggerschürfe in seinem Verlauf zeigen, dass die Dole damals in Tunnelbauweise erstellt wurde und daher die Erdschichten darüber weitgehend ungestört sein dürften. Dies ergibt einen Zuwachs von über $1000 \mathrm{~m}^{2}$ an potentiell intakter Fläche gegenüber früheren Annahmen.

\section{9/12 HÜNINGERSTRASSE 121, NOVARTIS, WSJ-355}

Anlass: Bodenaustausch im Vorfeld einer Neugestaltung der Oberfläche Untersuchungsdauer: April bis Juli 2009 Verantwortlich: Sophie Hüglin, Margit Dauner Text: Sophie Hüglin

Im Rahmen der Oberflächengestaltung westlich des Chipperfield-Buildings, Bau WSJ-355, wurde in einem begrenzten Bereich eine erhöhte Kontamination des Bodens festgestellt, was dazu führte, dass in dieser ca. $125 \mathrm{~m}^{2}$ grossen Zone ein Bodenaustausch durchgeführt wurde (siehe Abb. 46). Obwohl dabei archäologisch intakte Schichten bis in den anstehenden Kies hinein abgetragen wurden, wurde die Archäologische Bodenforschung zunächst nicht beigezogen. Als eine Mitarbeiterin zufällig an dem bereits ausgehobenen Bereich vorbeikam, war es aus Arbeitssicherheitsgründen nicht mehr möglich, die in etwa einem Viertel der Fläche erhaltenen Profile von 5 bzw. 6 m Länge zu reinigen und genauer aufzunehmen. Aus der Ferne waren keine möglicherweise vorgeschichtlichen Eintiefungen zu erkennen. 


\section{9/22 RHEINHAFEN ST. JOHANN 18,}

\section{ETAPPE 1}

Anlass: Sanierung des Hafenareals Zeitstellung: Bronzezeit, Spätlatènezeit, Neuzeit Untersuchungsdauer: Seit Juni 2009 Verantwortlich: Sophie Hüglin, Margit Dauner Text: Sophie Hüglin

Der grösste Teil des Rheinhafens St. Johann, der zurzeit noch im Besitz des Kantons ist, wird - mit Ausnahme der Wege zum und dem Rhein entlang - von der Novartis AG erworben und als so genannter Campus Plus in den Novartis-Campus integriert werden. Der Kanton Basel-Stadt hat sich im Rahmen des Kaufvertrags verpflichtet, die Gebäude des ältesten Hafens von Basel abzubrechen und kontaminierte Böden auszutauschen. Nicht nur der Bodenaustausch, sondern auch die geplante Landschaftsgestaltung in Zusammenhang mit dem öffentlichen Fuss- und Radweg entlang des Rheinufers werden in starkem Masse in archäologisch intakte Schichten eingreifen. Die vom Projekt betroffene Fläche liegt zumeist innerhalb des Perimeters der spätlatènezeitlichen Siedlung Basel-Gasfabrik, weshalb vorgängig zu den geplanten Arbeiten ca. $14000 \mathrm{~m}^{2}$ archäologisch untersucht werden müssen.

Als Erstes wurden bei noch laufendem Hafenbetrieb die zwei südwestlichsten Rangiergleise entfernt und eine Fläche von über $800 \mathrm{~m}^{2}$ geöffnet, in der bronzezeitliche, spätlatènezeitliche und neuzeitliche Befunde und Funde zutage traten (vgl. Abb. 46 und 47). Etwa ein Drittel der Fläche war von Mauerfundamenten der ehemaligen «Gasfabrik» tiefgründig gestört, so dass in diesen Bereichen die Dokumentation zügig abgeschlossen werden konnte. Ein weiteres Drittel mit intakter Stratigrafie konnte bereits gegraben und abschliessend dokumentiert werden. Das letzte Drittel besteht aus mehreren, über die Länge des Streifens verteilten «Inseln» und weist komplexe Befunde sowie voluminöse, sich mehrfach überschneidende Gruben auf. Diese Bereiche mussten später im Jahr gesichert und im Arbeitsablauf weitgehend zurückgestellt werden, um an anderen Stellen des Hafenareals für den Bauablauf dringlichere Flächen untersuchen zu können.
Vor-latènezeitliche Spuren lassen sich vor allem in den Profilen als Horizonte mit einer gewissen Häufung an verrundeten Keramikfragmenten und Kieseln fassen. Eintiefungen sind am ehesten noch im verlehmten Hochflutsand greifbar. An spätlatènezeitlichen Befunden konnten bis Jahresende vor allem zwei Komplexe am Südende des Grabungsstreifens genauer untersucht werden: zum einen ein mehrgliedriger Muldenkomplex, der aufgrund seiner hohen Dichte an Schlacken und Holzkohle vorläufig als Schmiedegrube angesprochen wird, und zum anderen ein wannenförmiger Erdofen (Abb.48), der zur Kategorie der so genannten «fours polynésiens» gehört. Solche vor allem in der Bronze- und der frühen Hallstattzeit, aber auch heute bei indigenen Völkern weit verbreitete Öfen dienen dazu, grössere Mengen an Fleisch oder Gemüse bei niedrigen Temperaturen langsam und dadurch schonend zu garen. Dazu wird im lehmigen Boden eine Wanne ausgehoben, mit Brennholz befüllt, und darüber werden grosse Gerölle aufgeschichtet. Beim Abbrennen sinkt der Holzstapel in sich zusammen und die Gerölle werden sehr heiss. Nun kann man einen Teil der Steine herausnehmen, das Gargut sorgfältig eingewickelt einbringen, heisse Steine und noch eine Erdschicht darüber legen. Die Speisen müssen nun - abhängig von Menge und Aussentemperatur - über eine längere Zeit garen.

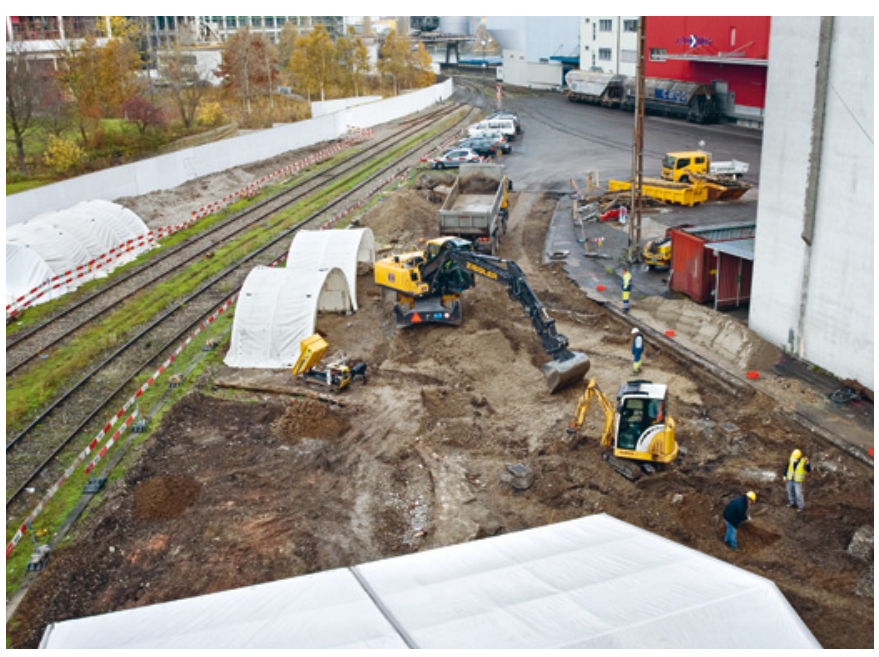

Abb. 47 Übersicht über die Grabungen im Rheinhafen St. Johann im November 2009 mit Blick nach Nordosten. Ganz links am Arealzaun zum Parkgelände des Novartis-Campus die Grabung 2009/22; in der Bildmitte der laufende Voraushub für die Grabungen 2009/27 und 2009/36; ganz rechts angeschnitten das Ultra-Brag-Silo. Foto: Michael Wenk. 
Die vorliegende Ofenanlage bildet eine langrechteckige Wanne mit abgerundeten Ecken; sie besitzt ein lichtes Mass von ca. $1,7 \mathrm{~m} \times 1 \mathrm{~m}$ und ist mindestens $0,4 \mathrm{~m}$ tief. Die Wandung ist vor allem in den oberen Randbereichen mehrere Zentimeter dick verziegelt; vermutlich sind diese Zonen auch darum besonders hart, weil der natürliche Kalkanteil des verlehmten Hochflutsandes gebrannt und durch die Erdfeuchte wieder gelöscht wurde. An anderen Stellen scheint die Wandung nicht verziegelt zu sein, bzw. zu fehlen. Unklar ist noch, ob es sich um eine Auskleidung mit Lehm oder nur um die verziegelte Schicht des Anstehenden handelt. Die Verfüllung der Ofenwanne besteht zuunterst aus einer dünnen Lage Holzkohle; darüber wurde verlehmter Hochflutsand eingefüllt oder eingeschwemmt, der viele Gerölle und das eine oder andere Keramikfragment, u.a. auch das Bruchstück eines Amphorenhenkels, enthält.

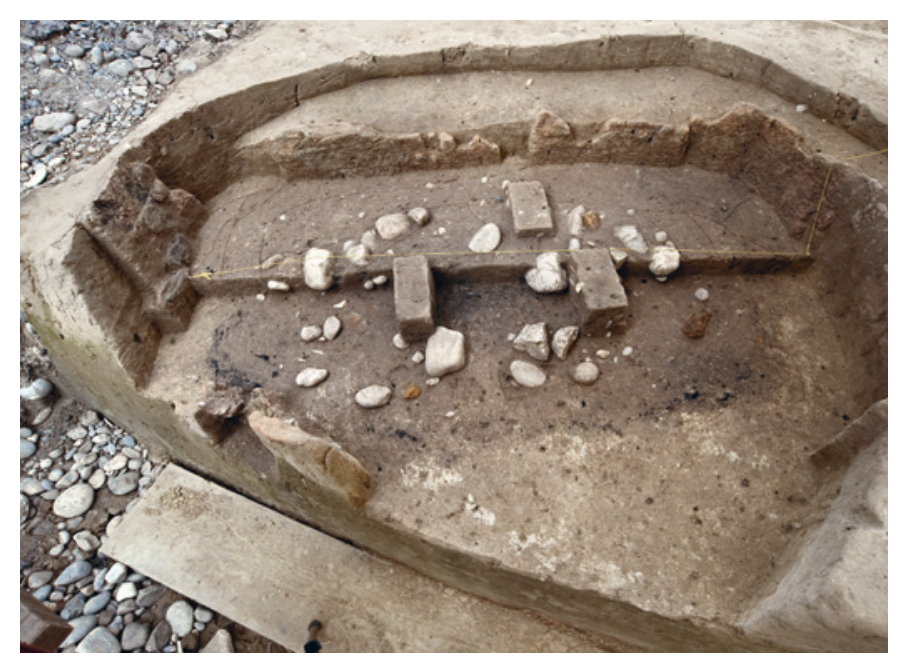

Abb. 48 Der wannenförmige Erdofen bzw. «four polynésien» diente vermutlich zum schonenden Garen grösserer Fleischstücke bei besonderen Anlässen.

Um seine Verfüllung besser charakterisieren zu können, wurden im Ofeninnern Profilschnitte angelegt und Material für mikromorphologische Proben als Sockel stehen gelassen. Foto: Michael Wenk.
Im Vergleich mit anderen Befunden von Erdöfen ist die Menge an Geröllen im Ofeninnern gering; die spätlatènezeitliche Datierung ist durch die Keramik gesichert. Parallelen gibt es innerhalb der Siedlung von Basel-Gasfabrik bisher keine, und auch andernorts sind zeitgleiche Öfen rar; ${ }^{56}$ doch hat man im nahe gelegenen elsässischen Sierentz 46 solcher Öfen aus der Urnenfelderzeit nachweisen können. ${ }^{57}$ Auch in den neuzeitlichen Schichten sind viele spätlatènezeitliche Fundobjekte anzutreffen, darunter auch Münzen und andere Metallgegenstände. Dies liegt wohl daran, dass man im vorletzten Jahrhundert beim Bau der mehrere Meter tief fundamentierten kreisförmigen Gasometer die Baugruben mit Material verfüllt hat, das man wenige Meter entfernt innerhalb des Mauerrings abgetragen hatte. Da man den Kies anderweitig gebrauchen konnte, handelt es sich dabei um das vorwiegend lehmige Mischmaterial der spätlatènezeitlichen Grubenverfüllungen. Zu diesem Zeitpunkt - d.h. vor 1911 - war die archäologische Fundstelle noch nicht entdeckt und also auch niemand auf die Fundstücke sensibilisiert. 


\section{9/27 RHEINHAFEN ST. JOHANN 18,}

\section{ETAPPE 2}

Anlass: Sanierung des Hafenareals Zeitstellung: Bronzezeit(?), Spätlatènezeit, Neuzeit Untersuchungsdauer: August 2009 bis Mai 2010 Verantwortlich: Susan Steiner, Margit Dauner Text: Susan Steiner

Auf der länglichen, rund $430 \mathrm{~m}^{2}$ grossen Zone zwischen dem Gleisbogen und der Fläche der Grabung 2009/36 wurden Funde und Befunde aus der Neuzeit, der Spätlatènezeit, sowie der älteren Vorgeschichte entdeckt (siehe Abb.46). Bei den neuzeitlichen Bodeneingriffen handelt es sich um frühe Gasleitungen und um Mauerfundamente von Gebäuden, die vorwiegend in der zweiten Hälfte des 19. Jahrhunderts errichtet wurden. Die Gasfabrik diente zwischen 1860 und 1931 der Gasversorgung der Stadt Basel. ${ }^{58}$ Mitten in der Grabungsfläche stand die östliche Hälfte des ältesten Gasbehälters aus dem Jahre 1860. Dieser runde Gaskessel hatte einen Durchmesser von etwa $20 \mathrm{~m}$.

In den Bereichen, die nicht vom tief fundamentierten Gaskessel gestört waren, wurden fünf spätlatènezeitliche Gruben entdeckt. Während im Norden ein Kiesrücken vorliegt, fällt die Oberkante des Rheinschotters gegen Süden ab. Die Senke war teilweise mit verlehmten Hochflutsanden verfüllt. Vier der fünf Gruben entdeckten wir in diesen sandigen Lehmschichten im südlichen Grabungsdrittel.

Eine dieser fünf Gruben wurde detailliert und vollständig untersucht, während die anderen vier am Grabungsrand zum Vorschein kamen und später im Rahmen anderer Grabungen untersucht wurden bzw. noch werden. So hatten etwa die beiden östlichsten Gruben ihre flächenmässigen Schwerpunkte in der angrenzenden Grabung 2009/36.

Die vollständig untersuchte Grube konnte über eine Tiefe von 1,70 $\mathrm{m}$ dokumentiert werden. Sie hatte eine etwas längliche, polygonale Form, wobei die Seiten leicht nach aussen gespannt wirkten. Diese Grube war innen vermutlich verschalt - etwa mit Holzbrettern oder einem Flechtwerk. Aufgrund ihrer Tiefe und der senkrechten Grubenwände handelt es sich wahrscheinlich um eine als Getreidesilo genutzte Einrichtung. Nach der Auflassung des Silos wurde die Eintiefung mit Siedlungsabfall, Bauschutt und Abraummaterial gefüllt. Das Besondere an der sekundären Verfüllung sind Rinderknochen, die im Sehnenverband in die Grube gelangten (Abb. 49). In den oberen Bereichen des vorwiegend aus kiesreichem sandigem Lehm bestehenden Oberbodenmaterials lagen - häufiger als in den unteren Grubenschichten - Buntmetallobjekte, u.a. mehrere spätlatènezeitliche Münzen und Fibelfragmente.

Die erwähnten Lehmschichten des südlichen Grabungsbereiches enthielten etwas Kies, vereinzelt auch kleine Holzkohlestücke und Keramikfragmente. Dies zeigt, dass es sich um Planien, also um von Menschen aufgebrachtes Material handelt. Diese Planien können zeitlich kurz vor den Gruben ange- legt worden sein oder deutlich früher. Die Keramikfunde aus den unteren Bereichen dieser kieshaltigen Lehmplanie haben andere Magerungsbestandteile und eine andere Oberflächenbeschaffenheit als die spätlatènezeitlichen Keramikscherben. Darum ist nicht ausgeschlossen, dass hier bronzezeitliche Funde und Befunde vorliegen.

Relikte aus der Bronzezeit wurden immer wieder auf dem Areal von Basel-Gasfabrik entdeckt. ${ }^{59}$ Für eine sichere Datierung dieser Funde und auch der Planie, in der sie gefunden wurden, sind Vergleiche des Fundmaterials und eine Auswertung der entsprechenden Befunde nötig.

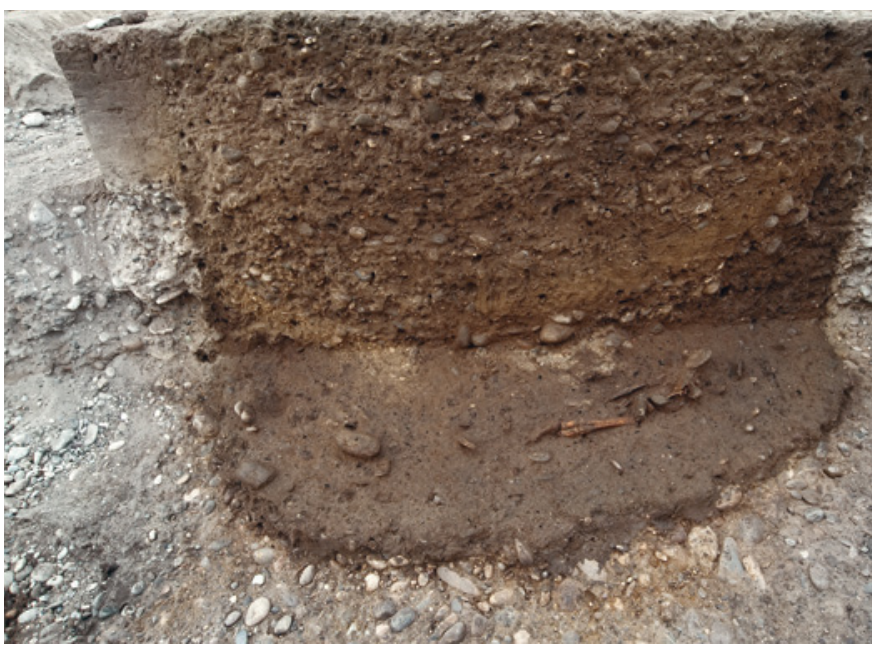

Abb. 49 Etwa im Zentrum der bereits tiefer abgebauten südlichen Grubenhälfte sind Rinderknochen zu sehen. Ein Rinderfuss mit Huf stammt von einem Jungtier und wurde als Ganzes, also noch im Sehnenverband, in die Grube gefüllt. Auch Wirbelsäulenabschnitte von Rindern gelangten in grösseren Stücken in diese Grube. Foto: Michael Wenk. 


\section{9/29 RHEINHAFEN ST. JOHANN 18,}

\section{ETAPPE 3}

Anlass: Sanierung des Hafenareals Zeitstellung: Geologischer Befund, Neuzeit Untersuchungsdauer: September bis November 2009 Verantwortlich: Sophie Hüglin, Margit Dauner, Maja Viazzoli Text: Sophie Hüglin

Das Grabungsareal umfasste ca. $225 \mathrm{~m}^{2}$ und lag zwischen dem gleich zu Beginn abzubrechenden Ultra-Brag-Silo im Osten und dem das Grabungsbüro beherbergenden westlichsten Gebäude auf dem Hafenareal, dem ehemaligen Bau WSJ-751 (siehe Abb. 46). Im Gegensatz zur unmittelbar nördlich anschliessenden Grabung 2009/36 waren in diesem Bereich keine eindeutigen vorgeschichtlichen Befunde zu fassen. Das gekappte Fundament einer vermörtelten Kalkbruchstein-Mauer gehört nach Lage, Ausrichtung und Bauweise zur südlichen Aussenwand des Kohlenschuppens der ehemaligen «Gasfabrik». ${ }^{60}$

\section{9/32 FABRIKSTRASSE 60, NOVARTIS,}

\section{STRASSE 8}

Anlass: Sondierbohrungen zur Abklärung der Bodenkontamination für die Verlegung des Allschwilerbachs Zeitstellung: Geologischer Befund Untersuchungsdauer: Oktober bis November 2009 Verantwortlich: Hannele Rissanen, Andreas Niederhäuser Text: Hannele Rissanen

Das Geotechnische Institut Basel führte eine Reihe von Sondierbohrungen in der Nähe der spätlatènezeitlichen Gräberfelder durch (siehe Abb.46). Ziel der archäologischen Begleitung der Bohrungen war das Gewinnen von Informationen über die archäologisch relevanten Bodenverhältnisse, den Erhaltungszustand und die Geologie in einer bisher archäologisch nicht genügend untersuchten Zone. Auch die nur punktuellen Beobachtungen an den Bohrkernen sind für die Planung der archäologischen Untersuchungen im Areal wichtig. Die natürliche geologische Gelände-Oberkante war an keiner der untersuchten Stellen intakt erhalten, jedoch wurden nur bei wenigen Bohrungen tief greifende Störungen festgestellt. In einer Bohrung konnte sogar ein archäologischer Horizont erfasst werden, dessen Oberkante direkt unterhalb des modernen Betonfundamentes liegt.

\section{9/36 RHEINHAFEN ST. JOHANN 18,} ETAPPE 4

Anlass: Sanierung des Hafenareals Zeitstellung: Bronzezeit, Latènezeit, Neuzeit Untersuchungsdauer: Seit November 2009 Verantwortlich: Sophie Hüglin, Margit Dauner Text: Sophie Hüglin

Die Grabungsfläche konnte aus feuerpolizeilichen Gründen erst nach Abschluss der Grabung 2009/29 geöffnet werden. Anfänglich stand die Untersuchung unter extremem Zeitdruck, da zunächst Mitte Januar mit den Abbrucharbeiten am unmittelbar östlich gelegenen Ultra-Brag-Silo hätte begonnen werden sollen. Zwei Rekurse konkurrierender Unternehmen vor dem Verwaltungsgericht Basel-Stadt um die Vergabe der Baumeisterarbeiten hatten aufschiebende Wirkung. Dies verschaffte der Grabung schliesslich nach und nach einen der aussergewöhnlich guten Erhaltung und hochkomplexen stratigrafischen Situation angemessenen zeitlichen Spielraum. Die Darstellung der Befunde erfolgt im kommenden Jahresbericht. 


\section{AUSSENBEZIRKE}

\section{9/1 KLEINHÜNINGERANLAGE (A)}

Anlass: Leitungsbau im Hinblick auf neue Tramlinie nach Weil (D) Zeitstellung: Frühmittelalter Untersuchungsdauer: Januar bis Dezember 2009 (wird 2010 fortgesetzt) Verantwortlich: Christoph Matt, Udo Schön, Cornelia Alder, Maja Viazzoli Text: Christoph Matt

Nach einer langen Planungsphase begannen die Arbeiten für den Bau der neuen Tramlinie Nr. 8 nach Weil (D). Die dadurch bedingten Bodeneingriffe tangierten im Bereich zwischen dem Restaurant Drei Könige und der Kreuzung Kleinhüningeranlage/Weilerweg ein für die Forschung wichtiges frühmittelalterliches Gräberfeld, das zwischen dem 5. und dem Beginn des 8. Jahrhunderts belegt worden war, und aus dem bis anhin über 260 Gräber bekannt sind. ${ }^{61}$ Der offizielle Spatenstich fand am 6. Dezember 2008 statt (mit dem Setzen des ersten Mastes für die Fahrleitungen), doch effektiv gebaut wurde erst ab Januar 2009. Im Berichtsjahr wurden alle Werkleitungen erneuert und ergänzt, im folgenden Jahr fand der eigentliche Geleise- und Strassenbau statt. Wir legen im nächsten Jahresbericht die Resultate der Untersuchungen dar.

\section{9/2 UFERSTRASSE 30, NOVARTIS, WKL-220, ZIELGRUBE MICROTUNNEL}

Anlass: Erstellen der Zielgrube für einen rheinquerenden Microtunnel Zeitstellung: Geologischer Befund Untersuchungsdauer: Januar und April 2009 Verantwortlich: Norbert Spichtig, Sophie Hüglin, Margit Dauner, Michael Wenk Text: Norbert Spichtig

Der Bodeneingriff lag im Bereich einer ehemaligen Rheininsel. Dort gibt es kaum gesicherte Aufschlüsse zur Topographie. Karl Stehlin hat 1918 im Bereich des Werkes Klybeck in grösserer Tiefe Funde gemacht, die darauf hinweisen, dass es auch hier auf der rechten Rheinseite eine spätlatènezeitliche Siedlung gab. Seither liess sich die Fundstelle allerdings nicht mehr fassen. Im Ostteil der Zielgrube waren intakte Schichten vorhanden, so dass sich die Oberkante des Rheinschotters und die Mächtigkeit des verlehmten Hochflutsandes grob von Hand einmessen liessen. Hinweise auf eine vorgeschichtliche Besiedlung - etwa in Form von Eintiefungen oder Funden - wurden nicht angetroffen.

\section{9/19 SCHALERSTRASSE 45}

Anlass: Neubau eines Mehrfamilienhauses Zeitstellung: Geologischer Befund Untersuchungsdauer: Mai 2009 Verantwortlich: Susan Steiner, Norbert Spichtig Text: Susan Steiner, Norbert Spichtig

Der Rückbau eines Gebäudes und die anschliessende Erstellung eines Mehrfamilienhauses an der Schalerstrasse 45und damit im Umfeld des frühmittelalterlichen Gräberfeldes Bernerring - veranlasste die Archäologische Bodenforschung, die Bodeneingriffe zu überwachen. Allerdings erbrachten weder die Kontrolle der Bauarbeiten noch das gezielte Absuchen der meterhohen Wände der fertig ausgehobenen Baugrube irgendwelche Hinweise auf antike Befunde oder Funde, obwohl grosse Partien des Baugruben-Geländes gegen die Schalerstrasse und den Bernerring hin ungestört erhalten waren. Deshalb wurden die Baugrubenwände als geologisch-topographische Aufschlüsse lediglich fotografisch dokumentiert und die Ausdehnung der Baugrube eingemessen. 


\section{9/21 MARGARETHENSTRASSE (A) 31}

Anlass: Oberflächen-Instandstellung Zeitstellung: Neuzeit

Untersuchungsdauer: Mai 2009 Verantwortlich: Norbert

Spichtig, Cornelia Alder Text: Norbert Spichtig

Um 18:32 Uhr am 28. Mai 2009 erhielt die Archäologische Bodenforschung einen Anruf vom Kriminalkommissariat BaselStadt. Das Kriminalkommissariat teilte mit, ein Passant habe in einer Rabatte an der Margarethenstrasse menschliche Gebeine entdeckt. Ein Augenschein vor Ort bestätigte, dass im offensichtlich erst vor Kurzem herbei transportierten Erdreich - Bewuchs fehlte vollständig - verstreut über die ganze Rabatte zahlreiche menschliche Skelettreste mehrerer Individuen lagen. Ausser wenigen neuzeitlichen Streufunden - mehrheitlich kleine Baukeramikreste - konnte trotz systematischen Absuchens der Oberfläche kein datierendes Fundgut geborgen werden. Aufgrund des Befundes, der Erhaltung der Knochen und der Beschaffenheit ihrer Oberfläche kamen der von der Polizei beigezogene Rechtsmediziner und der Verantwortliche der Archäologischen Bodenforschung übereinstimmend zum Schluss, dass hier keine Ermittlungen wegen eines strafrechtlich relevanten Deliktes angezeigt sind. Die mindestens etliche Jahrzehnte alten menschlichen Skelettreste waren zusammen mit dem Erdreich in die Rabatte eingebracht worden. So wurde aus einer scheinbar modernen Bluttat ein archäologischer Forschungsgegenstand.

Eine anthropologische Analyse der verstreuten Knochen zeigte, dass sie von mindestens fünf Individuen stammen, nämlich von drei Erwachsenen und zwei Kindern. Zudem liegt auch wenigstens ein Tierknochen vor. Da trotz intensiven Nachforschens über die Herkunft des Erdreichs nur eruiert werden konnte, dass es zuletzt in einer Baumschule in Arlesheim gelagert war, jedoch der eigentliche Ursprung und damit der Kontext, aus dem die Gebeine kommen, im Dunkeln blieb, wurde aus dem grauslichen Kriminalfall letztendlich ein archäologischer Befund von eher geringer Aussagekraft. 
Anlass: Neubau eines Hauses Zeitstellung: Unbestimmt Untersuchungsdauer: Oktober 2009 Verantwortlich: Christoph Matt Text: Christoph Matt

Aus Riehen wurde uns übermittelt, es sei auf einer Baustelle eine Grube in der Böschung zum Vorschein gekommen, und es eile. ${ }^{62}$ Die Baustelle, eine grosse, für den Neubau eines Mehrfamilienhauses ausgehobene Baugrube, lag zwar ausserhalb unserer archäologischen Zonen. Weil es aber im 19. Jahrhundert in unmittelbarer Nähe einen Friedhof gegeben hatte (Gottesacker an der Mohrhaldenstrasse, heute eine Grünanlage) ${ }^{63}$, dachten wir immerhin an die Möglichkeit einer Grabgrube.Ein Augenschein auf der Baustelle zeigte die fertig ausgehobene Baugrube mitten im Lössgebiet. Ihr Boden war zwar etwas fleckig, doch zeichneten sich darin bloss die angeschnittenen, leicht absinkenden Lehmschichten auf dem horizontalen Baugruben-Untergrund ab. In der Mitte der Böschung auf der Friedhofseite (beim Stumpweglein) zeigte sich tatsächlich eine schmale Grube (Abb. 50).

Es handelte sich offensichtlich weder um eine Grabgrube noch um einen verfüllten Leitungsgraben; dies liess sich eindeutig sagen, denn es fehlten sowohl Skelettreste als auch eine alte Leitung auf der runden Sohle. Die Sohle lag in über $2 \mathrm{~m}$ Tiefe und war etwa einen Meter breit. Die Verfüllung entsprach dem lehmig-mergeligen Umgebungsmaterial. Funde oder vom Menschen herrührende Einschlüsse kamen nicht zum Vorschein. Wir können die Struktur nicht weiter deuten. Im Grunde genommen ist nicht einmal klar, ob es sich um eine (lokale) Grube oder um einen (langgezogenen) Graben handelt.

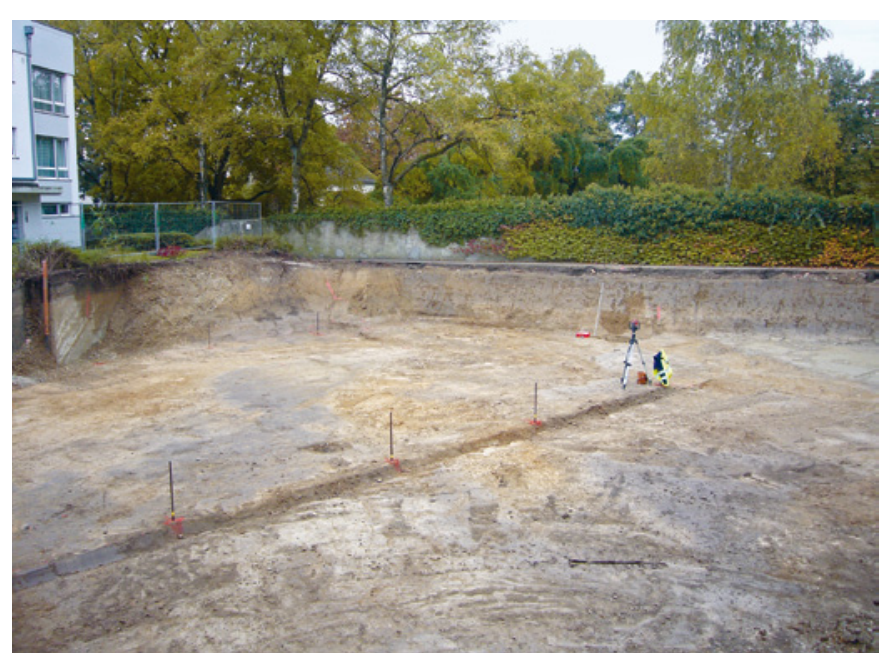

Abb. 50 Blick nach Nordwesten über die Baugrube zum Stumpgässlein. Die fragliche Grube liegt links vom Messgerät an der hinteren Baugrubenböschung. Foto: Christoph Matt.
Anlass: Neubau eines Hauses Untersuchungsdauer: Oktober 2009 Verantwortlich: Christoph Matt Text: Christoph Matt

Auf einer bisher noch unüberbauten Parzelle zwischen zwei Einfamilienhäusern sollte auf der Bischoffhöhe ein Neubau entstehen. ${ }^{64}$ Auf dieser Anhöhe kamen früher immer wieder Streufunde von Silex-Werkzeugen (d.h. aus Feuerstein) zum Vorschein, die zwar nicht einzigen, jedoch in der Regel dauerhaftesten Überbleibsel einer jungsteinzeitlichen Siedlung oder Begehung. Etwa zehn Fundstellen kennt man hier oben dank der jahrelangen Prospektionstätigkeit des freiwilligen Riehener Mitarbeiters der Archäologischen Bodenforschung, Hans Jürg Leuzinger. ${ }^{65}$ Ein Kontrollgang zur grossen Baugrube erbrachte allerdings ebenso wenig Funde oder Befunde wie das Absuchen des neben der Baugrube liegenden Aushubes (Abb.51). Die Baugrube lag erwartungsgemäss vollumfänglich im Lösslehm drin. Dieser war in den obersten Dezimetern etwas heller als weiter unten, zeigte sonst aber keine Besonderheiten. Der höhere Helligkeitswert der oberen Tonschicht dürfte den natürlich gebleichten und an Tonsubstanz verarmten Tonauswaschungshorizont anzeigen, der unmittelbar unter dem dünnen Humushorizont liegt. Die tieferen Horizonte sind dunkler. ${ }^{66}$

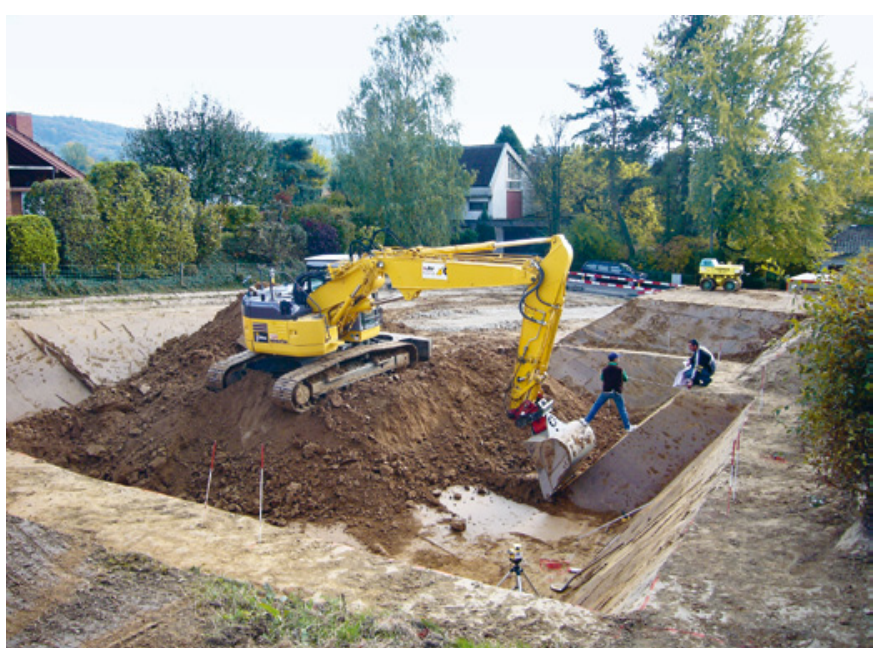

Abb. 51 Blick in die Baugrube. Foto: Christoph Matt. 


\section{9/37 RIEHEN, BOCKRAINWEG 20}

Anlass: Erweiterung eines Einfamilienhauses Zeitstellung: Geologischer Befund Untersuchungsdauer: November 2009 Verantwortlich: Christoph Matt Text: Christoph Matt
2009/39 RIEHEN, RAURACHERSTRASSE 156

Anlass: Leitungsbauten auf Allmend, Hausanschluss Zeitstellung: Römische Zeit Verantwortlich: Christoph Matt Text: Christoph Matt
Ein Architekt wies uns auf den Aushubbeginn für den Erweiterungsbau eines Einfamilienhauses hin, weshalb wir die Baustelle am Bockrainweg besichtigten (Abb.52). ${ }^{67}$ Sie lag zwar ausserhalb unserer archäologischen Zonen, doch relativ nahe kamen auch schon steinzeitliche Funde zum Vorschein, so dass wir einen Augenschein für sinnvoll hielten. Im zähen, schweren Lehm zeigten sich recht viele Brocken aus rotem Sandstein, der in der Gegend offenbar ansteht, dazu weissliche gerundete Kiesel. Dieses Sandsteinvorkommen wurde früher etwas weiter östlich auch abgebaut, nämlich bei der Flur mit dem bezeichnenden Namen «im roten Graben» in der Nähe des Maienbühls. ${ }^{68}$ Die «richtige» Steinzeit im Sinne von Silexabschlägen oder etwa eines Steinbeiles kam leider nicht zum Vorschein.

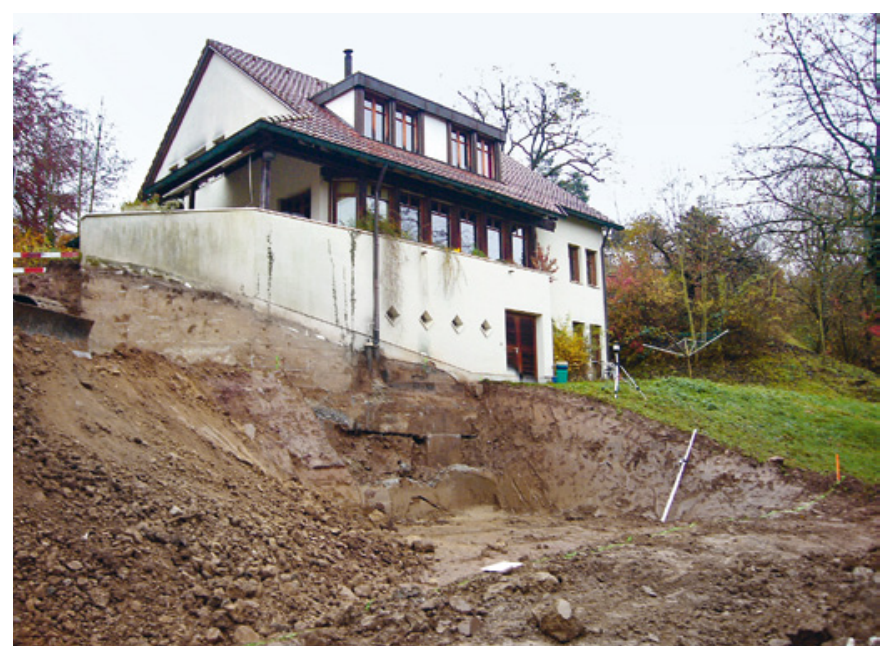

Abb. 52 Überblick über die Baustelle. Foto: Christoph Matt.
In der Rauracherstrasse und darum herum wurden im Jahr 2008 Werkleitungen gebaut. Das Gebiet liegt wenig ausserhalb der archäologischen Fundzone «Hörnli», wo der grosse Basler Zentralfriedhof gewissermassen eine römische Villa rustica unter sich begräbt. ${ }^{69}$ Wir haben die Bauarbeiten (Leitungserneuerungen innerhalb bestehender Trassees) nicht überwacht. Die Grabarbeiten schienen denn auch archäologisch ereignislos gewesen zu sein, bis sich im November des Berichtsjahres die Mutter eines fünfjährigen Buben meldete: Ihr Kind habe anlässlich der Bauarbeiten im Vorgarten einen Henkel gefunden und wolle wissen, ob er alt sei. Der Sohn hatte seine Mutter immer wieder dazu gedrängt, nachzufragen, bis sie der Archäologischen Bodenforschung anrief und sich erkundigte, «ob Louis den Henkel uns zeigen darf». Ein Termin war schnell gefunden, und wir waren angenehm überrascht, dass uns Louis nicht bloss einen neuzeitlichen Scherben, sondern einen veritablen römischen Amphorenhenkel vorlegte lungestempelt; Abb. 53). Die Fundgeschichte liess sich so rekonstruieren: Irgendwann im Jahre 2008 habe man im Zusammenhang mit den erwähnten Baumassnahmen eine Datenleitung von der Strasse ins Haus angelegt, und dabei sei «unmittelbar unter dem Küchenfenster» eben dieses Amphorenstück zum Vorschein gekommen. Es handelt sich dabei vermutlich um das Fragment einer Ölamphore vom Typ Dressel 20 11. bis 4. Jahrhundert n. Chr.). Die Lage unmittelbar beim Haus deutet auf einen Streufund hin (Baugrube!). Doch dürfte der Henkel wohl nicht weit verlagert worden sein und zum Umfeld der genannten Villa rustica gehören. ${ }^{\mathbf{7 0}}$

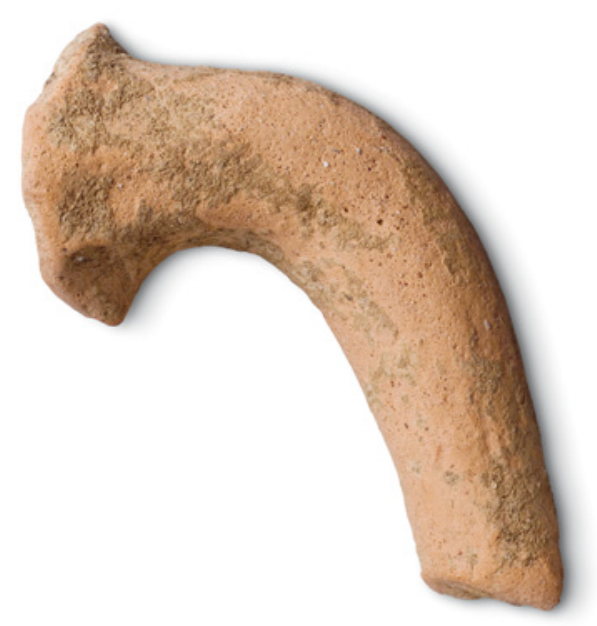

Abb. 53 Römischer Amphorenhenkel. Foto: Philippe Saurbeck. 
1 Ein herzliches Dankeschön ans Grabungsteam.

2 Siehe Kurzberichte: Sven Straumann, Versunkene Kulturen - unter dem Museum der Kulturen. Die Ausgrabung 2008/3 der Archäologischen Bodenforschung Basel-Stadt im Schürhof. Basler Stadtbuch 130, 2010, 129-137; Ausgrabungen und Funde im Jahr 2008, 2008/3 Münsterplatz 19 Museum der Kulturen (Sven Straumann), in: JbAB 2008.

3 Grabung 1978/24, Augustinergasse 2 [«Völkerkundemuseum»). R. Moosbrugger-Leu, Der Grabungsbefund Augustinergasse 2. Basler Zeitschr. für Gesch. u. Altertumskunde 79, 1979, 355-356 mit Abb. 41

4 Ausführlicher Beitrag zu den neuzeitlichen Befunden der Grabung 2008/3: Sven Straumann, Von Fechter und Werenfels zu Herzog \& de Meuron, in vorliegender Publikation.

5 Für die Sanierung zeichneten verantwortlich Münsterbaumeister A. Hindemann, Geophysiker M. Joppen und Baumeister A. Lutz, Baugeschäft Egeler Lutz AG Basel. Wir bedanken uns für die gute Zusammenarbeit auf der Baustelle.

6 1982/35 Martinskirchplatz (A) 4: Guido Helmig, Vorbericht über die Ausgrabungen auf dem Martinskirchsporn (1980/6, 1982/35, 1983/31). In: BZ 84, 1984, 328. Martinskirchplatz 4 (Kirchhof), 1996/9: Martinskirchplatz 4 (Kirchhof). In: JbAB $1996,12-13$

7 Bislang wurde die Schaffung eines direkten Zugangs um den Chorschluss herum zum Friedhof im Norden der Kirche als Grund für den Bau der Stützmauer angenommen. Werner Stöckli und Daniel Reicke, Die bauanalytischen Untersuchungen der Martinskirche von 1982. In: JbAB 1999, 271.

8 Sie entspricht z.B. der Mauer des Viereckturms im «Teufelhof»: Christoph Matt, Philippe Rentzel, Burkhardsche und Innere Stadtmauer - neu betrachtet. Archäologische und petrographische Untersuchungen. In: Jahresberichte der Archäologischen Bodenforschung 2002, 166-169 und Beilage 4 und 5 , L.

9 Frühe Steinmetzzeichen des 13. Jh. besitzen zwar oft einfache Formen, doch sind sie meist deutlich grösser: Christoph Ph. Matt, Christian Bing, Die archäologischen Untersuchungen im Bereich des Energieleitungstunnels (ELT) Gerbergasse - Barfüsserplatz - Steinenberg, 1991/2. Vorbericht. JbAB 1992, 91-98. Auch diejenigen des Münsters entsprechen unserem Kreuz nicht: E. La Roche, II. Zur Baugeschichte der Façade. In: Beiträge zur Geschichte des Basler Münsters, Hrsg.: Basler Münsterbauverein (Basel) 1882, 17, Taf. V. - Ders., III. Das Münster vor und nach dem Erdbeben, (Basel) 1885, 27, 54-56, Taf. IX.
10 Guido Helmig, Vorbericht über die Ausgrabungen auf dem Martinskirchsporn (1980/6, 1982/35 1983/31). In: BZ 84, 1984, insbes. 316, Abb. 32, und 328; Dokumentation: Zeichnung G 14, Fotos Nr. 65 und $68-70$.

11 Werner Stöckli und Daniel Reicke, Die bauanalytischen Untersuchungen der Martinskirche von 1982. In: JbAB 1999, 269-272, 279

12 Stephan Tramèr, 9. Stützmauer der Martinskirche, Rheinsprung 8 und 10, Basel (2003/346 und 2003/443). In. JbAB 2005, 227-237.

13 Daniel Reicke, Beobachtungen zur Baugeschichte der Basler «Pfalz» anlässlich der Sanierung 1994/95. JbAB 1994, 113-122. Reicke spricht dort von einer «Kanzel», während wir bei der Stützmauer am Rheinsprung jedoch den von der Denkmalpflege geprägten Begriff «Erker» verwenden. - Die von Reicke geäusserte Vermutung, dass es sich bei dieser «Pfalz-Kanzel» um eine nicht realisierte kleine Kapelle handeln könnte, wird jedoch wieder zurückgenommen. Für unseren Erker möchten wir eine solche Deutung ausschliessen.

14 Im Bereich vor der älteren Mauer wurde stellenweise bis auf $266.40 \mathrm{~m}$ ü. M. abgetieft.

15 Vgl. auch Kurzbericht zur Grabung 2008/22, in: Ausgrabungen und Funde im Jahr 2008, JbAB 2008.

16 A. Hagendorn/Ch. Stegmüller/S. Stelzle-Hüglin (mit Beitr. von C. Alder/Th. Doppler/D. Keller/Ch. Pümpin/Ph. Rentzel), Von Befestigungen und Grossbaustellen. Erste Ergebnisse der Ausgrabung Martinsgasse 6+8 (2004/1). In: JbAB 2004, 99-101.

17 Dieselben Befunde konnten auch bereits anlässlich der direkt benachbarten Grabung 1967/25 dokumentiert werden. M. Martin, Martinskirchplatz 3. In: Basler Zeitschr. für Gesch. u. Altertumskunde 67, 1967, XVI-XVII; XXI.

18 Heinrich Weiss, Versuch einer kleinen und schwachen Beschreibung der Kirchen und Klöster in der Stadt und Landschaft Basel, 1834, 4.

19 Beim Baumaterial handelt es sich um den für den Murus Gallicus charakteristischen Süsswasserkalkstein.

20 Siehe Coverstory in diesem Jahresbericht 2009

21 Zur Baugeschichte der Pfalz siehe D. Reicke, Beobachtungen zur Baugeschichte der Basler «Pfalz» anlässlich der Sanierung 1994/95. JbAB 1994, 113-122; G. Helmig (mit Beitr. von F. Maurer, B. Schärli, W. Schoch, M. Weder), Ausgrabungen im Umkreis des Basler Münsters. JbAB 1991, 49-51.
22 Siehe Beschreibung in C. H. Baer, Die Kunstdenkmäler des Kantons Basel-Stadt Bd. 1 (Basel 1932) 124.

23 Eine Abbildung des vollständigen Kupferstichs findet sich bei P.-A. Schwarz, Die Archäologische Informationsstelle «Aussenkrypta» unter der Pfalz des Basler Münsters. Arch. Denkmäler in Basel 1 (Basel 2001) 29.

24 Architekturbüro: Buchner Bründler Architekten AG, Basel (Bauleiter: Sebastian Pitz). - Zum Altbau siehe: Othmar Birkner, Hanspeter Rebsamen (Hrsg.), Inventar der neueren Schweizer Architektur 1850-1920 (INSA), Basel (Bern 1986) 203, zur Neueröffnung: David Wohnlich, Vom Massenschlag zum Komforthotel. In: Basler Zeitung vom 17.03.2010, 23

25 Verantwortlich waren die Herren M. Bleuler (IWB) und Bauführer Häner sowie Polier M. Situm (Spaini AG). - Zu alten Leitungsgrabungen siehe Fundbericht 1998/5 Hutgasse, Glockengasse, Sattelgasse, Schneidergasse (A) in JbAB 1998, 51 , mit Übersichtsplan Abb. 31 lenthält aktuelle und historische Überbauung).

26 André Salvisberg. Die Basler Strasssennamen (Basel 1999), 188 f., und Eugen A. Meier, Verträumtes Basel (Basel 1974), 68.

27 Eigentümer: Gregor und Irène Burch, Wangen b. Olten. Architekturbüro: Villa Nova Architekten AG (A. Pedrina).

28 Zuletzt: Guido Helmig, Basilia, Totentanz und Römergräber. In: Mille Fiori, Festschrift für Ludwig Berger. Forschungen in Augst Bd. 25 (Augst 1998), 123-130 (mit älterer Literatur). - Trotz der vorhandenen Keller können Skelettreste dieses Gräberfeldes offenbar unter Gebäuden noch vorhanden sein: siehe JbAB 2008, Fundchronik, Blumenrain 28, 2008/6.

29 Daniel Reicke, Totentanz 8 in Basel, «Zum Baldeck», ein Turmhaus im Umfeld des Predigerklosters. In: Mittelalter Moyen Age Medioevo Temp medieval. Zeitschrift des Schweizerischen Burgenvereins 1, 1996 Nr. 4, 92-101.

30 Ich danke den Eigentümern, den Herren Tino und Niklaus Krattiger, herzlich für die unkomplizierte Zusammenarbeit auf der Baustelle.

31 Laut KDM BS VI, 69-71, ist der Flügel nach 1830 ausgebaut worden. Demnach dürfte die Aufplanierung älter sein.

32 Alle Angaben nach KDM BS VI, 69-71. Ich danke auch dem Verfasser dieses Kunstdenkmälerbandes, Herrn Thomas Lutz, für anregende Gespräche. 
33 Da hatten die Kollegen von der Denkmalpflege mehr Glück, die im Hausinnern mehrere eingemauerte grosse flache «Schüsseln» mit fünflibergrossen Löchern fanden, wohl Stapel- oder Brennhilfen für den Hafnerofen.

34 Inv.Nr. 2009/13.41 (FK 24958), Inv.Nr. 2009/13.88 (FK 24959), Inv.Nr. 2009/13.117 (FK 24960), Inv.Nr. 2009/13.214 (FK 24966).

35 Inv.Nr. 2009/13.121-124 (FK 24961).

36 Dokumentation: Fotos D0041-45.

37 Eigentümer: Jürg Eichenberger, Sissach. Architekturbüro: Villa Nova Architekten AG.

38 Leider war infolge der Neuorientierung des aktuellen Jahresberichtes und des damit verbundenen Zeitplanes für die Autoren kein gemeinsamer Bericht mit den Kollegen der Denkmalpflege möglich (für die Untersuchungen der Bauforschung der Denkmalpflege im Spiesshof verantwortlich: Bernard Jaggi). Es ist zu hoffen, dass dies in Zukunft wieder gelingt. Eine intensive Diskussion der im Boden und im Aufgehenden festgestellten Befunde hat jedoch selbstverständlich stattgefunden! Ich danke Bernard Jaggi für seine wertvollen Hinweise zur Baugeschichte.

39 Nach: Bürgerhaus der Schweiz, Bd. 17, Kanton Basel-Stadt 1. Teil (Zürich und Leipzig 1926), LVII ff. Der untersuchte Raum im Erdgeschoss des Westflügels entspricht dort Taf. 128 Nr. 4.

40 Daniel Reicke, Untersuchungsbericht Heuberg 5/7 (D 1999/23). In: JbAB 1999, 223-225.

41 Nähere Angaben: KDM BS III, 429-432, und Kaspar Richner, Ein Längsschnitt durch die St. Johanns-Vorstadt. JbAB 1991, 151-158.

42 Bauleitung: Lucien Evard, IWB. Baugeschäft: A. Pelucchi AG (Polier D. Zarkovic).

43 Durchführung der Bohrung: Firma Glanzmann AG. Untersuchung: Geotechnisches Institut Basel. Ich danke Bauingenieur Rainer Zeh für die Zusendung der Bohrresultate. Eine weitere Bohrung vor dem abzubrechenden Flügel auf der Seite Spitalstrasse haben wir nicht eingesehen; sie lieferte ähnliche Resultate.

44 E. Blum, Th. Nüesch, Basel einst und jetzt, ein kulturhistorisches Lesebuch, Textteil zum gleichnamigen Bilderbuch (Basel 1913) 18.

45 Tiefbauamt: Thomas Bürki. Baugeschäft: Bertschmann AG (Bauführer: H. Landis, Polier: Marcello Tamburello).
46 Guido Helmig, Christoph Ph. Matt, Inventar der Basler Stadtbefestigungen - Planvorlage und Katalog. 1. Die landseitige Äussere Grossbasler Stadtmauer. In: JbAB 1989, insbes. 77 und $139 \mathrm{f}$.

47 Ich danke Stefan Tramèr (Basler Denkmalpflege) für den Hinweis auf das nicht gemeldete Bauprojekt.

48 KDM BS VI, 34 (Teiche), 43 f. (Mühlen).

49 Zur durch Seidenfärber verursachten Wasserverschmutzung, die geflösstes Holz unterhalb der Rheinbrücke stark im Wert minderte, siehe Bernhard Brendle, Der Holzhandel im alten Basel (Diss. Basel 1910), 28.

50 Christoph Ph. Matt, Die mittelalterliche Stadtbefestigung am Petersgraben und die Quartiere hinter der Stadtmauer. In: JbAB 1988, insbes. 63 und 74 f.; weitere Literatur: Daniel Bruckner, Fortführung von Christian Wurstisens «Basler Chronik» (Basel 1580), 3. Buch (Basel 1779), nach der Ausgabe R. Hotz (Basel 1983), 508. Stocker F(ranz) Alugust), Basler Stadtbilder (Basel 1890), 87.

51 Ich danke Herrn U. Bertozzzi (AUE) für die Fundmeldung. Baugeschäft: Morath und Crottaz (Polier: A. Toytemur).

52 Ich danke den Herren Dominik Amrein und Markus Hummel (AUE) für Zusammenarbeit und das Überlassen des Bohrberichtes. Baufirma/ Bohrung: Glanzmann AG. - Elias Kopf, Grundwasserbohrung auf Marktplatz. Die Umwelttage machen Umweltschutz und Nachhaltigkeit erlebbar. In: Basler Zeitung vom 26.05.2009, 15.

53 Christoph Matt, Dagmar Bargetzi, Archäologische Untersuchungen auf dem Marktplatz. In: JbAB 2006, 95-110 (insbes. Plan Abb. 2, S. 96)

54 Vgl. Hans Adolf Vögelin, Die Entwicklung des Äusseren St. Johann-Quartiers, 146. Neujahrsblatt, hrsg. v. d. Ges. z. Beförderung d. Guten u. Gemeinnützungen (Basel 1967) 63.

55 Im Rahmen des Projekts wurde damals auch ein Arbeitsschacht über dem Allschwilerbachkanal angelegt. Die archäologische Begleitung dieser Baumassnahme (vgl. Grabung 1982/28) ergab allerdings weder Funde noch Befunde.

56 Vgl. Marcel Honeck, Nichts als heisse Steine. Zur Deutung der Brenngruben der späten Bronzezeit und frühen Eisenzeit in Deutschland. Universitätsforschungen zur prähistorischen Archäologie, Bd. 166 (Bonn 2009).

57 Vgl. Virginie Rougier, Les structures de combustion à remplissage de galets chauffés de Sierentz. Maîtrise d’Archéologie, Université Marc Bloch, Strasbourg, Janvier 2001, $13 \mathrm{ff}$
$58 \mathrm{Vgl}$. Hans Adolf Vögelin, Die Entwicklung des Äusseren St. Johann-Quartiers, 146. Neujahrsblatt, hrsg. v. d. Ges. z. Beförderung d. Guten u. Gemeinnützungen (Basel 1967) 61

59 Vgl. Dieter Holstein, Die bronzezeitlichen Funde aus dem Kanton Basel-Stadt. Materialhefte zur Archäologie in Basel, Heft 7 (Basel 1991) 58-61.

60 Vgl. «Situation der Gasfabrik», Plan der baulichen Situation um 1930, Archiv ABBS.

61 Ulrike Giesler-Müller, Das frühmittelalterliche Gräberfeld von Basel-Kleinhüningen: Katalog und Tafeln. Derendingen 1992.

62 Wir danken dem Anwohner, Herrn Jean Nicolas Haas, für seine Aufmerksamkeit und Fundmeldung. - Aushubfirma: Ernst Frey AG

63 Michael Raith, Gemeindekunde Riehen. (Riehen 1980), 251-253.

64 Wir danken der Firma Sutter Aushub (Augst) für die Mitteilung des Baubeginns.

65 Leider ist er 2008 verstorben. Nachruf von Guido Lassau in JbAB 2007, 5 f.

66 Freundliche Auskunft von Philippe Rentzel (IPNA).

67 Wir danken dem Architekten Gerhard Kaufmann (Riehen) für die Baubeginn-Mitteilung.

68 Freundliche Auskunft von Philippe Rentzel (IPNA). Riehen - Geschichte eines Dorfes (Riehen 1972), 14

69 Riehen - Geschichte eines Dorfes (Riehen 1972), 43-48.

70 Wir danken dem aufmerksamen Louis Eckhardt und seiner verantwortungsbewussten Mutter herzlich für Melden und Überbringen des Fundes (Inv.Nr. 2009/39.1, FK 24968). 